Chapman University

Chapman University Digital Commons

Education (PhD) Dissertations

Dissertations and Theses

Summer 8-2020

\title{
School Psychologists and School Counselors' Perceptions of Preparation Received for the Provision of School-Based Mental Health Services
}

Sherika McKenzie

Chapman University, mcken143@mail.chapman.edu

Follow this and additional works at: https://digitalcommons.chapman.edu/education_dissertations

Part of the Child Psychology Commons, Counseling Psychology Commons, Counselor Education Commons, Educational Assessment, Evaluation, and Research Commons, Educational Methods Commons, Educational Psychology Commons, Elementary Education Commons, Other Education Commons, Other Psychology Commons, Other Social and Behavioral Sciences Commons, School Psychology Commons, Secondary Education Commons, Social Work Commons, Special Education and Teaching Commons, and the Student Counseling and Personnel Services Commons

\section{Recommended Citation}

McKenzie, S. T. (2020). School psychologists and school counselors' perceptions of preparation received for the provision of school-based mental health services [Doctoral dissertation, Chapman University]. Chapman University Digital Commons. https://doi.org/10.36837/chapman.000183

This Dissertation is brought to you for free and open access by the Dissertations and Theses at Chapman University Digital Commons. It has been accepted for inclusion in Education (PhD) Dissertations by an authorized administrator of Chapman University Digital Commons. For more information, please contact laughtin@chapman.edu. 
School Psychologists and School Counselors' Perceptions of Preparation Received for the Provision of School-Based Mental Health Services

A Dissertation by

Sherika T. McKenzie

Chapman University

Orange, $\mathrm{CA}$

Donna Ford Attallah College of Educational Studies

Submitted in partial fulfillment of the requirements for the degree of Doctor of Philosophy in Education School Psychology

August 2020

Committee in charge:

Michael Hass, Ph.D., Chair

Randy Busse, Ph.D.

Pedro Olvera, Psy.D. 
The dissertation of Sherika T. McKenzie is approved.

Midanghare

Michael Hass, Ph.D., Chair

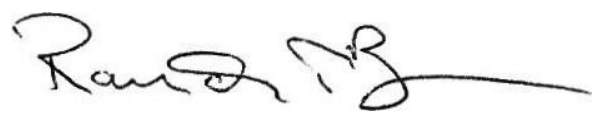

Randy Busse, Ph.D.

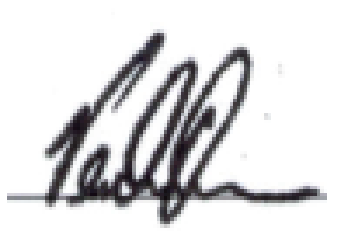

Pedro Olvera, Psy.D.

August 2020 
School Psychologists and School Counselors' Perceptions of the Preparation Received for the Provision of School-Based Mental Health Services

Copyright (C) 2020

by Sherika T. McKenzie 


\section{ACKNOWLEDGEMENTS}

First and foremost, I would like to give love and praise to my Lord and Savior for instilling in me the motivation and determination to pursue and complete my doctoral degree. I feel truly blessed to achieve this accomplishment, and I am excited about my future endeavors.

I would like to dedicate my dissertation to my family. My parents, Malvia and Quentin, immigrated to the United States as children from Jamaica in the 1970s. My parents, along with their families, were in search of living the "American Dream." My father enlisted in the United States Marines at the age of 18 , so he could give back to this country. After meeting in the United States, my parents married and created a family of their own. Ultimately, they were able to provide their six children the opportunity to achieve the "American Dream," and I am forever grateful for that. I would like to give a special "Thank You" to my mother. You have been the backbone of this family and have always supported us in so many ways. You have shown incredible strength and overcame many obstacles so that you could provide for your children. You have always told my siblings and I that we could be whatever we wanted to be in life and always encouraged us to achieve whatever goals we set for ourselves. Thank you for your endless love and guidance, and thank you for being my biggest cheerleader! I also would like to thank my five siblings, Shameeka, Shamar, Shonté, Shamelle, and Sherelle, for being great role models for myself, for each other, and now for our nieces and nephew. We have always supported each other's goals. You are the best brothers and sisters ever, and I would never want to change the bond that we all share. We will always be the "McKenzie Six-Pack!" To my family, "I will always love you forever and a day!"

My experience at Chapman University has been wonderful. During my time at Chapman University, I was able to interact with amazing classmates and learn from very knowledgeable 
professors. I was given opportunities to increase my knowledge in the field of school psychology and build upon my skills as a practitioner. Therefore, I am truly grateful for my time at Chapman University.

I would like to thank my dissertation committee for all your encouragement and support. Firstly, my dissertation chair, Dr. Michael Hass. I always knew that I wanted to have you as my dissertation chair because of the outstanding contribution you have made to the fields of educational psychology and mental health. I hope to one day make a significant impact on these fields as you have. I truly appreciate all the guidance that you have provided to me throughout this process and truly cherish all that I was able to learn from you. Thank you for everything! Dr. Randy Busse, I thank you for being on my dissertation committee. You helped to rekindle my interest in learning about and examining statistics. You also helped me in gaining a better understanding of how to analyze data. Your interesting approach to quantitative research has inspired me to want to continue to explore future research opportunities. Dr. Pedro Olvera, thank you for participating in my dissertation committee. You have been present in my journey from when I began my master's program in Educational Psychology to now finishing my doctorate. I appreciate all the support you have given me. Also, thank you for all the letters of recommendation you have written for me over the years.

I would also like to give thanks to Dr. Kelly Kennedy for working with me throughout my time as a student at Chapman University. You helped me to hone my research skills, and you provided excellent feedback when I was deciding on my research methodology approach.

Lastly, thank you to everyone who believed in me! And remember to never give up on your dreams! 


\begin{abstract}
School Psychologists and School Counselors' Perceptions of the Preparation Received for the Provision of School-Based Mental Health Services

by Sherika T. McKenzie
\end{abstract}

School psychologists and school counselors are increasingly playing an essential role in the provision of school-based mental health services (SBMHS). This is especially true in California. Unfortunately, there are a few studies that have examined how California school psychologists and school counselors perceive their training to provide SBMHS, how they perceive their role in providing these services, and what they regard as their needs for professional development. The purpose of this study is to determine the extent to which California school psychologists and school counselors believe that their formal pre-service education and later in-service professional experiences have prepared them to provide SBMHS. This study also examines the extent that California school psychologists and school counselors feel prepared to deliver various SBMHS. An online survey was created to answer the study's research questions, which is in the form of a descriptive survey design. A questionnaire was created and altered appropriately for the two groups of professionals. An overall sample size of 156 was obtained. Overall, the findings suggest that the California school psychologists and school counselors in this study agree that their formal pre-service education, except for their undergraduate program, prepared them to provide SBMHS. Also, participants strongly agree that both workshops/trainings and in-service professional experiences prepared them to provide SBMHS. There were no significant differences between the two groups' responses regarding pre-service education or later in-service professional experiences. However, there were significant differences between the two groups' responses to questions regarding developing and implementing behavior intervention plans 
(BIPs), providing behavior interventions, and conducting social-emotional/behavioral assessments and interpreting results. In each of these cases, school psychologists expressed feeling more prepared than school counselors to provide these services. Most participants expressed a need to receive more training in the form of workshops or other professional development to support them in their positions for the provision of SBMHS. As we continue to see a rise in schools becoming the primary location for mental health services for children and adolescents, school psychologists and school counselors should continue to receive ongoing training to support them in their roles as SBMHS providers. 


\section{TABLE OF CONTENTS}

$\underline{\text { Page }}$

ACKNOWLEDGEMENTS ................................................................................................ IV

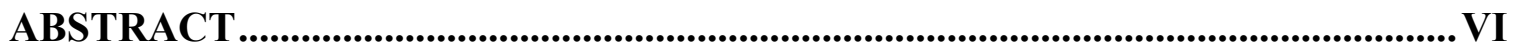

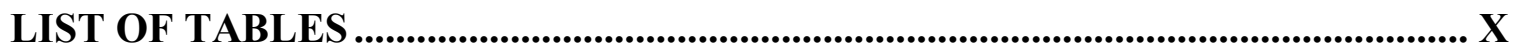

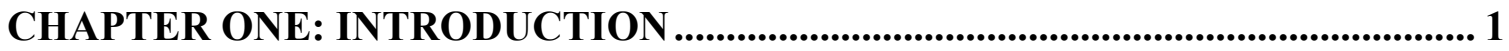

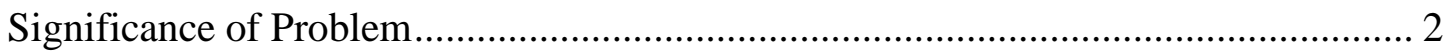

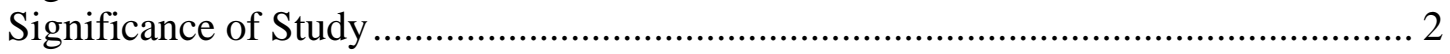

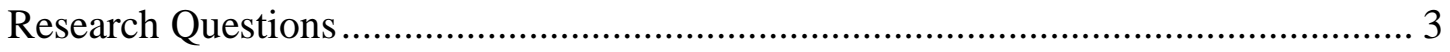

CHAPTER TWO: LITERATURE REVIEW ........................................................... 4

Mental Health Disorders Among Youth ................................................................. 4

Internalizing Disorders...................................................................... 5

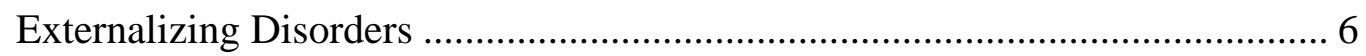

Possible Risks for Untreated Mental Health Disorders .................................... 7

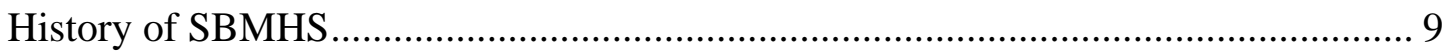

Three-Tiered Approach to Addressing Mental Health .................................. 10

Special Education and SBMHS ........................................................... 12

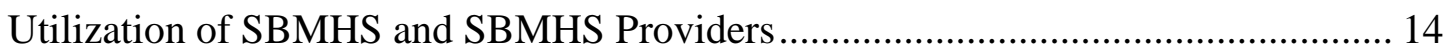

Barriers to the Utilization of SBMHS ........................................................... 16

SBMHS Providers............................................................................ 18

Efficacy and Effectiveness of Services ........................................................... 20

Provision of SBMHS by School Psychologists and School Counselors ................... 23

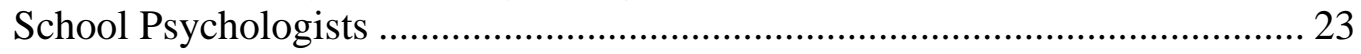

School Counselors ............................................................................ 27

Studies including School Psychologists and School Counselors...................... 30

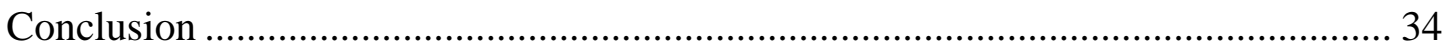

CHAPTER THREE: METHODOLOGY ............................................................... 35

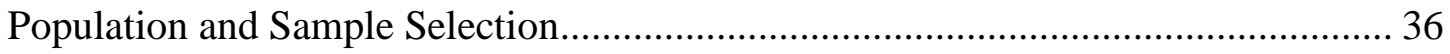

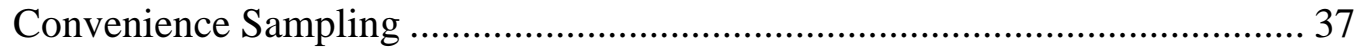

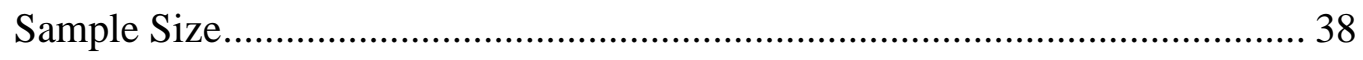

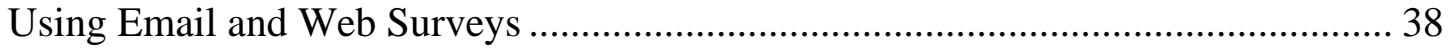

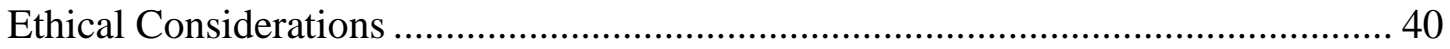

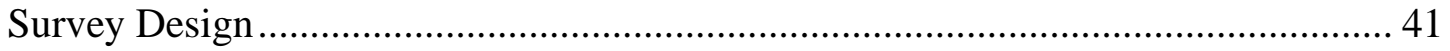

Quantitative and Qualitative Online Survey Research ................................. 42

Survey Questions ................................................................................. 42 


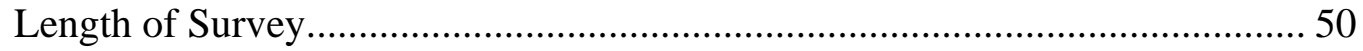

Determining Validity of Measure ……………………....................................... 50

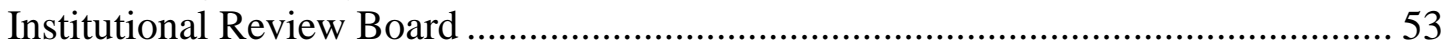

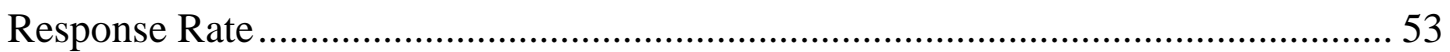

Current Research Method Summary ..................................................................... 54

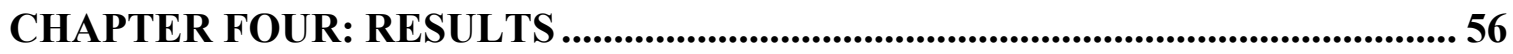

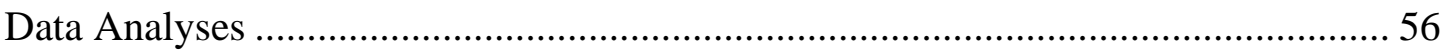

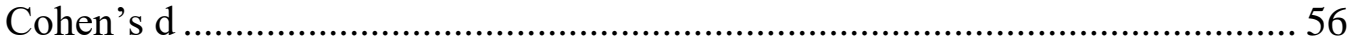

Spearman's Rho Correlation Coefficient.......................................................... 57

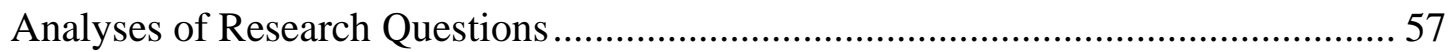

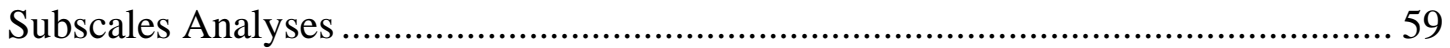

Education and Professional Experience Subscales ………………………...... 59

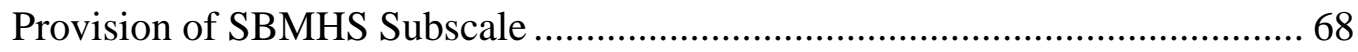

Importance and Competence Subscale ……………………………………..... 77

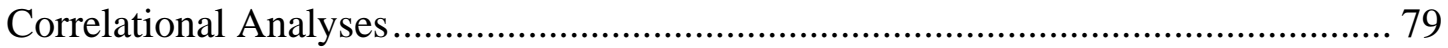

Additional Comments and Feedback from Survey ................................................. 81

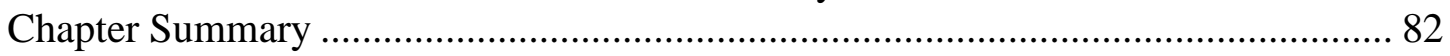

CHAPTER FIVE: DISCUSSION.................................................................................. 84

Discussion of Findings................................................................................... 84

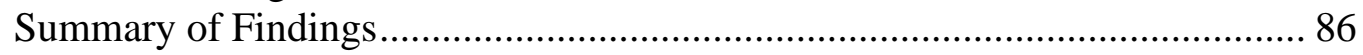

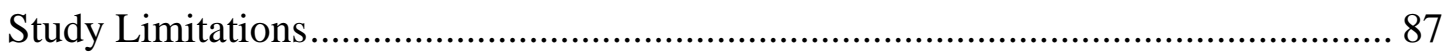

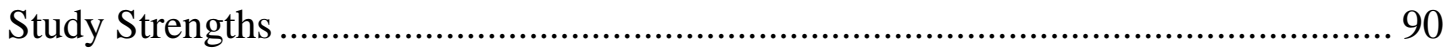

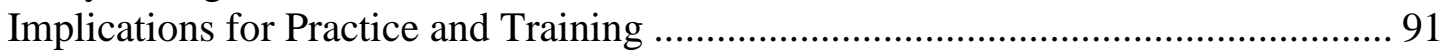

Implications for Future Research...................................................................... 92

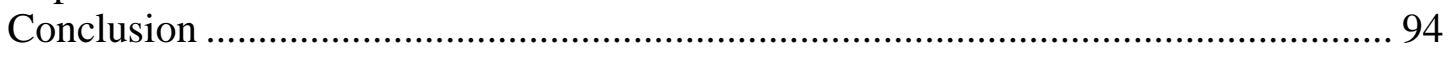

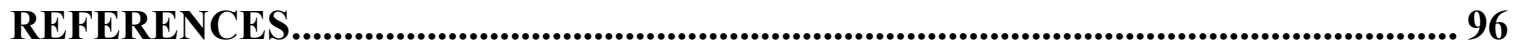

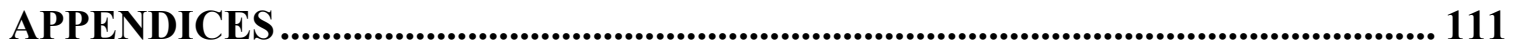




\section{LIST OF TABLES}

$\underline{\text { Page }}$

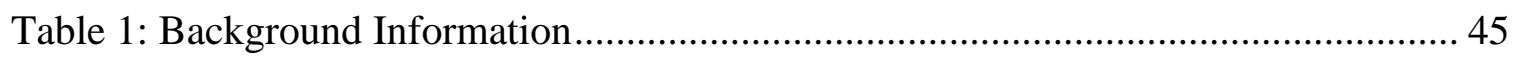

Table 2: Educational Preparation and Experience Subscale ....................................... 59

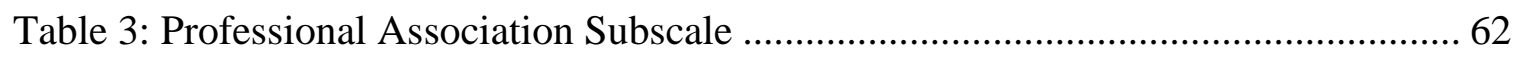

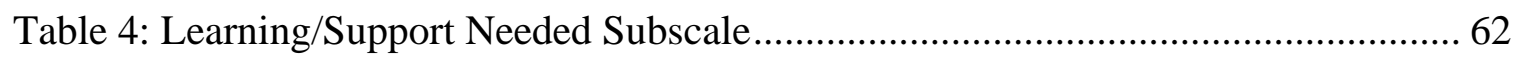

Table 5: Additional Graduate Level Coursework and State Registrations/Licenses Subscale

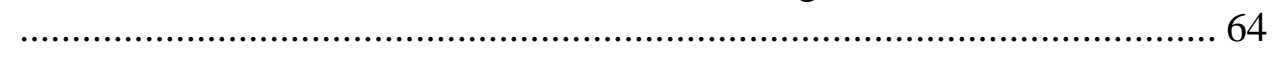

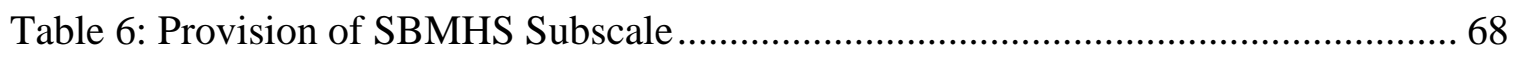

Table 7: Importance and Competence Subscale .................................................... 77

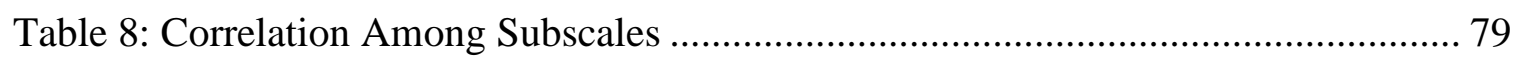

Table 9: Correlations Among Independent Variable and Subscale Scores ..................... 80 


\section{Chapter One: Introduction}

The mental health struggles of children and adolescents in the United States has become pressing in recent literature (e.g., Brener \& Demissie, 2018; Guerra, Rajan, \& Roberts, 2019; Splett, George, Zaheer, Weist, Evans, \& Kern, 2018). In the last 25 years, there has been a significant increase in the literature addressing mental health concerns among youth and mental health services for children and adolescents. Some of this literature (e.g., Crespi \& Hughes, 2004; Flaherty, Weist, \& Warner, 1996) has suggested that the accessibility of mental health services is a critical issue, even though at the same time, there is an increased need for these services.

According to Crespi and Hughes (2004), a large number of adolescents required mental health services toward the end of the $20^{\text {th }}$ century. This increase was observed in the rising number of admissions, of approximately 6,500 to 200,000 adolescents, into inpatient psychiatric treatments within 20-years per Hewlett (as cited in Crespi \& Hughes, 2004). However, many parents faced barriers, such as a lack of insurance coverage, which prevented them from obtaining the services their children needed (Crespi \& Hughes, 2004). Because of these barriers and so children and adolescents could more easily receive the necessary mental health support, many of these services were provided in schools (Crespi \& Hughes, 2004; Flaherty et al., 1996).

Eklund, Meyer, Way, and Mclean (2017) argue that because most children in the United States go to school for several hours a day, schools are the most accessible location for youth to obtain mental health services. This trend has been identified since the 1990s. For example, Burns et al. (1995) found that although only $16 \%$ of children who had a mental health problem received mental health services, of those who did receive services, $70-80 \%$ of children received these services from providers in an educational setting. School-based mental health services 
(SBMHS) have the potential to remove many of the barriers hindering children from obtaining mental health services and to enhance the organization of these services (Committee of School Health, 2004).

\section{Significance of Problem}

School psychologists and school counselors are increasingly playing an essential role in the provision of SBMHS. This is especially true in California. About nine years ago, the state of California saw a shift in who holds the responsibility of providing mental health services to students. Due to the termination of California's Assembly Bill (AB) 3632 and implementation of AB114 on June 30, 2011, the delivery and financing of mental health services had gone from being the responsibility of child welfare departments and county mental health services to being the responsibility of school districts (Lawson \& Cmar, 2016). As a result, some school districts began to utilize staff such as school psychologists and school counselors to deliver these services within the school setting.

Unfortunately, there are a few studies that have examined how school psychologists and school counselors perceive their training to provide SBMHS, how they perceive their role in providing these services, and what they regard as their needs for professional development. An extensive review of literature did not uncover any studies focused on the perceptions of California school psychologists and school counselors' preparation to provide SBMHS.

\section{Significance of Study}

This study is important because it will provide insight into how California school psychologists and school counselors perceive the preparation they received to provide SBMHS. The purpose of this study is to determine the extent to which school psychologists and school counselors in California believe that their formal pre-service education and later in-service professional experiences have prepared them to provide SBMHS. This researcher will also 
examine the extent that school psychologists and school counselors in California feel prepared to deliver various mental health services. By conducting this study, this researcher hopes to add to the fields of school psychology and school counseling by providing survey data that could be used as a basis for future research. In addition, data from this study can hopefully provide graduate programs and school districts in California information on how to possibly support future and current school psychologists and school counselors in the provision of SBMHS.

\section{Research Questions}

This study will address two research questions which each include one sub-question:

Research question 1. To what extent do school psychologists and school counselors in California believe that their formal education (i.e., undergraduate, graduate, training/workshops) has prepared them to provide school-based mental health services?

Research question 1a. Do school psychologists and school counselors in California differ from one another in their perceptions of how well their formal education (i.e., undergraduate, graduate, training/workshops) has prepared them to provide school-based mental health services?

Research question 2. To what extent do school psychologists and school counselors in California believe that their professional experiences have prepared them to provide schoolbased mental health services?

Research question 2a. Do school psychologists and school counselors in California differ significantly from one another in their perceptions of how well their professional experiences have prepared them to provide school-based mental health services? 


\section{Chapter Two: Literature Review}

This chapter begins by briefly discussing the prevalence of mental disorders among youth. This chapter continues with a review of what the literature says about the (a) history of school-based mental health services (SBMHS) in the United States, (b) utilization of SBMHS by students, and (c) SBMHS providers. Lastly, literature that focuses on school psychologists and school counselors, and the role they play in the provision of SBMHS is reviewed.

\section{Mental Health Disorders Among Youth}

To understand the need for mental health services for children and adolescents, it is imperative to understand the impact of mental health on children and adolescents. The United States Department of Health and Human Services (1999) stated that "Mental health in childhood and adolescence is defined by the achievement of expected developmental cognitive, social, and emotional milestones and by secure attachments, satisfying social relationships, and effective coping skills" (p. 123). Moore et al. (2016) argue that having good mental health assists in the development of healthy relationships, gives a firm basis for developing skills for self-regulation

(i.e., behavior used to soothe or calm self), and reinforces learning. Therefore, in the early stages of childhood, good mental health is important for a child to flourish (Moore et al., 2016). However, the ability to achieve good mental health can be hindered by a child's psychosocial and mental health problems (i.e., mental health disorders).

Approximately $14-20 \%$ of children have a mental health disorder (National Academy of Sciences, 2009). The concept of childhood mental illness, however, did not arise until the late $19^{\text {th }}$ century. They were not generally viewed as exclusive to children or different from the mental illnesses experienced by adults until the early $20^{\text {th }}$ century (Hoagwood, Burns, Kiser, Ringeisen, \& Schoenwald, 2001). In comparison to adults, children experience changes to their physiological, neuronal, and psychological states much more rapidly and over a shorter amount 
of time than adults (Hoagwood et al., 2001). However, similarly to adults, children and adolescents can experience a variety of mental illnesses. These include internalizing disorders (e.g., anxiety, mood disorders) and externalizing disorders (e.g., behavior disorders, substance use disorders).

\section{Internalizing Disorders}

Gresham and Kern (as cited in Marsh, 2016) describe internalizing behavior as behaviors that are focused inward towards the individual. Internalizing behaviors are often associated with behavioral symptoms such as withdrawal and social isolation (Madigan, Atkinson, Laurin, \& Benoit, 2013). The two primary and most common types of internalizing disorders are anxiety disorders and depression or mood disorders (Goldstein \& DeVries, 2017; Marsh, 2016).

Anxiety disorders. The Child Mind Institute (2017) reports that the most common mental health disorders in youth are anxiety disorders. Ghandour et al. (2019) found that 7.1\% of children between the ages of 3-17 have anxiety problems. Merikangas et al. (2010) indicate that by age $18,31.9 \%$ (nearly 1 out of 3 ) adolescents will meet the criteria for an anxiety disorder (e.g., Specific Phobia, Social Phobia, Separation Anxiety, Post Traumatic-Stress Disorder, Panic Disorder, and Generalized Anxiety Disorder). The American Psychiatric Association (APA, 2013) mentions in the Diagnostic and Statistical Manual of Mental Health Disorders, $5^{\text {th }}$ Edition (DSM-V) that anxiety disorders vary from each other in the objects or situations that cause anxiety, fear, or avoidance behavior, and related thoughts. According to Kessler et al. (2005), the average age onset for anxiety disorders can be as early as the age of 7 . Since most anxiety disorders develop in childhood, they are likely to continue into adulthood if untreated (APA, 2013).

Mood disorders. Merikangas et al. (2010) mention that $14.3 \%$ of youth between the ages of 13 and 18 are affected by mood disorders (e.g., Major Depressive Disorder or Dysthymia, 
Bipolar Disorder I, and Bipolar Disorder II). Ghandour et al. (2019) discovered that among children aged 3-17, 3.2\% had depression. The average onset of depression or related mood disorders is typically around adolescence (Forness, Freeman, Paparella, Kaufmann, \& Walker 2012). Marsh (2016) states, "Mood disorders are characterized by disturbances in mood that affect overall functioning" (p. 320), which includes one's eating habits, sleeping patterns, and ability to carry out daily tasks (APA, 2013). According to Gresham and Kern (as cited in Marsh, 2016) and Johnson, Johnson, and Walker (2011), children and adolescents with mood disorders are often at greater risk for suicide.

\section{Externalizing Disorders}

Furlong, Morrison, and Jimerson (2004) describe externalizing behavior as behaviors that are outwardly displayed towards the social environment. Children may be considered as exhibiting externalizing behavior if they are aggressive, have a difficult temperament, or are impulsive (Furlong et al., 2004). Two types of externalizing disorders among children and adolescents are behavioral disorders and substance use disorders (Goldstein \& DeVries, 2017; Marsh, 2016).

Behavioral disorders. Behavioral disorders [e.g., Attention Deficit-Hyperactivity Disorder (ADHD), Oppositional Defiant Disorder, and Conduct Disorder] are the second most common disorders experienced by youth (Merikangas et al., 2010). Ghandour et al. (2019) found that $7.4 \%$ of children aged 3-17 had a behavioral/conduct problem. However, according to Merikangas et al., (2010), approximately $19.1 \%$ of youth between the ages of 13-18 experience a behavior disorder, and the median age onset for behavior disorders is 11-years-old. Teens that have behavior disorders are faced with many risks. For example, teens with ADHD are at risk of failing school, having an accident (i.e., car accident), injuring themselves, or falling into trouble with the law (Child Mind Institute, 2017). 
Substance use disorders. The use of substances among teens is not uncommon. According to Merikangas et al. (2010), 11.4\% of teens have a substance use disorder (alcohol abuse/dependence, drug abuse/dependence). The average onset age for substance abuse disorder is 14-years-old (Swendsen et al., 2012). The main feature of this disorder is a group of cognitive, behavioral, and physiological symptoms that suggest that one continues to use a substance regardless of the problems related to that substance (APA, 2013). Roberts, Roberts, and Xing (2007) suggest that there is a significant increase with age regarding the prevalence of substance use and abuse. Unfortunately, the use of substances in adult years and more severe external disorders such as antisocial personality disorder are risk factors of adolescent substance use (Meyers \& Dick, 2010).

Dikel (2014) mentions that the use of illegal drugs can imitate mental health disorders such as anxiety disorders, mood disorders (e.g., major depression, bipolar disorder), and psychotic disorders. Since there is a possibility for comorbidity of other mental health disorders (e.g., ADHD and bipolar disorder) and substance use disorder, it is important for coexisting mental health disorders to be treated in the course of receiving treatment for the substance abuse disorder (Dikel, 2014). This type of treatment would ideally take place within a cohesive treatment program for dual-diagnosis (Dikel, 2014), which is typically provided in a clinical setting and not in a school setting.

\section{Possible Risks for Untreated Mental Health Disorders}

Approximately $78.1 \%$ of US children with depression between ages 3-17 received mental health support compared to $59.3 \%$ of children with anxiety and $53.5 \%$ of children with behavioral/conduct problems (Ghandour et al., 2019). Mental health support could be beneficial for many youth and could even prevent greater risks later in development. Far too often, many adolescents with mental health disorders do not receive treatment (Child Mind Institute, 2017). 
In 2011, Merikangas et al. showed that $40 \%$ of adolescents with ADHD, $60 \%$ of adolescents with depression, and $80 \%$ of adolescents with anxiety disorders did not receive treatment for their conditions.

Untreated mental health disorders can have critical adverse effects on children. These can include poor academic achievement, classroom behavior problems, poor attendance, or low motivation towards schoolwork (Joe, Joe, \& Rowley, 2009). Failure to provide adequate attention to the mental health of children and adolescents may lead to lifelong consequences. More specifically, untreated mental health disorders can lead to higher rates of juvenile incarceration, cases of school dropout, cases of familial dysfunction, drug abuse, and unemployment (Committee on School Health, 2004).

Because untreated mental health problems can lead to involvement with the juvenile justice system and incarceration, the juvenile justice system has become the de facto mental health service system for many youth. For example, approximately $70 \%$ of youth in juvenile justice systems have mental health disorders, and $20 \%$ of these adolescents have severe disorders that cause significant impairment, making it difficult for them to successfully function in school and the community without significant supports (Skowyra \& Cocozza, 2007).

In addition to personal negative consequences, untreated mental illness can reduce the safety and productivity of the societies in which these subjects live (World Health Organization, 2003). Determining the positive and negative influences that impact mental health can lead to early intervention, and this intervention can lessen the impact of these disorders (Kieling et al., 2011). Therefore, it is potentially vital for youth with mental health disorders to have access to mental health services so that they do not go down a dangerous path, even if these services are delivered within the school setting. 


\section{History of SBMHS}

Although schools in California only recently took greater responsibility for providing mental health services, the provision of mental health services in schools is not a recent phenomenon. Hoagwood and Erwin (1997) write that the importance of providing mental health services in schools in the United States was first acknowledged in Chicago during the 1800s. By the end of the 1800s, mental health services for children were instated by offering counseling services to children who had school-related problems in response to the rising number of adolescents sent to adult jails (Kutash, Duchnowski, \& Lynn, 2006).

By 1922, child guidance clinics had been built throughout the country and were staffed primarily by social workers (Kutash et al., 2006). As the clinics continued to grow, they began to include multidisciplinary teams (Kutash et al., 2006; Pumariega \& Vance, 1999). Staff for these clinics began to include various professionals, such as pediatricians, psychologists, psychoanalysts, and psychiatrists (Pumariega \& Vance, 1999). These teams, which were developed to work particularly with school districts, encouraged community-based and nonhospital-based support for children (Kutash et al., 2006). Low-cost services that focused on the needs of children and families were also provided by the clinics. These services included treatment models that included individual psychodynamic therapy, crisis intervention, family therapy, and day treatment services (Pumariega \& Vance, 1999).

Throughout the 1970s, SBMHS grew to consist of various interventions delivered directly and indirectly within schools (Hoagwood \& Erwin, 1997). School-based clinics were created during this time. These clinics offered mental health services as part of a broader package of health services, including on-site medical screenings, physical exams, treatment for accidents, minor illnesses, family planning counseling, and assistance with personal struggles (Flaherty et al., 1996). During the 1990s, custom SBMHS were created for students who were in jeopardy of 
failing school or who were impacted by crises, such as the suicide of someone around them (Hoagwood \& Erwin, 1997). As SBMHS continued to develop, more customized programs and interventions geared towards specific areas (e.g., anxiety, anger, grief, bullying, and peer relationships) became more common in schools.

\section{Three-Tiered Approach to Addressing Mental Health}

Kieling et al. (2011) argue that, if possible, early intervention could potentially stop the development of mental health problems in children and adolescents. Once these disorders are diagnosed, more intense and targeted treatments are typically needed. This information suggests the need for SBMHS to take both proactive and a preventive approach as well as a reactive approach that focuses on the treatment of already existing disorders.

Adelman and Taylor (2012) outlined a continuum of services consisting of integrated subsystems that would encourage healthy development and the prevention of problems, allow for early intervention to negate the onset of problems, and support those with more chronic and severe problems. Following a continuum of services, a three-tiered model of services has often been used to group aspects of mental health programs within schools or districts. Examples of these three-tiered models may include the Response to Intervention (RTI) or Multi-tiered System of Supports (MTSS). Schools are the best environment in which to reach a higher number of children; therefore, a three-tiered model approach is an optimal way to conceptualize an array of interventions that would prevent the development of psychiatric issues among students (Fazel, Hoagwood, Stephan, \& Ford 2014). These tiers can include various levels of intervention. However, this paper will focus on the following levels of intervention: (1) prevention, (2) intervention, and (3) more intensive intervention.

Tier 1: Prevention. Tier 1 includes various preventive mental health services that target all students (Committee on School Health, 2004) and can be considered a more universal 
approach (Fazel et al., 2014). Strategies, such as Positive Behavior Interventions and Supports (PBIS), may be used to assist overall student wellness. This is in addition to the offering of counseling services (California Association of School Psychologists [CASP], 2014). According to Anello et al. (2016), PBIS functions as a layered system of interventions centered on prevention. Other methods, such as cognitive-behavioral approaches and techniques for stress reduction, have also been used at this tier level (Fazel et al., 2014).

Primary prevention approaches are put in place to encourage positive behavior for all students (Anello et al., 2016). Kutash and colleagues (2006) write that schools take on the prevention of emotional and behavioral problems and recognize potential issues that inhibit educational progress. Preventive interventions created to focus on children who are likely to develop emotional or behavioral struggles have been known to lessen symptoms and encourage the utilization of positive coping strategies (Hoagwood et al., 2001). However, approaches at this tier level may be difficult to execute because they are comprehensive and require the combined effort of all school employees and members of the administration (Fazel et al., 2014).

Tier 2: Intervention. Typically, the $15-20 \%$ of students who do not respond to Tier 1 prevention interventions and are at risk of or already demonstrating early levels of behavioral problems receive Tier 2 interventions (Anello et al., 2016). Tier 2 includes mental health services geared towards students who have one or more mental health needs but can effectively participate in many academic, social, or miscellaneous activities throughout the day (Committee on School Health, 2004). This level of intervention may include a Check-In/Check-Out system (e.g., Campbell \& Anderson, 2011; Simonsen, Myers, \& Briere, 2011) with individual students or a small group intervention that utilizes group curriculum programs (e.g., Second-Step, Strong Teens) to increase and maintain appropriate behavior (CASP, 2014). This tier may also address 
behavioral aspects for students who have individualized education programs (IEPs) or individual health service plans for behavioral problems (Committee on School Health, 2004).

Tier 3: More intensive intervention. Tier 3 targets the $1-5 \%$ of students who are nonresponsive to Tier 2 interventions (Anello et al., 2016). Tier 3 typically addresses the needs of students who have severe mental health disorders and symptoms (Committee on School Health, 2004). According to the Policy Leadership Cadre for Mental Health in Schools (as cited in Committee on School Health, 2004), these students usually need a multidisciplinary team of specialists to provide services to them such as special education services, coordination between school and social agency, individual and family therapy, and pharmacotherapy. Interventions at this level are geared towards decreasing the severity and frequency of challenging student behaviors (Anello et al., 2016). Individual counseling often takes place during this level of intervention. Students at this tier may benefit from counseling that is provided individually and that assists students in developing coping and problem-solving skills (CASP, 2014). Services through Educationally Related Mental Health Services (ERMHS)/Educationally Related Intensive Counseling Services (ERICS), as described in the following section, may be provided at this tier level for students in special education, depending on the school district.

\section{Special Education and SBMHS}

There is not only a need for mental health support in schools but also a specific need for mental health support for students in special education programs. Important federal initiatives have assisted the quick development of SBMHS in the United States (Paternite, 2005), such as the Education for All Handicapped Children passed by Congress in 1975 (Kutash et al., 2006). This law states that every student is allowed access to a free, public education, including special education and related support services (Hoagwood \& Erwin, 1997). The Individuals with 
Disabilities Education Act (IDEA) was later enacted in 1990 and amended in 1997 (Jacob, Decker, \& Timmerman-Lugg, 2016).

IDEA shifted the responsibility of addressing student mental health to educational systems when the student's health affected their potential academic success (Fazel et al., 2014). IDEA also mandated that education systems would ultimately need to provide all support services necessary to assist in educating students with disabilities (Kutash et al., 2006). Students were then eligible for several support services, including consultations with teachers, counseling (individual, group, or family), and residential treatment placements (Hoagwood \& Erwin, 1997). Now known as Individuals with Disabilities Educational Improvement Act of 2004 (IDEIA 2004) (Atkins, Hoagwood, Kutash, \& Seidman, 2010; Jacob et al., 2016), this law “mandates that students with emotional and behavioral disorders, along with students with other disabilities who have mental health needs be provided with mental health services as required to benefit from their special education programs [20 U.S.C $\S \S 1401$ et seq.]” (Lawson \& Cmar, 2016, p. 1). Therefore, it is required by law that schools provide mental health services when that service is essential to a child's education (Committee on School Health, 2004).

SBMHS in California. Over the past few decades, there has been a growing need for more intensive mental health services for special education students (e.g., Lawson \& Cmar, 2014; Santiago, Kataoka, Forness, \& Miranda, 2014). Certain states are finding ways to address these needs. For example, the legislative history of California regarding mental health services for disabled students offers a significant and distinctive take on the influence of state policy on the ability of schools to create effective models of service delivery while meeting the mental health needs of students (Lawson \& Cmar, 2016). California schools now take more 
responsibility in addressing the mental health needs of their students when those needs are impacting their educational performance. Prior to July 2011, however, this was not the case.

In 1984, California legislature passed Assembly Bill (AB) 3632, which required county mental health departments to provide psychological counseling services to pupils who were most severely impacted (CASP, 2014) and needed these services to benefit from special education (Beam, Brady, \& Sopp, 2011). On June 30, 2011, AB3632 was replaced by AB114, which requires all local educational agencies (LEAs) to take responsibility for all mental health services (Beam et al., 2011; CASP, 2014). In response to the enactment of AB114, school districts reconceptualized and altered their guidelines for providing mental health services to students with disabilities (Lawson \& Cmar, 2016). LEAs created a range of counseling services that were educationally related, which have been commonly referred to as Educationally Related Mental Health Services (ERMHS)/Educationally Related Intensive Counseling Services (ERICS) (CASP, 2014). CASP describes ERMHS/ERICS as more intensive services, which may include an increase in the duration or frequency of these services or work with specialized staff. They also acknowledge that some of these services may include counseling services, parental counseling and training, psychological services, social work services in schools, and residential placement. To receive ERMHS/ERICS, a student would need to qualify for special education under IDEIA 2004.

\section{Utilization of SBMHS and SBMHS Providers}

Adelman and Taylor (2012) contend that mental health systems and education systems emphasized one or both of the following objectives as the reason to increase mental health support in schools: (1) adequate access to mental health services is granted to students (and their families) through schools, and (2) schools attending to psychosocial, mental health, and physical health concerns will result in higher school performances and increase the well-being of students. 
The first objective generally reflects mental health advocates' and agencies' viewpoints and plan to enhance mental health services, while the second objective reflects the viewpoint and plan of student support specialists and some leaders for improvement of schools (Adelman \& Taylor, 2012). However, these objectives may be challenging to carry out in the school setting if students' mental health struggles are not addressed.

In their earlier work, Adelman and Taylor (2000) suggested that, for schools to operate adequately and for students to learn and perform successfully, mental health and psychosocial issues need to be a focus. As mental health services take place within the school setting, schools can concentrate more on learning barriers that may impact students at some point in their schooling (Eklund et al., 2017). This is especially true due to the strong connection between mental health and academic functioning. Mental health problems can impair a student's ability to function academically, and poor academic performance can make mental health problems worse (Paulus, Ohmann, \& Popow, 2016). Children have a decreased ability to learn and benefit from their school environment if their behavioral, emotional, or social difficulties are not dealt with (Rones \& Hoagwood, 2000).

Foster et al. (2005) conducted a national study not only to identify the mental health struggles that are most often encountered in United States public schools but also to gain an idea of the mental health services offered. Approximately 83,000 schools (elementary, middle, and high schools) and their corresponding school districts participated in the study. According to their findings, 73\% of the schools indicated that social, interpersonal, or familial problems was the most common concern regardless of student gender (Foster et al., 2005). The second and third most common problems for male students were aggression or disruptive behavior and behavioral problems related to neurological disorders. On the other hand, the second and third 
most common problems for female students were anxiety and adjustment problems. Foster and colleagues noted that all students were entitled to receive mental health services in $87 \%$ of schools, not only students in special education. Most of the schools provided case management and individual and group counseling services. In addition, over $80 \%$ of schools offered mental health assessments, consultation for behavior management, crisis intervention, and referrals to specialized programs (Foster et al. 2005).

\section{Barriers to the Utilization of SBMHS}

Data from the National Longitudinal Study of Adolescent Health (Add Health), a study that examined a national sample that was drawn from 132 schools representative of middle and high school adolescents in the United States in 1995, allowed Slade (2002) to show that approximately 3 out of 5 adolescents attend a school in which on-site mental health counseling services are available. Slade writes that, in 1994, school-based services were used less often than non-school-based services (4.4\% vs. $8.8 \%$ ). Data from the study shows that students who attend schools with mental health counseling services are more likely to receive counseling at school than students who attended schools that did not have services on-site $(p<.001)$, however, the rate that counseling was received outside of the school setting did not essentially show any difference $(p=.757)$ (Slade, 2002). The results of the study imply that schools have had and can have a significant, positive effect on how adolescents use mental health counseling services (Slade, 2002).

Williams and Chapman (2015) conducted a similar study. Williams and Chapman conducted their study primarily to perform a multilevel analysis and examine whether the accessibility of SBMHS influences the likelihood that adolescents with mental health needs will

utilize mental health services. Williams and Chapman used data obtained from the Add Health, a nationally representative probability school-based survey. The Add Health survey data from 
Wave 1 included 20,745 adolescents in $7^{\text {th }}-12^{\text {th }}$ grade, who were chosen based on unequal probability from 132 schools. The subsample of the survey for the study included adolescents with mental health needs from Wave 1 in-home interviews conducted between April 1995 and December 1995 during the Add Health study ( $\mathrm{n}=8,034)$. Williams and Chapman (2015) found that it was $40 \%$ more likely that a student with mental health needs would obtain the necessary services in any sector if they attended schools with SBMHS as opposed to those without SBMHS $(\mathrm{OR}=1.40, p<.001)$. This indicates that schools play a primary role in the provision of mental health services for adolescents (Williams \& Chapman, 2015).

Green et al. (2013) utilized data from the National Comorbidity Survey Adolescent Supplement (NCS-A) to study the relationship between school mental health resources and the use of SBMHS by students, in addition to services in different divisions of the child mental health system. The NCS-A initially took place from 2001 to 2004 in a dual-frame (household and school), which included a national sample of adolescents (ages 13-17) and the parents of those adolescents. Green and colleagues (2013) focused only on the school sample for their study, which included 320 schools. They studied the relationships between predictors at the schoollevel with individual-level usages of mental health services in the entire sample. The results of the study suggest that there is significant variation between the number and form of mental health resources that schools provide (Green et al., 2013). Green et al. report that the majority of schools have some prevention (85\%) or early identification (89\%) and acknowledge the provision of individual, group, or family counseling (88.2\%). According to Green and colleagues, there is an essential connection between school involvement in early identification, the use of services by adolescents who have early or mild mental disorders, and those with behavior disorders. 
DeFosset, Gase, Ijadi-Maghsoodi, and Kuo (2017) conducted a qualitative study to explore how youth express their mental health problems, specifically regarding their attendance at school, and to explain their experiences with and views of SBMHS. For the study, 18 out of the 39 interviews conducted in fall 2013 were analyzed. The 18 interviews chosen were a subgroup of youth that reported facing mental health struggles. The results from the study imply that the main barriers in schools related to supporting mental health needs include poor relationships with adults and students' negative attitudes regarding mental health services (DeFosset et al., 2017).

\section{SBMHS Providers}

SBMHS are necessary for children and adolescents to receive the mental health support they need to make educational progress. To accomplish this, schools must utilize different providers. School providers responsible for the implementation of SBMHS may have different professional backgrounds (i.e., school psychologists, school counselors, school social workers, school nurses). However, not all SBMHS providers are school employees. Students may receive SBMHS from outside public health providers contracted by school districts. These providers may include social workers, marriage and family therapists, or clinical counselors. When this is the case, SBMHS stress the partnerships between schools and their communities to execute a full continuum of services (e.g., promotion, prevention, early intervention, and treatment) (Anello et al., 2016). If allowed adequate collaboration with schools, public health providers can help develop a continuum of interventions designed to have a substantial impact on the safety, health, learning ability, and overall well-being of adolescents (Adelman \& Taylor, 2006). Nastasi (2004) claims that collaboration amongst professional specialties, organizations, and systems is the goal 
of both general education and comprehensive mental health. Although this is a shared goal between these systems of support, the experiences of service providers seem to vary.

Massey, Armstrong, Boroughs, Henson, and McCash (2005) examined the experiences of service providers for their study. The researchers aimed to find the similarities and differences in the service providers' experiences that could then be linked to the difficulties and necessary support needed for the implementation, process development, and maintainability of programs within school systems. These service providers were funded by the Safe Schools/Healthy Students Initiatives (SS/HSI) grants. For the study, participants included focus groups of 22 service-providing staff members and senior program supervisors. Social workers, counselors, and school psychologists were also among the participants. According to Massey and colleagues (2005), these participants were a part of prevention-oriented efforts programs (e.g., training on gang awareness and social marketing) and intervention-oriented efforts (e.g., anger management training and services for familial mental health support). These focus groups were categorized as school-system prevention programs, school-system intervention programs, community-based prevention programs, and community-based intervention programs. The groups were held over six weeks.

The findings from Massey and colleagues centered around the following: (a) the differences among groups regarding difficulties incorporating services into schools, (b) the differences among groups in the sustainability attempts among internal or external providers, and (c) matters involving obtaining informed consent and maintaining confidentiality in the school setting. External providers faced school integration challenges, including the struggle to gain access to school administrators, build relationships with school personnel, and comprehend where they fit within the school structure. In addition to this, the challenge of school 
administration support influenced the success of these programs and their ability to integrate into schools. Internal providers indicated that they had more opportunities to become involved within the school (Massey et al., 2005). Regarding the sustainability of the providers' efforts, external providers sought to uphold the integrity of program efforts by defending the service unit by performing tasks such as writing grants, presenting to the community agencies that provide funding, and addressing the school board. Internal providers demonstrated sustainability by emphasizing internal distribution of program information, marketing the program to administrators in the district, and providing trainings to staff to integrate their programs within the curriculum. The concern regarding informed consent and confidentiality was due to the providers not having a clear process for gaining parent consent and service cooperation, which led to providers feeling uncomfortable with the possible problems surrounding informed consent and confidentiality (Massey et al., 2005).

\section{Efficacy and Effectiveness of Services}

According to Crisp, Gudmundsen, and Shirk (2006), it is imperative to examine whether schools are viable sites for the provision of treatment as treatment research shifts from efficacy to effectiveness studies. Streiner (2002) explained that efficacy asks questions about whether or not treatment works under ideal conditions, while effectiveness focuses on questions that determine if treatment works in the real world. Counseling interventions not only need to demonstrate efficacy with youth, but these services need to be shown to be effective when delivered in schools (Baskin \& Slaten, 2014). Therefore, schools need to find ways to support research on the efficacy and effectiveness of SBMHS.

Smith and colleagues (2007) discuss 8 goals from Satcher's 2000 Surgeon General Report that address the development of a practical yet effective mental health care system for children in the United States. These goals include: 
1. Promoting awareness and reducing the stigma associated with mental illness;

2. Promoting scientifically proven prevention and treatment programs;

3. Improving assessment and recognition of mental health needs;

4. Eliminating racial/ethnic and socioeconomic disparities in access to mental health care;

5. Improving the mental health infrastructure;

6. Increasing access to and coordination of quality mental health services;

7. Training front-line providers to recognize mental health issues and use scientifically proven prevention and treatment services; and

8. Monitoring access to and coordination to quality mental health care. (p. 7-5). While keeping these goals in mind, schools can work towards having an effective SBMHS system, which can then support the argument that there should be greater resources directed toward more SBMHS. The next two studies showcase how different SBMHS programs demonstrated efficacy in school settings.

In their review, Rones and Hoagwood (2000) examined the evidence for the effectiveness of SBMHS by reviewing literature from 1985-1999. The authors chose this timeframe because this was the time when SBMHS significantly increased. Their review discovered some important features of the execution process of programs.

These key program components include (i) consistent program implementation; (ii) inclusion of parents, teachers, or peers; (iii) use of multiple modalities (e.g., the combination of informational presentations with cognitive and behavioral skill training); (iv) integration of program content into general classroom curriculum; and (v) developmentally appropriate program components. (Rones \& Hoagwood, 2000, p. 237). 
Programs with the greatest evidence of effectiveness were those that were geared towards altering certain behaviors and skills related to the intervention (e.g., depression, conduct problems, drug use). The study also uncovered that effectiveness was related to programs that had developmentally appropriate concepts and curricula (Rones \& Hoagwood, 2000).

Per Baskin et al. (2010), being able to empirically demonstrate that SBMHS services are effective is a significant problem when requesting more resources. This issue leads Baskin and colleagues to ask the following questions "Are counseling interventions in school efficacious for k-12 youth? Are there moderators that make them more efficacious?" (p. 879). For their metaanalytic review study, Baskin and colleagues examined the efficacy of school interventions, including counseling and psychotherapy for youth. The authors also focused on exploring moderator variables that may impact the efficacy of services. Participant moderators (e.g., age, gender, ethnicity) and intervention moderators (e.g., therapist training, treatment modality, number of individuals receiving treatment) were the focus of their analysis.

Data from 107 studies that comprised of 132 treatment interventions were analyzed. Some of the key findings from the review include: (1) interventions were more effective for adolescents $(d=0.59)$ rather than for children $\left(d=0.35 ; Q_{b}=7.96, p=.005\right)$; (2) same-gender groups (female: $d=0.54$; male: $d=0.51$ ) performed significantly well when compared to mixedgender groups ( $d=0.33)$; (3) professionals who were licensed $(d=0.62)$ outperformed paraprofessionals $(d=0.45)$, and paraprofessionals outperformed graduate students $(d=0.17)$ in providing interventions $\left(Q_{b}=24.69, p<.001\right)$. There was a significant difference between the overall effect size $(d=0.45)$ of the study and zero. This overall result indicates that the use of counseling in schools is upheld by the significant efficacy discovered in the study (Baskin et al., 2010). 


\section{Provision of SBMHS by School Psychologists and School Counselors}

The delivery of SBMHS will vary across different school sites and providers. School psychologists and school counselors, for example, are two common kinds of providers. If they work together, school psychologists and school counselors can provide support to students and help them with their school experiences (Astramovich \& Loe, 2006).

\section{School Psychologists}

School psychologists receive training in both education and psychology, "with a focus on child development, behaviors, learning, curriculum and instruction, psychological assessment, consultation, and collaboration" (Dikel, 2014, p. 172). The National Association of School Psychologists (NASP, 2010) argues that direct educational and mental health services for children and adolescents are provided by school psychologists. These psychologists are also responsible for collaborating with educators, parents, and other professionals to create supportive learning and social environments for all students. As mentioned in the California Education Code Section 49424, school psychologists provide the following services: consultation with stakeholders (i.e., school administrators, teachers, parents, community agencies, pupil personnel service workers), psychoeducational assessment of specific learning disability and behavioral disability, and psychological counseling and other therapeutic methods delivered to children and parents (California Department of Education, 2019b).

As part of the NASP (2010) Model for Comprehensive and Integrated Services, the role school psychologists take regarding students' mental health is described as follows:

\section{Interventions and Mental Health Services to Develop Social and Life Skills}

School psychologists have knowledge of biological, cultural, developmental, and social 
influences on behavior and mental health, behavioral and emotional impacts on learning and life skills, and evidence-based strategies to promote social-emotional functioning and mental health.

School psychologists, in collaboration with others, demonstrate skills to use assessment and data-collection methods and to implement and evaluate services that support socialization, learning, and mental health. (p. 325).

School psychologists' duties include the delivery of counseling, instruction, and providing mentorship for students who struggle socially, emotionally, or behaviorally (Dikel, 2014). Skills training is also provided by school psychologists to help students who struggle with anger management, problem-solving, self-regulation, and socializing (Dikel, 2014). Although school psychologists can play a major role in addressing students' mental health, they also can have varied perceptions regarding the provision of SBMHS.

Hanchon and Fernald's (2013) study centered on the provision of school-based counseling by school psychologists. A national sample was taken in which 771 school psychologists completed an online survey. The survey examined the current practices of school psychologists while providing counseling, the types and levels of training received to provide counseling, and the opinions of psychologists regarding the need and importance of their provided school counseling (Hanchon \& Fernald, 2013). A strength of their study is that there was a large sample size; however, a limitation to this is that a large percentage (78\%) of the sample responses only came from 12 states, which does not necessarily represent a national response.

Hanchon and Fernald's study indicated that approximately $92 \%$ of participants received counseling training. Specifically, an average of $2.68(S D=1.86)$ counseling courses were taken 
among participants, as indicated through a descriptive analysis. Based on a 5-point scale from (1) It did not prepare me at all, (3) It prepared me sufficiently, and (5) It prepared me very well, respondents indicated that they felt best prepared to deliver individual counseling $(M=2.93 ; S D$ $=110)$, group counseling $(M=2.75 ; S D=1.06)$, and crisis response $(M=2.62 ; S D=1.12)$ (Hanchon \& Fernald, 2018). However, about $40 \%$ of participants noted that they view themselves as less than "sufficiently" prepared. Feelings of one's competency regarding the provision of counseling services was based on a range from (1) Not at all competent to (5) Very competent. The average rating among about $72 \%$ of respondents was $3.20(S D=1.13)$, indicating that most providers felt "Sufficiently competent" (Hanchon \& Fernald, 2013). Despite this, there was a significantly smaller number of participants actually applying their skills. This was the case even though those participants had conveyed a desire to become more involved in counseling. A majority of the participants believed in the importance of counseling as a service provided by school psychologists. However, they also indicated that others external to the field did not necessarily agree with this idea (Hanchon \& Fernald, 2013).

Both the barriers and support for the provision of SBMHS by school psychologists were emphasized in a study performed by Suldo, Friedrich, and Michalowski (2010). The goal of Suldo and colleagues was to determine why southeastern school psychologists were not delivering the desired level of service necessary to address children's mental health needs. Participants included 39 school psychologists from two school districts in a southeastern state. Eleven focus groups were held, and data were collected from fall 2006-2007. Suldo and colleagues (2010) indicate that the barriers mentioned most frequently included issues using schools as the location for delivering services and inadequate departmental and district administration support. The primary barrier, however, was personal concerns of whether the 
subject had received adequate professional preparation applicable to the field of mental health. The enabling factors mentioned most often by participants included adequate district and departmental support, successful assimilation into the school site, and individual characteristics (e.g., being able to set personal boundaries, relying on one's own parental experiences, remaining objective) (Suldo et al., 2010). Results from the study further insinuate that support from the community and a high personal opinion regarding competence may further guide specialists as they provide SBMHS (Suldo et al., 2010).

Eklund and colleagues (2017) took a slightly different approach for their study, in which they focused on the services that school psychologists were providing, the barriers to the provision of SBMHS by school psychologists, and recognizing if the delivery of SBMHS relates to the ratio of school psychologists to students. The study included 192 school psychologists from 82 school districts in a western state. The participants completed the SBMH Services and Advocacy Survey, which was developed by the authors, electronically. The school psychologists participating in the study provided SBMHS, such as individual counseling, group counseling, crisis intervention, and consultations with teachers. Eklund and colleagues (2017) note that some of the barriers reported include services provided by another school provider, not enough time to deliver services, and not enough support from the administration at the school and/or district level.

One of the analyses used in Eklund and colleagues' study is a chi-square test, which was used to assess the relationship among school psychologist to student ratio and the delivery of SBMHS by participant. This analysis showed that there was a significant relationship between the school psychologist to student ratio and providing SBMHS $\left[X^{2}(4, N=192)=13.31, p=.01\right]$. 
Eklund and colleagues emphasize that the number of hours of SBMHS delivered decreased as the ratio of school psychologists to students increased.

\section{School Counselors}

School counselors help students to develop academics, careers, goals, personal and social skills, and plans (Dikel, 2014). Per the California Education Code Section 49600, school counselors are trained educators (California Department of Education, 2019a). The California Department of Education also mentions that school counselors organize comprehensive counseling programs' objectives, strategies, and activities as agents on district school guidance teams.

In regard to addressing students' mental health, the American School Counselor Association (ASCA, 2015) believes that school counselors are responsible for identifying and responding to the need for prevention, early intervention, and crisis interventions for mental health. They are also responsible for identifying the behavioral support needed by students for their developmental and psychosocial wellness. ASCA (2015) also claims that the role and training of school counselors (e.g., delivering school counseling core curriculum, providing responsive services, recognizing warning signs, and identifying and addressing the mental health issues of students) uniquely qualifies them to provide these interventions, along with other referral services.

School counselors deliver individual and group counseling to students who are at-risk and to students who mental health disorders have been identified, and to address the developmental, preventive, and remedial needs of students (Dikel, 2014). In addition to providing counseling, consultation and collaboration may take place regarding identified concerns and needs for students between school counselors and other stakeholders (e.g., teachers, administrators, parents/guardians, other educational and community resources) (Dikel, 2014). 
Perkins, Oescher, and Ballard (2010) gathered information on the importance of school counselors and their involvement in not only the academic and career development of students but also their personal and social development. They asked, "How important is it for elementary school counselors to provide short-term personal/social counseling with individual students, groups, and families?" (p. 10). They administered the School Counselor Role Survey, developed by Perkins, via email, and received 353 returned surveys from elementary level staff (e.g., school counselors, school principals, teachers, and counselor educators). Participants provided responses based on a 5-point scale of (1) Not Important at All to (5) Extremely Important.

Perkins et al. (2010) concluded that participants primarily viewed the role of school counselors as addressing the personal and social problems of students. This role corresponds to the perspective of school counselors as mental health professionals as opposed to employees concerned mostly with academic and career development. Each group of participants found the role to be, overall, at least "somewhat important" (Perkins et al., 2010). Specifically, data analysis showed a $M=4.56$ and $S D=0.46$ based on school counselors' responses in the area of Personal/Social. Based on a series of ANOVA and Scheffe Post-Hoc analyses, the area of Personal/Social was presented with the following data: Type SS (between groups): SS = 5.77, df $=3 ; M S=1.92, F=8.18, p=.000 ;$ Post-Hoc $=$ Counselor Educators - Teachers, School Counselors - Principals, and School Counselors - Teachers. In addition, there was a significant difference in the area of Personal/Social between school counselors with principals and teachers (Perkins et al., 2010).

To take a more in-depth look at school counselors' perceptions of their training and experiences, Walley and Grothaus (2013) conducted a study in which they used qualitative methods to examine school counselors from eight secondary schools. They examined these 
counselors' preparation for their role and their ability to identify and respond to mental health issues among adolescents. The study found that relevant undergraduate classwork and experience gained while working or volunteering improved the abilities of new school counselors.

According to the participants, exposure to educational coursework was basic and limited (Walley \& Grothaus, 2013). To support the needs of secondary school students, participants would have liked more information on mental health. The participants also indicated that further knowledge specific to their schools regarding the identification of and response to adolescent mental issues was something learned on the job (e.g., from peers, from attending conferences and workshops, and through reading and research) (Walley \& Grothaus, 2013).

Carlson and Kees (2013) also examined school counselors' training in and comfort with providing mental health counseling interventions in the public-school setting based on the participants' self-report. The authors targeted members of the American School Counselor Association (ASCA). The study used the web-based School-Based Mental Health Services Survey, developed by Carlson, for their research purposes. There were only 120 surveys returned, which may be considered a small number of responses since surveys were initially sent out to the 1045 school counselors on the distribution list. Survey items included a 100-point sliding scale to indicate percentage.

Results of the study indicate that school counselors are more comfortable with the problems regularly brought to them by students and are rather confident in their ability to follow through with job expectations (Carlson \& Kees, 2013). However, the participants noted a higher level of discomfort when working with students formally diagnosed with mental health disorders. Data from the study show that participants expressed having more confidence when participating in consultation with parents, teachers, and administrators $(N=119, M=93.67, S D$ 
$=9.30)$ and least confident in using the DSM to diagnose client issues $(N=103, M=41.57, S D=$ 29.25). Eighty-eight percent of participants indicated that they are unable to provide the necessary services to students due to inadequate time caused by the needs of the school environment (Carlson \& Kees, 2013).

\section{Studies including School Psychologists and School Counselors}

Current literature examining both school psychologists and school counselors' perceptions regarding SBMHS is rather scarce. However, the following information includes studies conducted within the last eleven years in the United States that include both school psychologists and school counselors as respondents.

The primary focus of Dixon's (2009) study was to investigate SBMHS providers' perceptions about SBMHS and what makes the providers qualified to provide these services. SBMHS providers who participated in the study consisted of 358 school psychologists, school counselors, and school social workers recruited through the Florida Association of School Psychologists, Florida School Counselors Association, and Florida Association of School Social Workers. In addition to 90 directors and supervisors of student services. These participants completed a self-administered Perception of School Mental Health Services survey. Data were also drawn from an archival database that consisted of SBMHS supervisors and directors of student services who were surveyed during the 2006-2007 school year.

According to Dixon, findings from the study consisted of services such as counseling, crisis intervention, mental health consultation, and suicide prevention being considered as SBMHS among school mental health professionals. Assessments, consultation regarding academic concerns, early interventions, specialized intervention, and universal screenings were services that were not typically seen as mental health services (Dixon, 2009). There was a unanimous agreement that school psychologists were most qualified of the three school mental 
health professionals to provide normative and authentic assessments (Dixon, 2009). However, Dixon acknowledged that there was inconsistency between school mental health providers and administrators, apart from school psychologists, regarding the qualifications of providers to deliver services. For instance, administrators rated to a lesser degree when compared to the SBMHS providers, that school counselors were the most qualified to deliver majority of SBMHS (Dixon, 2009). In addition to this, the SBMHS professionals and administrators were unable to provide a well-defined definition for school social workers' qualifications and functions (Dixon, 2009).

Hill, Ohmstede, and Mims (2012) focused on exploring Nebraska schools' need for mental health services, how they are provided, and school professionals' level of satisfaction on the provision of these services. Participants included school psychologists, school counselors, and administrators. A survey was used to collect data, which was created by the researcher. A total of 62 usable surveys were analyzed.

Results from the study suggest that the following areas differ significantly regarding the different mental health services (e.g., individual therapy, group therapy, bully prevention, drug and alcohol prevention, crisis prevention, suicide prevention and education) within Nebraska schools: (1) need for different mental health services; (2) provision of mental health services; (3) satisfaction with the provision of the different types of mental health services (Hill et al., 2012). Twenty percent of participants reported that all services were not provided due to lack of resources, while $14 \%$ noted that there were not enough professionals to provide services in the school. Twenty-two percent of respondents reported that they did not have mental health services because the services were not needed in the school. Twelve percent indicated that services were provided for a short amount of time and on an individual basis. In addition, school counselors 
were found to provide majority of the mental health services. Overall, the three groups of respondents had similar perceptions of the need, provision, and satisfaction of services (Hill et al., 2012). For example, by using a one-way analysis of variance the authors found the following for individual therapy: Need (scale from $1=$ Strongly Disagree to $5=$ Strongly Agree) - -Administrators $[M=4.16(S D=.61)]$, School Counselors $[M=3.50(S D=1.26)]$, School Psychologists $[M=3.87(S D=1.01)], F=1.61$; Provision (scale from $1=$ Not Provided to $5=$ Adequately Provided $)$-- Administrators $[M=2.64(S D=1.05)]$, School Counselors $[M=2.83$ $(S D=1.21)]$, School Psychologists $[M=2.65(S D=1.12)], F=.12$; Satisfaction (scale from $1=$ Very Dissatisfied to $5=$ Very Satisfied $)$--Administrators $[M=3.20(S D=.89)]$, School Counselors $[M=3.33(S D=1.25)]$, School Psychologists $[M=3.19(S D=1.03)], F=.07$.

Schmidt's (2016) study centers on the self-perceived levels of preparedness of practitioners, confidence levels, and assessment methods for youth suicide risk. Respondents included 339 professional counselors, school counselors, school psychologists, psychologists, and social workers from school districts in Maryland and Virginia and several outpatient mental health clinics located in the mid-Atlantic area of the United States. The participants completed a 23-item survey.

Significant findings from the study consist of deficient and varying levels of preparedness and confidence regarding suicide assessment (Schmidt, 2016). According to Schmidt, confidence in their preparedness abilities were noted by $73 \%$ of individuals who indicated using formal assessment versus about $50 \%$ who use informal assessments $\left(\mathrm{X}^{2}=12.79, \mathrm{df}=1\right.$, Cramer's V $=$ $.206, p=.000)$. Practitioner confidence levels when conducting informal nonstructured suicide risk assessments and formal assessments showed significant differences $\left(X^{2}=23.54, \mathrm{df}=1\right.$, Cramer's $\mathrm{V}=.280, p=.000$ ). Ultimately, $95.6 \%$ of the participants who used formal suicide risk 
assessments conveyed higher levels of confidence as opposed to $70.1 \%$ of respondents who used non-structured informal suicide risk assessments (Schmidt, 2016). Results also suggest that preparedness and training in assessing suicide are linked to the confidence levels of practitioner when assessing the youth's risk of suicide (Schmidt, 2016).

Gamble and Lambros (2014) took a qualitative research approach for their study. Gamble and Lambros utilized a school psychologist trainees cohort enrolled in a counseling class to conduct semi-structured interviews. These interviews focused on determining possible barriers to mental health services for minority students in public school districts located in Los Angeles and Orange Counties in California. Additionally, the interviews centered on finding out which mental health services were delivered most often to students, determining which students frequently received mental health services, and figuring out what resources schools need to enhance the delivery of mental health services. Respondents interviewed included 39 school-based mental health professionals (i.e., 36 school psychologists, 1 school counselor, and 2 clinical therapists) from public-school districts in Los Angeles and Orange Counties. The participants were from elementary, middle, and/or high schools. The student population in majority of the schools were comprised of students of color, which includes " 25 schools with a population of $45 \%$ or more Latino, four schools with $45 \%$ or more Asian/Asian Pacific Islander, three schools with $45 \%$ or more Caucasian and seven schools multicultural - no racial/ethnic group over $45 \%$ and more than four groups represented" (Gamble \& Lambros, p. 27).

Results from the study suggest that culturally-related issues frequently hinder efforts to support minority access to services, and mental health services need to be improved by having more careful tracking of data and decision-making (Gamble \& Lambros, 2014). Individual and group counseling were reported as services delivered most often, while referrals to outside 
agencies were also made. In regard to which students received services most frequently, the data suggested that students who received the services corresponded with the demographics of the school's student body (Gamble \& Lambros, 2014). Findings also suggest that there should be more training and professional development in addition to more staff designated to provide mental health (Gamble \& Lambros, 2014).

\section{Conclusion}

The literature on both school psychologists and school counselors is limited, specifically literature on studies including school psychologists and school counselors in California in relation to SBMHS. However, after reviewing multiple sources and studies on children's and adolescents' mental health and SBMHS in the United States, this researcher was able to draw several conclusions. First, schools play a significant role in a student's ability to access, use, and receive mental health services. Second, school psychologists and school counselors take on roles as SBMHS providers, but they are not always able to apply their skills due to factors, such as a lack of time, a high caseload, other demands of their job, or their comfort level.

Current literature (e.g., Carlson \& Kees, 2013; Eklund et al., 2017; Gamble \& Lambros, 2014; Suldo et al., 2010; Walley \& Grothaus, 2013) suggests that service providers should receive further training and professional development to better support student mental health. Also, future research should further examine the perceptions of SBMHS providers regarding the preparation they received for their role. Therefore, this study will explore California school psychologists and school counselors' perceptions of the preparation received for the provision of SBMHS. 


\section{Chapter Three: Methodology}

The methodological approach for this study is in the form of survey research. This researcher created an online survey to address the research questions for this study, in the form of a descriptive survey research design. The survey was administered via Qualtrics and included items regarding formal education, professional experiences, mental health services, and background information. The following research questions and sub-research questions will be addressed:

Research Question 1. To what extent do school psychologists and school counselors in California believe that their formal education (i.e., undergraduate, graduate, training/workshops) has prepared them to provide school-based mental health services?

Research Question 1a. Do school psychologists and school counselors in California differ from one another in their perceptions of how well their formal education (i.e., undergraduate, graduate, training/workshops) has prepared them to provide school-based mental health services?

Research Question 2. To what extent do school psychologists and school counselors in California believe that their professional experiences have prepared them to provide schoolbased mental health services?

Research Question 2a. Do school psychologists and school counselors in California differ from one another in their perceptions of how well their professional experiences have prepared them to provide school-based mental health services?

California school psychologists and school counselors are the participants for this study. Participants were recruited through the California Association of School Psychologists (CASP) and the California Association of School Counselors (CASC) online organizations. According to 
the CASP website, CASP has more than 1,900 members and "is the largest statewide organization of school psychologists in the nation and the strongest voice for psychologists practicing in California schools" (CASP, 2019). The members of CASP consist of professionals who work in school districts and private practice throughout California (CASP, 2019). Similar to CASP, the CASC website states that "CASC is the largest statewide nonprofit organization supporting school counselors in California" (CASC, 2019). CASC has more than 3000 members, which is made up of school counselors, counselor educators, graduate students, and those who are connected to school counseling in California (CASC, 2019). CASP and CASC are considered the largest statewide organizations for school psychologists and school counselors in California. Therefore, by surveying these organizations, there was a good chance of gathering survey data from school psychologists and school counselors throughout the state of California and not just from one California region. Also, additional participants, from a broader selection of school psychologists and school counselors in California, were recruited for this study.

\section{Population and Sample Selection}

Thousands of groups and organizations have transitioned to online methods, where they provide information to consumers (Wright, 2005). There are numerous populations (e.g., students, employees, professional organization members) for which email addresses are almost universal and are readily accessible (Fowler, 2014). These groups and organizations also provide researchers with the opportunity to obtain access to various populations that associate with them (Wright, 2005), which goes for both the California Association of School Psychologists (CASP) and the California Association of School Counselors (CASC) online organizations. CASP and CASC grant researchers the opportunity to survey their online members by using a nonprobability survey sampling method. 
The majority of online questionnaires now take on a nonprobability form (Vehovar \& Manfreda, 2017). According to Fricker (2008), nonprobability samples occur when the determination of either all respondents or units in the sample cannot be established, or when each individual can choose to participate in the survey or not. For example, a survey may be displayed on a website where it is up to the individuals perusing through the site to choose to partake in the survey (Fricker, 2008). For this type of sample, there is less time and effort needed, and the survey is generally less expensive to create (Fricker, 2008). Dillman, Smyth, and Christian (2014) stated that nonprobability methods are becoming more advanced with regards to who is invited to participate in the survey. In general, nonprobability samples are chosen based on availability and convenience (Ritter \& Sue, 2007).

Unfortunately, nonprobability sampling does not go without its pitfalls. As stated by Sue and Ritter (2012), nonprobability samples do not use random selection practices and, therefore, may or may not provide a good representation of the population. In their earlier work, Ritter and Sue (2007) mention that sample size cannot be calculated and determined from a nonprobability sample. Moreover, there are often relatively low response rates for nonprobability samples (Dillman et al., 2014). However, nonprobability sampling can be useful since it may provide a representation of a subgroup of the population (Van Selm \& Jankowski, 2006). Thus, nonprobability samples obtained from CASP and CASC online organizations and from a broader selection of California school psychologists and school counselors were used, specifically by using a convenience sampling approach.

\section{Convenience Sampling}

Per Patton (as cited in Mertens, 2015) and Etikan, Musa, and Alkassim (2016), convenience sampling means that those who participate in the study were selected because they 
are readily available. Sue and Ritter (2012) described convenience sampling as a nonsystematic method to recruit respondents that permit possible participants to be part of the sample by selfselecting into it. As a result, there is less time and effort involved in convenience sampling than there is in generating probability samples; however, statistical inference is challenging because there are no formulas for statistical inference to estimate a sample size when this type of sample is used (Sue \& Ritter, 2012). Nevertheless, this is usually the most common sampling strategy used, even though it may be the least desirable one (Mertens, 2015). According to Etikan et al. (2016), generalizability is the primary emphasis when using convenience sampling. However, Allison (1999) and Mertens (2015) suggest that a researcher should not try to generalize the findings from a convenience sample to other population pools due to its limitations. For that reason, the results of this study cannot be generalized to all school psychologists and school counselors in California.

\section{Sample Size}

A few guidelines for an appropriate nonprobability sample size suggested by Hill (1998) include the following: (a) sample should be between 30 to 500, (b) about 10\% target population, and (c) largest afforded sample. For example, the sample size should be about 140 if the target population is 1400 (Hill, 1998). Gall, Gall, and Borg (as cited in Mertens, 2015) recommended a sample size of 100 for the main subgroup and 20-50 for any minor subgroups when using surveys. A sample size of $N=156$ [School Psychologists (SP): $n=92$; School Counselors (SC): $n=64)$ was obtained for this study.

\section{Using Email and Web Surveys}

There are two major types of online surveys, which include email and web surveys (Fowler, 2014; Vehovar \& Manfreda, 2017). For these surveys, respondents reply by either responding to an email questionnaire through an email application, or respondents are prompted 
to go to a website to complete a survey form (Fowler, 2014; Gaiser \& Schreiner, 2009; Vehovar \& Manfreda, 2017). Respondents can also be sent a link to the survey invitation through email (Fowler, 2014).

Emailing a link to possible participants may seem simple; however, each online professional organization may have different requirements that one must follow before the organization allows for an online survey to be sent out to their members. For instance, the CASP (2019) website mentions that online surveys need to be submitted electronically to CASP for review before the dissemination of the survey. For the current study, a required fee of $\$ 150$ was paid to the online CASP organization. In return, the link to the survey was posted to the CASP website for a month and sent out in two of their weekly email blasts.

The process for submitting a survey online for CASC differs from the process for CASP. For instance, CASC (2019) requires a survey to be submitted electronically to the CASC Online Review Board by following the same process one would go through to submit an article for publication in one of their weekly CASC Counselor Connection newsletters that are sent out via email. There is no fee required to have a survey posted in the CASC Connection. Access to the survey link is also posted online on the CASC Connection webpage. The school counselor survey was submitted four times (one time per week) to CASC to be posted in their CASC Connection; however, the link to the survey only functionally worked on the website when submitted the $2^{\text {nd }}$ and $4^{\text {th }}$ week. Also, this researcher forwarded the survey links to a broader selection of California school psychologists and school counselors due to the low number of responses obtained during the first three weeks that the surveys were posted and sent out by CASP and CASC. 


\section{Ethical Considerations}

Throughout the research process, the ethical considerations that could have had an impact on this research study were considered. For instance, there are three ethical concepts, which include confidentiality, anonymity, and informed consent, that are the center of institutional and professional research governance based on the 'human subjects model' (Eynon, Fry, \& Schroeder, 2017). This model considers the rights of human subjects as primary and the goals of researchers as secondary (Bassett \& O’Riordan, 2002). In regards to confidentiality and anonymity, Mertens (2015) defined these two terms as follows:

Confidentiality means that the privacy of individuals will be protected in that the data they provide will be handled and reported in such a way that the data cannot be associated with the research participants personally.

Anonymity means that no uniquely identifying information is attached to the data, and thus no one, not even the researcher, can trace the data back to the individual providing them. (p. 353).

To maintain confidentiality and anonymity, Fowler (2014) stated that online surveys can be structured so that there is no connection between responses and the identity of participants. However, promises of maintaining confidentiality and anonymity can be more difficult than expected at times (Mertens, 2015). Due to this issue, Baez (as cited in Mertens, 2015) recommended that researchers should seriously inquire about what confidentiality will withhold or disclose throughout the research process. Therefore, sharing information regarding confidentiality with respondents may lead to more buy-in to complete the online survey.

As for informed consent, Toepoel (2016) stated that providing informed consent is something that participants have the right to do. Eynon and colleagues (2017) suggested that 
those who decide to partake in any research project should do so on the foundation of informed consent, where the participants know what the aim of the research is and what they are consenting to do, know the possible risks and benefits for participating, and have details of other options that may be beneficial to them. However, providing informed consent does not go without its challenges. Eynon and colleagues acknowledged that the degree to which people are able or competent to provide informed consent differs extensively, and this is harder to assess online. Consequently, it is more difficult to ascertain if the respondent comprehends what they are agreeing to (Eynon et al., 2017; Toepoel, 2017) when deciding to participate in online studies, which can be a problem because there is often no real-life interaction between the respondent and the researcher (Toepoel, 2017). Regardless of these challenges, Eynon and colleagues (2017) stated that the benefit of consenting online when compared to consenting faceto-face is that respondents are likely not to feel as much pressure to take part in and stay in the study and are more likely to begin and fully participate in the research.

To obtain informed consent from participants for the online survey, an 'information statement' was presented in the introduction (see Appendices A and B). This statement explained the purpose of the study, at the commencement of the questionnaire. Also, a link explaining consent (see Appendix C) was attached at the bottom of the introduction in the questionnaire. The participants consented to participate in this survey by beginning the survey questionnaire.

\section{Survey Design}

The appearance of an online survey is essential. Sue and Ritter (2012) stated that the best survey questionnaires appear professional and interesting, are easy to understand, are welcoming and not overwhelming, makes responding to questions a clear and straightforward process, and are available to each person in the target population. Fowler (2014) stated that there are two 
components to designing a survey instrument, which include choosing what to measure and creating and examining questions that will be useful measures.

\section{Quantitative and Qualitative Online Survey Research}

While creating the online survey, this researcher decided to collect primarily quantitative data and some qualitative data. Toepoel (2016) stated, "Quantitative research is used to quantify a research problem by way of generating numerical data that can be used for statistical testing. Qualitative research is primarily used to gain an understanding of underlying reasons, opinions, or motivations" (p. 2). Toepoel (2016) stated that quantitative online surveys are used if one desires to answer a question regarding large groups of individuals and/or generalize its findings by making implications from the sample to a general population. Qualitative online surveys, on the other hand, answer 'why' or 'how' questions (Toepoel, 2016). This style of survey often includes open-ended questions, thus presenting the option to freely respond in any way the participant decides (Toepoel, 2016). Having an idea of the type of data that will be collected led to the creation of research questions, which ultimately led to the development of survey questions that may or may not have been included in the final online questionnaire.

\section{Survey Questions}

Sue and Ritter (2012) stated that a survey question is a measurement tool that allows researchers to gather data on the behavior, knowledge, and/or opinion of a respondent. Mertens (2015) mentioned that when developing survey questions, one should explain to oneself the reason each question is being asked. Therefore, the survey items in this study were structured in a way that assisted in gathering information to answer this study's research questions.

Not only is the content of the survey items viewed as important, but the order of the questions can also be important. Hence, it is usually best to start with the most salient and interesting questions (Dillman et al., 2014; Toepoel, 2016). Mertens (2015) suggested that when 
creating survey questions, one should decide on the extent of structure that is most fitting (e.g., closed and/or open-ended formats).

Closed-ended questions. For closed-ended questions, a list of answer choices is provided, from which respondents select their response (Dillman et al., 2014; Toepoel, 2016). Nominal and ordinal categories usually take the form of closed-ended questions (Dillman et al., 2014). A nominal question includes people or events that are organized into unordered groups (Fowler, 2014) and have no natural order (Dillman et al., 2014). An example of a nominal question for a survey is, "Do you identify as male, female, or other?" For ordinal questions, categories are organized or placed in ordered categories along a continuum (Dillman et al., 2014; Fowler, 2014). Ordinal questions typically include scalar questions. A scalar question is one of the most commonly used forms of questions (Toepoel, 2017). For determining the number of scale points to use to answer a scalar question, Dillman and colleagues (2014) suggested using a 5-7-point scale. Toepoel (2016) recommended using a format such as a 7-point scale; however, Toepoel (2017) later mentioned that scales between 5 to 11-points are commonly used. A Likertscale is a regularly used scale (DeVellis, 2003; Toepoel, 2017) that typically measures attitudes, beliefs, and opinions (DeVellis, 2003). For Likert-scale questions, respondents answer where they fit on a continuum (e.g., agree-disagree) (Etikan et al., 2016; Toepoel, 2017).

Agree/disagree items. Agree/disagree (A/D) questions are commonly used in survey research (Fowler, 2014; Etikan et al., 2016) because space is saved when the scale is introduced once in the questionnaire (Dillman et al., 2014; Etikan et al., 2016). A/D questions are popular because they tend to allow measuring almost any construct quite effectively (Etikan et al., 2016). When using an A/D scale, Patten (2014) recommended that items should have simple statements that provide responses from "Strongly Agree" to "Strongly Disagree" so respondents can simply 
move through items without having to 'switch gears,' especially when the attitude scales have 20 or more items that connect to the same construct. In the current study, A/D scales are included in the online questionnaires for both California school psychologists and school counselors due to the convenience of having similar response choices presented to the respondents for the majority of the closed-ended items in the first and third sections of the questionnaire.

Selecting a response. When using a self-administered questionnaire, closed-ended questions should be used because these questions can be answered by merely clicking a box from a set of responses the researcher provides (keeping in mind that effortlessness of response is important to increase the return of questionnaires) (Fowler, 2014). For this reason, respondents for this study were allowed to click on answer choices to indicate their responses to the closedended items presented in the online questionnaires.

Open-ended questions. Fowler (2014) stated that having open-ended questions will allow researchers the opportunity to acquire unanticipated answers given it is likely that the responses may describe the true views of the respondents because the responses are in their own words. An advantage of open-ended questions is that respondents can freely provide the information they want to provide without being obligated to respond within a certain selection (Dillman et al., 2014; Toepoel, 2016). Allowing for open-ended responses can provide insight into tough questions, routing errors, and misinterpretations (Toepoel, 2017). Therefore, four open-ended questions were included in the questionnaires to gather more information from participants than what would typically be provided through closed-ended responses.

Demographic questions. Objectionable questions, such as questions in a demographic section, often are located towards the end of the survey (Dillman et al., 2014; Patten, 2014; Sue \& Ritter, 2012; Toepoel, 2016). These questions are located in the back of a questionnaire 
because respondents are not as likely to quit when getting to these questions, and these questions appear less intolerable when considering already answered questions (Dillman et al., 2014; Patten, 2014; Toepoel, 2016). The demographic section of a questionnaire is usually labeled something like "Background Information," and this section inquires about respondents' characteristics (Mertens, 2015). Demographic questions request background information regarding respondents such as gender, age, and level of education (Sue \& Ritter, 2012).

The background data are generally used to describe respondents (Patten, 2014; Sue \& Ritter, 2012) and, at times, compare the characteristics of those in the sample with identified characteristics of the population (Sue \& Ritter, 2012). These data are also used to categorize and compare sample subgroups (Sue \& Ritter, 2012). For example, the demographic data (see Table 1) from this study will be used to compare the perceptions of newer school psychologists and school counselors to veteran school psychologists and school counselors.

Table 1

Background Information

\begin{tabular}{|c|c|c|c|}
\hline \multicolumn{4}{|c|}{ 34. I identify as: } \\
\hline & SP & $\mathrm{SC}$ & Total \\
\hline & $\underline{N=92}$ & $N=64$ & $\underline{N=156}$ \\
\hline & $\%(n)$ & $\%(n)$ & $\%(n)$ \\
\hline Male & $17.39 \%(16)$ & $18.75 \%(12)$ & $17.95 \%(28)$ \\
\hline Female & $82.61 \%(76)$ & $78.13 \%(50)$ & $80.08 \%$ (126) \\
\hline Other & 0 & $3.13 \%(2)$ & $1.28 \%(2)$ \\
\hline \multicolumn{4}{|c|}{ 35. Age: } \\
\hline \multirow[t]{4}{*}{$M(S D)$} & $\mathrm{SP}=40.74(11.06)$ & $\mathrm{SC}=43.21(11.82)$ & \\
\hline & SP & SC & Total \\
\hline & $\underline{N=92}$ & $N=64$ & $\underline{N=156}$ \\
\hline & $\%(n)$ & $\%(n)$ & $\%(n)$ \\
\hline $24-25$ & $1.09 \%(1)$ & $3.13 \%(2)$ & $1.92 \%(3)$ \\
\hline $26-35$ & $41.30 \%(38)$ & $28.13 \%(18)$ & $35.90 \%(56)$ \\
\hline $36-45$ & $25 \%(23)$ & $29.69 \%(19)$ & $26.92 \%(42)$ \\
\hline $46-55$ & $18.48 \%(17)$ & $18.75 \%(12)$ & $18.50 \%(29)$ \\
\hline
\end{tabular}




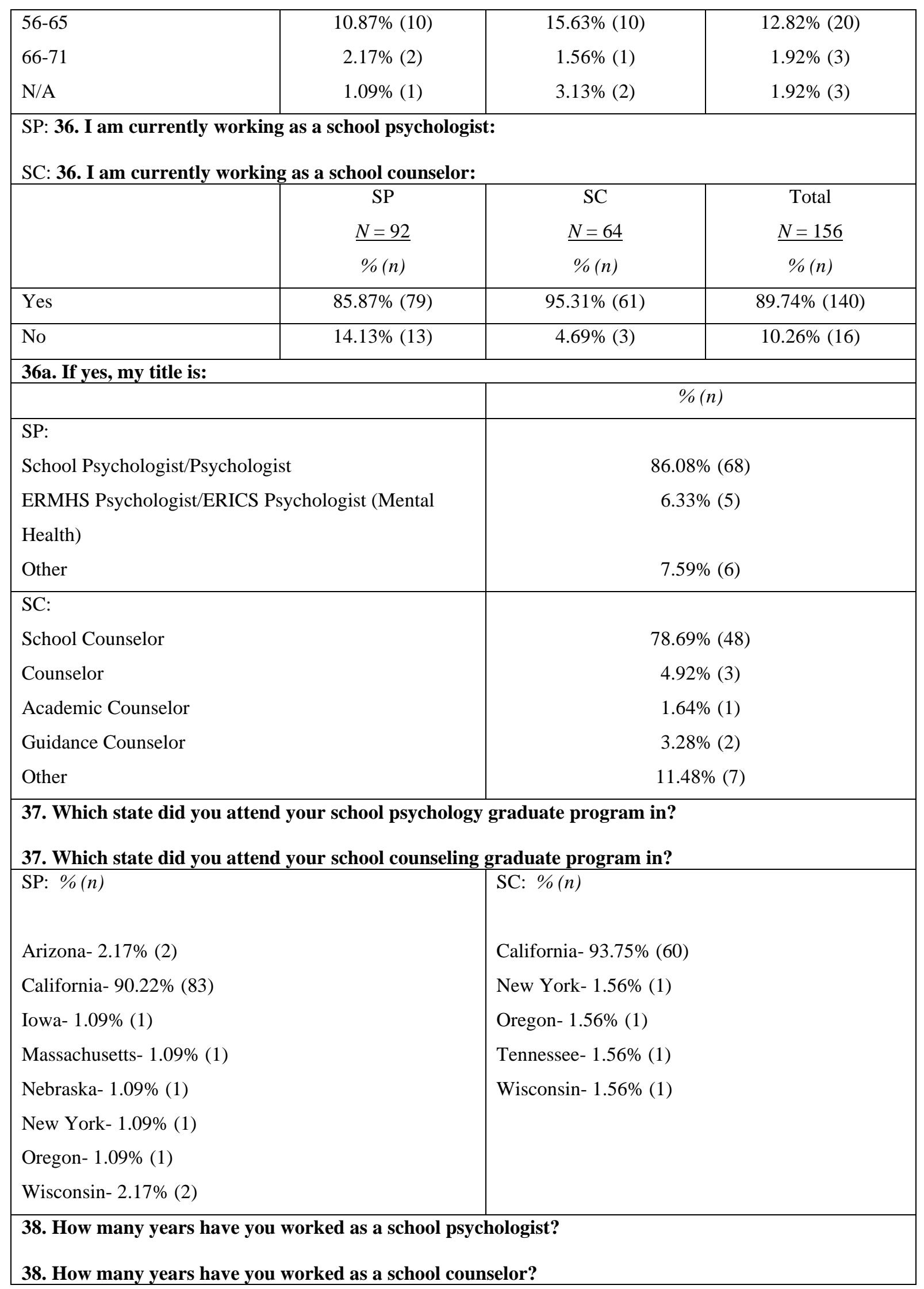




\begin{tabular}{|c|c|c|c|}
\hline$M(S D)$ & $\mathrm{SP}=3.55(1.56)$ & $\mathrm{SC}=3.75(1.58)$ & \\
\hline & $\begin{array}{c}\text { SP } \\
N=92 \\
\%(n)\end{array}$ & $\begin{array}{c}\mathrm{SC} \\
N=64 \\
\%(n)\end{array}$ & $\begin{array}{c}\text { Total } \\
\frac{N=156}{\%(n)}\end{array}$ \\
\hline Less than a year & $4.35 \%(4)$ & $3.13 \%(2)$ & $3.84 \%(6)$ \\
\hline $1-5$ years & $27.17 \%(25)$ & $26.56 \%(17)$ & $26.92 \%(42)$ \\
\hline $6-10$ years & $26.09 \%(24)$ & $20.31 \%(13)$ & $23.72 \%(37)$ \\
\hline $11-15$ years & $13.04 \%(12)$ & $14.06 \%(9)$ & $13.46 \%(21)$ \\
\hline $16-20$ years & $9.78 \%(9)$ & $14.06 \%(9)$ & $11.54 \%(18)$ \\
\hline More than 20 years & $19.57 \%(18)$ & $21.88 \%(14)$ & $20.51 \%(32)$ \\
\hline \multicolumn{4}{|c|}{$\begin{array}{l}\text { 39. What is your primary placement as a school psychologist? } \\
\text { 39. What is your primary placement as a school counselor? }\end{array}$} \\
\hline & $\begin{array}{c}\text { SP } \\
N=92 \\
\%(n)\end{array}$ & $\begin{array}{c}\mathrm{SC} \\
N=64 \\
\%(n)\end{array}$ & $\begin{array}{c}\text { Total } \\
N=156 \\
\%(n)\end{array}$ \\
\hline Preschool & $5.43 \%(5)$ & 0 & $3.21 \%(5)$ \\
\hline Elementary & $44.57 \%(41)$ & $21.88 \%(14)$ & $35.26 \%(55)$ \\
\hline Middle School & $14.13 \%(13)$ & $29.69 \%(19)$ & $20.51 \%(32)$ \\
\hline High School & $22.83 \%(21)$ & $40.63 \%(26)$ & $30.13 \%(47)$ \\
\hline $\begin{array}{l}\text { Alternative } \\
\text { Program/Placement }\end{array}$ & $13.04 \%(12)$ & $7.81 \%(5)$ & $10.90 \%(17)$ \\
\hline \multicolumn{4}{|c|}{ 39a. If you have a secondary placement, please indicate level: } \\
\hline & $\begin{array}{c}\mathrm{SP} \\
\frac{N=56}{\%(n)}\end{array}$ & $\begin{array}{c}\mathrm{SC} \\
N=23 \\
\%(n)\end{array}$ & $\begin{array}{c}\text { Total } \\
\frac{N=79}{\%(n)}\end{array}$ \\
\hline Preschool & $7.14 \%(4)$ & 0 & $5.06 \%(4)$ \\
\hline Elementary & $28.57 \%(16)$ & $21.74 \%(5)$ & $26.58 \%(21)$ \\
\hline Middle School & $26.79 \%(15)$ & $39.13 \%(9)$ & $30.38 \%(24)$ \\
\hline High School & $16.07 \%(9)$ & $26.09 \%(6)$ & $18.99 \%(15)$ \\
\hline $\begin{array}{l}\text { Alternative } \\
\text { Program/Placement }\end{array}$ & $21.43 \%(12)$ & $13.04 \%(3)$ & $18.99 \%(15)$ \\
\hline \multicolumn{4}{|c|}{ 40. Type of primary school site: } \\
\hline & $\begin{array}{c}\mathrm{SP} \\
N=92 \\
\%(n)\end{array}$ & $\begin{array}{c}\mathrm{SC} \\
N=64 \\
\%(n)\end{array}$ & $\begin{array}{c}\text { Total } \\
N=156 \\
\%(n)\end{array}$ \\
\hline Urban & $39.13 \%(36)$ & $35.94 \%(23)$ & $37.82 \%(59)$ \\
\hline
\end{tabular}




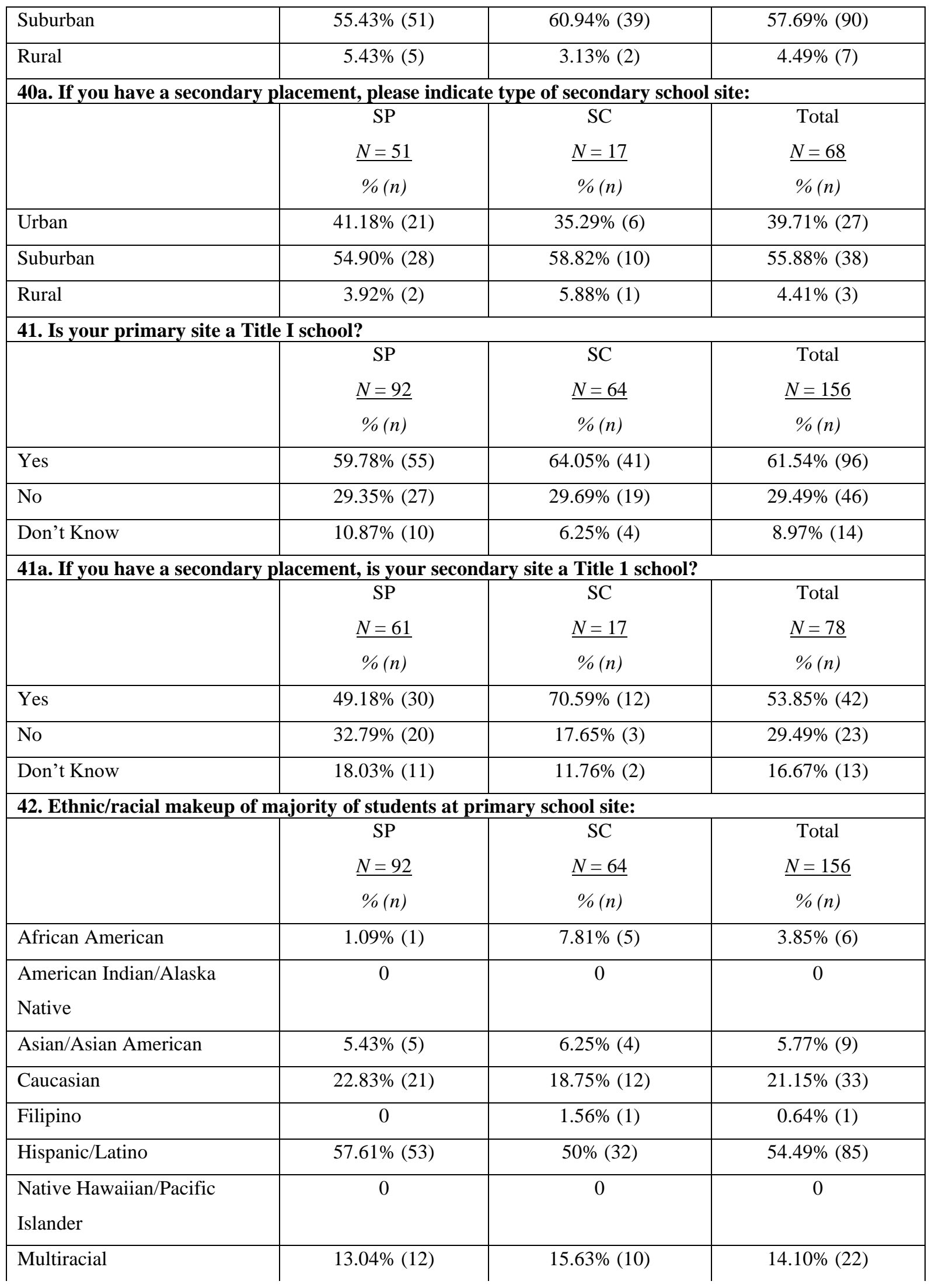




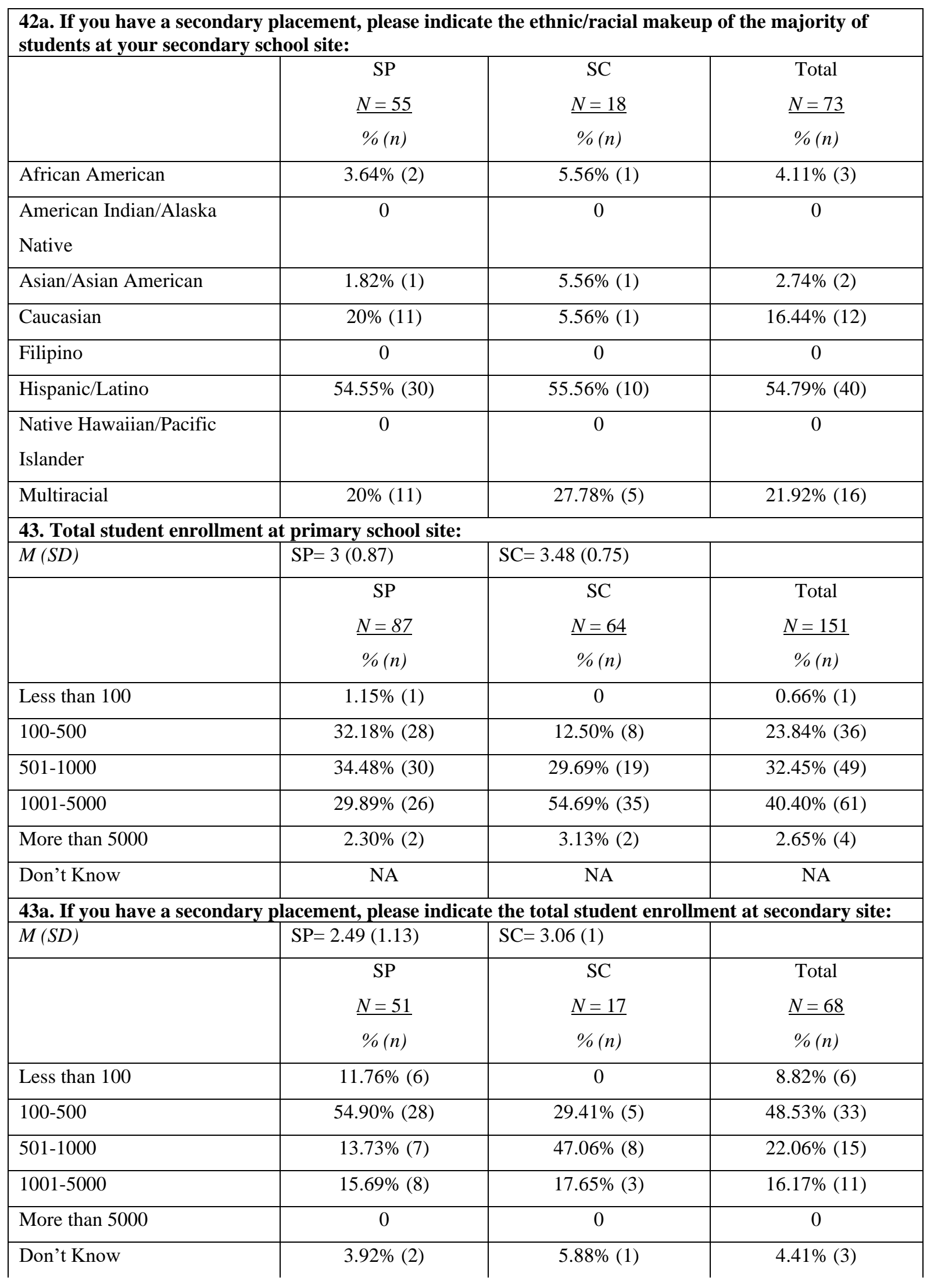




\begin{tabular}{|c|c|c|c|c|c|}
\hline $\begin{array}{l}\text { SP: 44. In my ro } \\
\text { health services } \\
\text { SC: } 44 \text {. In my ro } \\
\text { health services }\end{array}$ & $\begin{array}{l}\text { school psych } \\
\text { roviding coun } \\
\text { school couns } \\
\text { roviding coun }\end{array}$ & $\begin{array}{l}\text { ist, I currently } \\
\text { ng, conducting } \\
\text {, I currently s } \\
\text { ng, conducting }\end{array}$ & $\begin{array}{l}\text { pend _ \% ( } \\
\text { ental health f } \\
\text { nd_ \% (0-1 } \\
\text { ental health f }\end{array}$ & $\begin{array}{l}00 \text { my time } \\
\text { us assessmen } \\
\text { my time pro } \\
\text { us assessment }\end{array}$ & $\begin{array}{l}\text { viding mental } \\
\text { etc.): } \\
\text { ding mental } \\
\text { etc.): }\end{array}$ \\
\hline \multicolumn{3}{|c|}{ SP } & \multicolumn{3}{|c|}{$\mathrm{SC}$} \\
\hline \multicolumn{3}{|c|}{$N=92$} & \multicolumn{3}{|c|}{$N=64$} \\
\hline Minimum \% & Maximum \% & $M(S D)$ & Minimum \% & Maximum $\%$ & $M(S D)$ \\
\hline 0 & 100 & $35.42(26.79)$ & 5 & 96 & $48.91 \%(24.92)$ \\
\hline
\end{tabular}

$\mathrm{SP}=$ School Psychologists; $\mathrm{SC}=$ School Counselors

\section{Length of Survey}

According to Toepoel (2016), five to ten minutes is best for survey length; keeping in mind that this may not be possible for every study. Some online surveys may take more than ten minutes to complete, but as long as the survey measure is captivating, this may not be such a big issue. However, the shorter the length of time it takes to complete an online survey, the better. The completion time for the survey for this study is approximately 10-15 minutes.

\section{Determining Validity of Measure}

In educational research, validity is likely the most important single part of the research design (Muijs, 2011). Validity centers on whether we are measuring what we are seeking to measure (Muijs, 2011; Pallant, 2016). Specifically, for this online survey, it was of utmost importance to determine the content validity of the measures. Content validity is when the manifest variables' content is correct to assess the latent concept that we are attempting to measure (Muijs, 2011).

Two rounds of content validation took place before implementing the survey. The first round of content validation included an expert panel of three university trainers with expertise in school-based mental health services and survey construction. For the content validation, a drafted survey and content validation form (see Appendices D and E) were sent to the expert panel for individual review. The content validation allowed the panel members to provide quantitative and 
qualitative feedback regarding the following: wording, survey intent, order of questions, understandability, response choices, and clarity. The content validation form included ten items where the panel members were able to select a response of $1=$ Disagree entirely, $2=$ Neutral, or $3=$ Agree completely. Three additional questions allowed respondents to write in their responses regarding the survey. Out of a possible score of 30 (range 10-30), the panel members' responses averaged out to 29.3. Revisions were made for clarity, such as changing item 22 from "I have provided behavior interventions to students" to "I have developed and implemented behavior intervention plans (BIPs) to students" and changing item 35 regarding age from a scale response to an open response. In addition, an item was added to the questionnaires regarding the group's national professional association (i.e., National Association of School Psychologists; American School Counselor Association).

The second round of content validation included 10 professionals ( 5 school psychologists and 5 school counselors). Each professional received the revised draft of the survey for their respective profession (i.e., school psychologists received the school psychologist survey; school counselors received the school counselor survey) to review and the content validation form (same form provided to the expert panel) to complete individually. All 10 professionals returned feedback. The school counseling professionals provided more qualitative feedback than the school psychology professionals. For the quantitative feedback, the ten scaled content validation items were again out of a possible score of 30 (range of 10-30). The school psychologists' survey received an average score of 29.8 out of 30 based on the 5 school psychologists' responses. The school counselors' survey, on the other hand, received an average score of 28.6 out of 30 based on the 5 school counselors' responses. These scores indicate that the surveys demonstrate adequate content validity. 
The qualitative feedback that was considered for the survey revision addressed the ordering of responses and content. For instance, it was suggested to order the Likert-scale responses from negative to positive (e.g., "Strongly Disagree" to "Strongly Agree") rather than positive to negative. On the school counselors survey, a respondent mentioned that school counseling programs are more likely to follow the American School Counselor Association (ASCA) National Model rather than receive program approval from ASCA. Therefore, item 7 was changed from "Was your school counseling program approved by the American School Counselor Association (ASCA)?" to "Did your school counseling program follow the American School Counselor Association (ASCA) National Model?" However, item 7 on the school psychologists survey was left as "Was your school psychology program approved by the National Association of School Psychologists (NASP)?". Another recommendation from a respondent included providing examples of prevention for item 21 . This item was changed from "I have directly participated in programs related to primary prevention or mental health promotion with students" to "I have directly participated in programs related to primary prevention or mental health promotion (e.g., suicide prevention campaigns, emotion regulation groups, mindfulness, etc.) with students." The related subsequent item $21 \mathrm{a}$ was similarly changed to provide the same examples. The final questionnaires consisted of 44 items (see Appendices $F$ and G); however, some items included subitems based on whether the participant responded by clicking "Yes" to the item.

Sue and Ritter (2012) suggested that the content validity panel members should not be able to take part in the actual survey. Therefore, a preventive step was taken to inform the content validation participants that they should not complete the final questionnaire for the online survey if they received it through email or saw it posted on the CASP or CASC websites. 


\section{Institutional Review Board}

In the United States, nearly all universities and most other organizations that perform research that is federally funded have an Institutional Review Board (IRB) that is responsible for overseeing research that includes human subjects/participants (Fowler, 2014). According to Mertens (2015), one should always contact the institution's IRB early on in one's process for planning research to ascertain its policies and procedures. Generally, IRB's concerns are about research that has some type of threat to participants (Fowler, 2014). Therefore, it is the responsibility of the researchers to guarantee, as much as they can, that respondents will not be harmed by partaking in the study (Eynon et al., 2017).

The necessary online forms for Chapman University's IRB were completed early on in the research process. After a review of the IRB submission, Chapman University's IRB granted approval to move forward with this research study. Shortly after, the online surveys were sent out.

\section{Response Rate}

After gathering survey data, it was important to examine the response rate for both surveys. Fowler (2014) stated that the response rate is used to examine a data collection effort. It is merely the number of individuals/units who completed the survey divided by the number of eligible individuals/units sampled (Fowler, 2014; Mertens, 2015). Fowler stated that there has been no agreement on an appropriate minimum response rate. Johnson and Christensen (as cited in Mertens, 2015) stated that a response rate of about $70 \%$ is usually acceptable. However, this suggestion for a response rate is based on the idea that nonrespondents and respondents are alike (Mertens, 2015).

As per Van Selm and Jankowski (2006), it is impossible to calculate the response rate for an online survey. A reason for this impossibility is because only the number of surveys 
completed will be known, and there is no way to know the number of people who may have seen the survey but decided not to participate (Kaye \& Johnson, 1999). A way to handle this issue, according to Van Selm and Jankowski (2006), is to place a counter on the survey site that will keep count of the number of times people visit the site.

Through the online survey site Qualtrics, a counter was used to determine how many respondents opened the survey, partially completed the survey, and completed the survey. The following was gathered based on the counter for the school psychologist survey: a total of 129 individuals saw the survey; out of the 129 individuals, 6 individuals partially completed the survey, and 92 individuals completed the survey. Based on the counter for the school counselor survey, the following was gathered: a total of 111 individuals saw the survey; out of the 111 individuals, 7 individuals partially completed the survey, and 64 individuals completed the survey.

By having a counter on the survey, an approximation of the response rate can be obtained by dividing the number of returned surveys by the number of times the survey site is visited (Van Selm \& Jankowski, 2006). Based on the number of completed surveys and the number of times the survey was viewed, the school psychologist survey has a response rate of $73.32 \%$, and the school counselor survey has a response rate of $57.66 \%$.

\section{Current Research Method Summary}

This study was designed to examine California school psychologists and school counselors' perceptions regarding the extent to which they believe that their formal pre-service education and later in-service professional experiences have prepared them to deliver SBMHS. The two research questions for the study are descriptive. The two sub-research questions examine the extent that California school psychologists and school counselors differ from one 
another in their perceptions regarding their educational preparation and professional experiences regarding the provision of SBMHS.

An online survey was created to answer the study's research questions, which is in the form of a descriptive survey design. A questionnaire was created and altered appropriately for the two groups of professionals. For instance, the questionnaires included the same items regarding formal education, professional experiences, mental health services, and background information; however, the questionnaire sent to the school psychologists differed from the one sent to school counselors on items regarding educational background and titles.

An 'information statement' was presented at the commencement of the questionnaire to obtain informed consent. The majority of the items in the questionnaire are closed-ended. The closed-ended questions included items based on a Likert-scale (e.g., agree-disagree), yes-or-no questions, and demographic questions. Four open-ended questions were used to gather additional information.

Two rounds of content validation took place prior to sending out the final survey. Chapman University's IRB provided approval for this study to commence. The final survey was administered via Qualtrics and took about 10-15 minutes to complete. The survey links were sent out, and nonprobability samples were obtained through CASP and CASC online organizations and through obtaining responses from a broader selection of school psychologists and school counselors by way of convenience sampling. An overall sample size of 156 was obtained for this study. Participants' responses were provided anonymously, and response rates were calculated. The results of the survey are presented in the next chapter. 


\section{Chapter Four: Results}

This chapter provides the statistics and statistical analyses of the data from the surveys completed by California school psychologists and school counselors regarding their perceptions about their formal education (i.e., undergraduate, graduate, training/workshops) and professional preparation for the provision of school-based mental health services. Individually, descriptive statistics from the study were examined. Effect sizes were computed using Cohen's $d$ formula $\left[\left(M_{1}-M_{2}\right) / S D_{\text {pooled }}\right]$ to compare school psychologists to school counselors. In addition, Spearman's rho correlation coefficients analyses were used via SPSS to determine correlations between years of experience to Likert-scale subscales.

\section{Data Analyses}

Based on the survey design, descriptive statistics were analyzed. Per Mertens (2015), descriptive statistics describe or show numerous characteristics that are common amongst the total sample and summarize data on one variable (e.g., mean, median, mode, standard deviation). For this study, the main focus is on the means and standard deviations that are derived from the study, as well as the numbers and percentages of responses.

\section{Cohen's d}

Cohen's $d$ was used to examine the differences between school psychologists and school counselors. Pallant (2016) states that Cohen's $d$ shows differences amongst groups based on the units of standard deviation (calculated by subtracting two means and dividing by the pooled standard deviation). Cohen (1988) suggests the following for determining effect sizes based on Cohen's $d: 0.2=$ small effect, $0.5=$ medium effect, and $0.8=$ large effect. For this study, effect sizes were calculated on mean item differences. 


\section{Spearman's Rho Correlation Coefficient}

Spearman's rho correlation coefficient analyses were run via SPSS. Spearman's rho

analysis examines the relationship between two ordinal variables (Muijs, 2011). Specifically, a correlation coefficient is computed based on rankings instead of being based on the actual data (Ho, 2014; Muijs,2011). With this analysis, there will be variation between -1 and +1 (Muijs, 2011). For instance, -1 suggests that there is a perfect negative correlation, +1 is a perfect positive correlation, and 0 shows that there is no relationship between the two variables. Dancey and Reidy (as cited in Akoglu, 2018) suggest the following to determine the strength of a correlation: $0=$ Zero, $+/-0.1$ to $+/-0.3=$ Weak, $+/-0.4$ to $+/-0.6=$ Moderate,$+/-0.7$ to $+/-0.9=$ Strong, $+/-1=$ Perfect. A positive correlation indicates that as a variable increases, the other variable also increases (Pallant, 2016). A negative correlation indicates that as a variable increases, the other variable decreases (Pallant, 2016). For this study, Spearman's rho analyses were run to examine correlations between the following subscales: educational preparation and experience subscale (examining formal educational preparation and professional experience separately), and importance and competence subscale. Spearman's rho analyses were also used to determine correlations between item 38 regarding years in profession to the aforementioned subscales.

\section{Analyses of Research Questions}

Two primary research questions guided this study, as well as one sub-research question for each primary research question:

Research Question 1. To what extent do school psychologists and school counselors in California believe that their formal education (i.e., undergraduate, graduate, training/workshops) has prepared them to provide school-based mental health services? 
This research question is descriptive. The California school psychologist or school counselor's belief on whether their formal education has prepared them for the provision of SBMHS is the descriptive variable.

Research Question 1a. Do school psychologists and school counselors in California differ from one another in their perceptions of how well their formal education (i.e., undergraduate, graduate, training/workshops) has prepared them to provide school-based mental health services?

This sub-research question is addressed by using Cohen's $d$ formula to compare school psychologists and school counselors' mean scores on items that address perceptions of their formal education.

Research Question 2. To what extent do school psychologists and school counselors in California believe that their professional experiences have prepared them to provide schoolbased mental health services?

This research question is descriptive. The California school psychologist and school counselor's belief on whether their professional experiences have prepared them for the provision of SBMHS is the descriptive variable.

Research Question 2a. Do school psychologists and school counselors in California differ in their perceptions in believing that their professional experiences have prepared them to provide school-based mental health services?

This sub-research question is addressed by using Cohen's $d$ formula to compare school psychologists and school counselors' mean scores on items that address perceptions of their professional experiences. 


\section{Subscales Analyses}

Several subscales were created to examine scores for specific areas regarding education and professional experience, professional association, additional graduate-level course work and state registrations/licenses, provision of SBMHS, and importance and competence. Open-ended questions were also examined, and information regarding the most frequents responses are presented.

\section{Education and Professional Experience Subscales}

A subscale was created to determine participants' perceptions regarding their formal education and professional preparation to provide SBMHS. This subscale consists of six items (items 1-6; possible score range 6-30). The responses for each of these five items include a Likert-scale range from $1=$ Strongly Disagree to $5=$ Strongly Agree (see Table 2).

Table 2

Educational Preparation and Experience Subscale

On a scale from 1 to 5 ( 1 = Strongly Disagree to $5=$ Strongly Agree), please select one response for each of the following items regarding your perceptions of your educational preparation and experiences for the provision of school-based mental health services as a school psychologist.

1. My undergraduate program coursework prepared me to provide school-based mental health services:

\begin{tabular}{|c|c|c|c|}
\hline$M(S D)$ & $\mathrm{SP}=2.28(1.15)$ & $\mathrm{SC}=2.44(1.27)$ & $d=0.13$ \\
\hline & $\begin{array}{c}\mathrm{SP} \\
N=92 \\
\%(n)\end{array}$ & $\begin{array}{c}\mathrm{SC} \\
N=64 \\
\%(n)\end{array}$ & $\begin{array}{c}\text { Total } \\
N=156 \\
\%(n)\end{array}$ \\
\hline Strongly Disagree & $26.09 \%(24)$ & $28.13 \%(18)$ & $26.92 \%(42)$ \\
\hline Disagree & $42.39 \%(39)$ & $32.81 \%(21)$ & $38.46 \%(60)$ \\
\hline Neutral & $15.22 \%(14)$ & $14.06 \%(9)$ & $14.74 \%(23)$ \\
\hline Agree & $9.78(9)$ & $17.19 \%(11)$ & $12.82 \%(20)$ \\
\hline Strongly Agree & $6.52 \%(6)$ & $7.81 \%(5)$ & $7.05 \%(11)$ \\
\hline
\end{tabular}

SP: 2. My school psychology program coursework prepared me to provide school-based mental health services:

SC: 2. My school counseling program coursework prepared me to provide school-based mental health services:

$M(S D)$

$\mathrm{SP}=3.61(1.08)$

$\mathrm{SC}=3.83(1.07)$

$d=0.20$ 


\begin{tabular}{|c|c|c|c|}
\hline & $\begin{array}{c}\text { SP } \\
N=92 \\
\%(n)\end{array}$ & $\begin{array}{c}\mathrm{SC} \\
N=64 \\
\%(n)\end{array}$ & $\begin{array}{c}\text { Total } \\
\frac{N=156}{\%(n)}\end{array}$ \\
\hline Strongly Disagree & $5.43 \%(5)$ & $3.13 \%(2)$ & $4.49 \%(7)$ \\
\hline Disagree & $10.87 \%(10)$ & $10.94 \%(7)$ & $10.90 \%(17)$ \\
\hline Neutral & $20.65 \%(19)$ & $15.63 \%(10)$ & $18.59 \%(29)$ \\
\hline Agree & $43.48 \%(40)$ & $40.63 \%(26)$ & $42.31 \%(66)$ \\
\hline Strongly Agree & $19.57 \%(18)$ & $29.69 \%(19)$ & $23.72 \%(37)$ \\
\hline \multicolumn{4}{|c|}{$\begin{array}{l}\text { SP: 3. My school psychology practicum experience prepared me to provide school-based mental } \\
\text { health services: } \\
\text { SC: 3. My school counseling practicum experience prepared me to provide school-based mental } \\
\text { health services: }\end{array}$} \\
\hline \multirow[t]{2}{*}{$M(S D)$} & $\mathrm{SP}=3.24(1.12)$ & $\mathrm{SC}=3.59(1.16)$ & $d=0.31$ \\
\hline & $\begin{array}{c}\text { SP } \\
N=92 \\
\%(n)\end{array}$ & $\begin{array}{c}\mathrm{SC} \\
N=64 \\
\%(n)\end{array}$ & $\begin{array}{c}\text { Total } \\
\frac{N=156}{\%(n)}\end{array}$ \\
\hline Strongly Disagree & $7.61 \%(7)$ & $7.81 \%(5)$ & $7.69 \%(12)$ \\
\hline Disagree & $20.65 \%(19)$ & $10.94 \%(7)$ & $16.67 \%(26)$ \\
\hline Neutral & $21.74 \%(20)$ & $15.63 \%(10)$ & $19.23 \%(30)$ \\
\hline Agree & $40.22 \%(37)$ & $45.31 \%(29)$ & $42.31 \%(66)$ \\
\hline Strongly Agree & $9.78 \%(9)$ & $20.31 \%(13)$ & $14.10 \%(22)$ \\
\hline \multicolumn{4}{|c|}{$\begin{array}{l}\text { SP: 4. My school psychology internship prepared me to provide school-based mental health services } \\
\text { SC: 4. My school counseling internship prepared me to provide school-based mental health services }\end{array}$} \\
\hline \multirow[t]{2}{*}{$M(S D)$} & $\mathrm{SP}=3.78(1.00)$ & $\mathrm{SC}=3.86(1.12)$ & $d=0.08$ \\
\hline & $\begin{array}{c}\text { SP } \\
N=92 \\
\%(n)\end{array}$ & $\begin{array}{c}\mathrm{SC} \\
N=64 \\
\%(n)\end{array}$ & $\begin{array}{c}\text { Total } \\
N=156 \\
\%(n)\end{array}$ \\
\hline Strongly Disagree & $3.26 \%(3)$ & $4.69 \%(3)$ & $3.85 \%(6)$ \\
\hline Disagree & $9.78 \%(9)$ & $9.38 \%(6)$ & $9.62 \%(15)$ \\
\hline Neutral & $14.13 \%(13)$ & $14.06 \%(9)$ & $14.10 \%(22)$ \\
\hline Agree & $51.09 \%(47)$ & $39.06 \%(25)$ & $46.15 \%(72)$ \\
\hline Strongly Agree & $21.74 \%(20)$ & $32.81 \%(21)$ & $26.28 \%(41)$ \\
\hline \multicolumn{4}{|c|}{$\begin{array}{l}\text { 5. Attending workshops/trainings has helped me in my role in providing school-based mental healtl } \\
\text { services: }\end{array}$} \\
\hline$M(S D)$ & $\mathrm{SP}=4.11(1.04)$ & $\mathrm{SC}=4.25(0.83)$ & $d=0.15$ \\
\hline & $\begin{array}{c}\text { SP } \\
N=92 \\
\%(n)\end{array}$ & $\begin{array}{c}\mathrm{SC} \\
N=64 \\
\%(n)\end{array}$ & $\begin{array}{c}\text { Total } \\
N=156 \\
\%(n)\end{array}$ \\
\hline
\end{tabular}




\begin{tabular}{|c|c|c|c|}
\hline Strongly Disagree & $3.26 \%(3)$ & $1.56 \%(1)$ & $2.56 \%(4)$ \\
\hline Disagree & $5.43 \%(5)$ & $3.13 \%(2)$ & $4.49 \%(7)$ \\
\hline Neutral & $13.04 \%(12)$ & $6.25 \%(4)$ & $10.26 \%(16)$ \\
\hline Agree & $33.70 \%(31)$ & $46.88 \%(30)$ & $39.10 \%(61)$ \\
\hline Strongly Agree & $44.57 \%(41)$ & $42.19 \%(27)$ & $43.39 \%(68)$ \\
\hline \multicolumn{4}{|c|}{$\begin{array}{l}\text { SP: 6. My experience as a school psychologist has prepared me to provide school-based mental health } \\
\text { services: } \\
\text { SC: } 6 \text {. My experience as a school counselor has prepared me to provide school-based mental health } \\
\text { services: }\end{array}$} \\
\hline \multirow[t]{2}{*}{$M(S D)$} & $\mathrm{SP}=4.33(0.86)$ & $\mathrm{SC}=4.59(0.63)$ & $d=0.34$ \\
\hline & $\begin{array}{c}\text { SP } \\
N=92 \\
\%(n)\end{array}$ & $\begin{array}{c}\mathrm{SC} \\
N=64 \\
\%(n)\end{array}$ & $\begin{array}{c}\text { Total } \\
\frac{N=156}{\%(n)}\end{array}$ \\
\hline Strongly Disagree & $1.09 \%(1)$ & 0 & $0.06 \%(1)$ \\
\hline Disagree & $4.35 \%(4)$ & $1.56 \%(1)$ & $3.21 \%(5)$ \\
\hline Neutral & $6.52 \%(6)$ & $3.13 \%(2)$ & $5.13 \%(8)$ \\
\hline Agree & $36.96 \%(34)$ & $29.69 \%(19)$ & $33.97 \%(53)$ \\
\hline Strongly Agree & $51.09 \%(47)$ & $65.63 \%(42)$ & $57.05 \%(89)$ \\
\hline
\end{tabular}

$\mathrm{SP}=$ School Psychologist $\mathrm{SC}=$ School Counselor $M=$ Mean $; D=$ Standard Deviation; $d=$ Cohen's $d$

For item 1 regarding undergraduate coursework in Table 2, the majority of participants' $(38.46 \%, n=60 ; \mathrm{SP}: M=2.28, S D=1.15 ; \mathrm{SC}: M=2.44, S D=1.27 ; d=0.13)$ ratings fall in the "Disagree" range. The majority of the school psychologists' and school counselors' responses for item 2- program coursework $(42.31 \%, n=66$; SP: $M=3.61, S D=1.08$; $\mathrm{SC}: M=3.83, S D=$ $1.07 ; d=0.20)$, item 3 - practicum experience $(42.31 \%, n=66 ; \mathrm{SP}: M=3.24, S D=1.12 ; \mathrm{SC}: M$ $=3.59, S D=1.16 ; d=0.31)$, and item 4- internship experience $(46.15 \%, n=72 ; \mathrm{SP}: M=3.78$, $S D=1 ; \mathrm{SC}: M=3.86, S D=1.12 ; d=0.08)$ fall in the "Agree" range. Item 5- attending workshops/trainings $(43.39 \%, n=68 ; \mathrm{SP}: M=4.11, S D=1.04 ; \mathrm{SC}: M=4.25, S D=0.83 ; d=$ $0.15)$ and item 6- professional experience $(57.05 \%, n=89 ; \mathrm{SP}: M=4.33, S D=0.86$; $\mathrm{SC}: M=$ 4.59, $S D=0.63 ; d=0.34)$ fall in the "Strongly Agree" range. 
Table 3

Professional Association Subscale

SP: 7. Was your school psychology program approved by the National Association of School Psychologists (NASP)?

\begin{tabular}{|l|c|}
\hline & SP \\
& $\underline{N=92}$ \\
$\%(n)$ \\
\hline Yes & $70.65 \%(65)$ \\
\hline No & $18.48 \%(17)$ \\
\hline Don' Know & $10.87 \%(10)$ \\
\hline
\end{tabular}

SC: 7. Did your school counseling program follow the American School Counselor Association (ASCA) National Model?

\begin{tabular}{|l|c|}
\hline & SC \\
& $\underline{N=64}$ \\
\hline Yes & $\%(n)$ \\
\hline No & $67.19 \%(43)$ \\
\hline Don't Know & $17.19 \%(11)$ \\
\hline
\end{tabular}

$\mathrm{SP}=$ School Psychologist; $\mathrm{SC}=$ School Counselor

Results from the professional association subscale in Table 3, which includes item 7

(possible response of $1=$ Yes, $2=$ No, and $3=$ Don't Know), show that the majority of school

psychologists $(70.65 \%, n=65)$ attended graduate programs that were approved by the National Association of School Psychologists (NASP). In addition, the majority of school counselors' $(67.19 \%, n=43)$ school counseling graduate programs followed the American School Counselor Association (ASCA) National Model.

Table 4

Learning/Support Needed Subscale

SP: 8. What course(s) did you take during your school psychology program related to mental health?

SC: 8. What course(s) did you take during your school counseling program related to mental health?

\begin{tabular}{|c|c|}
\hline \multicolumn{1}{|c|}{ SP } & \multicolumn{1}{c|}{$\begin{array}{c}n=60 \\
\text { Themes } \\
\text { Themes }\end{array}$} \\
\hline 1. Counseling (Not Specified) & 1. Group Counseling \\
2. Group Counseling & 2. Theories \\
\hline
\end{tabular}




\begin{tabular}{|c|c|}
\hline & \\
\hline 3. Psychopathology/Disorders & 3. Crisis Intervention \\
\hline 4. Individual Counseling & 4. Unsure \\
\hline 5. Behavior & 5. Counseling (Not Specified) \\
\hline 6. Assessment & 6. Psychopathology/Disorders \\
\hline 7. Theories & 7. Law/Ethics \\
\hline 8. Crisis Intervention & 8. Assessment \\
\hline 9. Mental Health & 9. Practicum \\
\hline 10. Collaboration \& Consultation & 10. Cultural Counseling \\
\hline $\begin{array}{l}\text { SP: 9. What would you have liked to have learned } \\
\text { the provision of school-based mental health service }\end{array}$ & n't in your school psychology program regarding \\
\hline $\begin{array}{l}\text { SC: } 9 \text {. What would you have liked to have learned } \\
\text { the provision of school-based mental health service }\end{array}$ & n't in your school counseling program regarding \\
\hline SP & $\mathrm{SC}$ \\
\hline$\underline{n=84}$ & $\underline{n=59}$ \\
\hline Themes & Themes \\
\hline 1. Counseling/Therapy (Not Specified) & 1. Suicidal Risk Assessments/Risk Assessment \\
\hline 2. Suicide Risk Assessments/Risk Assessments & 2. SBMSHS \\
\hline 3. Cognitive Behavioral Therapy & 3. Resources \\
\hline 4. Group Counseling & 4. Trauma Counseling \\
\hline 5. Evidence-Based Programs & 5. Nothing \\
\hline 6. Progress Monitoring & 6. Brief Solution-Focus Counseling \\
\hline 7. Group Counseling & 7. Mental Health \\
\hline 8. Goal Writing & 8. Hands-On Experience \\
\hline 9. Nothing & 9. Behavior Intervention; \\
\hline 10. SBMHS & 10. 504 Plans \\
\hline $\begin{array}{l}\text { 10. What kind of support would you need in you } \\
\text { school-based mental health services? Please specify }\end{array}$ & $\begin{array}{l}\text { nt position to feel more competent in providing } \\
\text { box below: }\end{array}$ \\
\hline SP & $\mathrm{SC}$ \\
\hline$\underline{n=86}$ & $\underline{n=59}$ \\
\hline Themes & Themes \\
\hline $\begin{array}{l}\text { 1. Training/Professional } \\
\text { Developments/Workshops }\end{array}$ & $\begin{array}{l}\text { 1. } \quad \text { Training/Professional } \\
\quad \text { Developments/Workshops }\end{array}$ \\
\hline 2. Time & 2. Smaller caseload \\
\hline 3. None & 3. Time \\
\hline 4. Professional Developments & 4. Support \\
\hline 5. Evidence-Based Programs & 5. Evidence-Based Programs \\
\hline
\end{tabular}




\begin{tabular}{|l|l|}
\hline 6. Smaller Caseload & 6. Supervision \\
7. Support & 7. Nothing \\
8. Resources & 8. School Policies/Procedures \\
9. Progress Monitoring & 9. Resources \\
10. Experience & 10. Support \\
\hline
\end{tabular}

$\mathrm{SP}=$ School Psychologist; $\mathrm{SC}=$ School Counselor

Participants were allowed to write in responses for items 8-10 on the Learning/Support Needed subscale (see Table 4). The top 10 frequent responses for each item are listed. The top response for item 8 regarding courses related to mental health taken during their graduate program by school psychologists is Counseling (Not Specified), and for school counselors is Group Counseling. For item 9 regarding what participants would have liked to learn in their programs, school psychologists' top response was Counseling/Therapy (Not Specified), and for school counselors is Suicidal Risk Assessment/Risk Assessment. Both school psychologists and school counselors' top response for item 10 regarding the support that they would need in their current position to feel more competent in providing SBMHS is Training/Professional Developments/Workshops.

\section{Table 5}

Additional Graduate Level Coursework and State Registrations/Licenses Subscale Please select from the following items regarding your completed graduate-level course work and/or state registrations or licenses related to the provision of mental health services.

SP: 11. In addition to my school psychology training, I have completed another master's or specialist level program (e.g., school counseling, social work, marital family therapy):

SC: 11. In addition to my school counseling training, I have completed another master's or specialist level program (e.g., school psychology, social work, marital family therapy):

\begin{tabular}{|l|c|c|c|}
\hline & SP & SC & Total \\
& $\frac{N=92}{\%(n)}$ & $\frac{N=64}{\%(n)}$ & $\frac{N=156}{\%(n)}$ \\
\hline Yes & $39.13 \%(36)$ & $29.69 \%(19)$ & $35.26 \%(55)$ \\
\hline No & $60.87 \%(56)$ & $70.31 \%(45)$ & $64.74 \%(101)$ \\
\hline 11a. If yes, please select the area(s) of the other master's or specialist level program(s) you attended: \\
\hline \multicolumn{2}{|c|}{ SP }
\end{tabular}




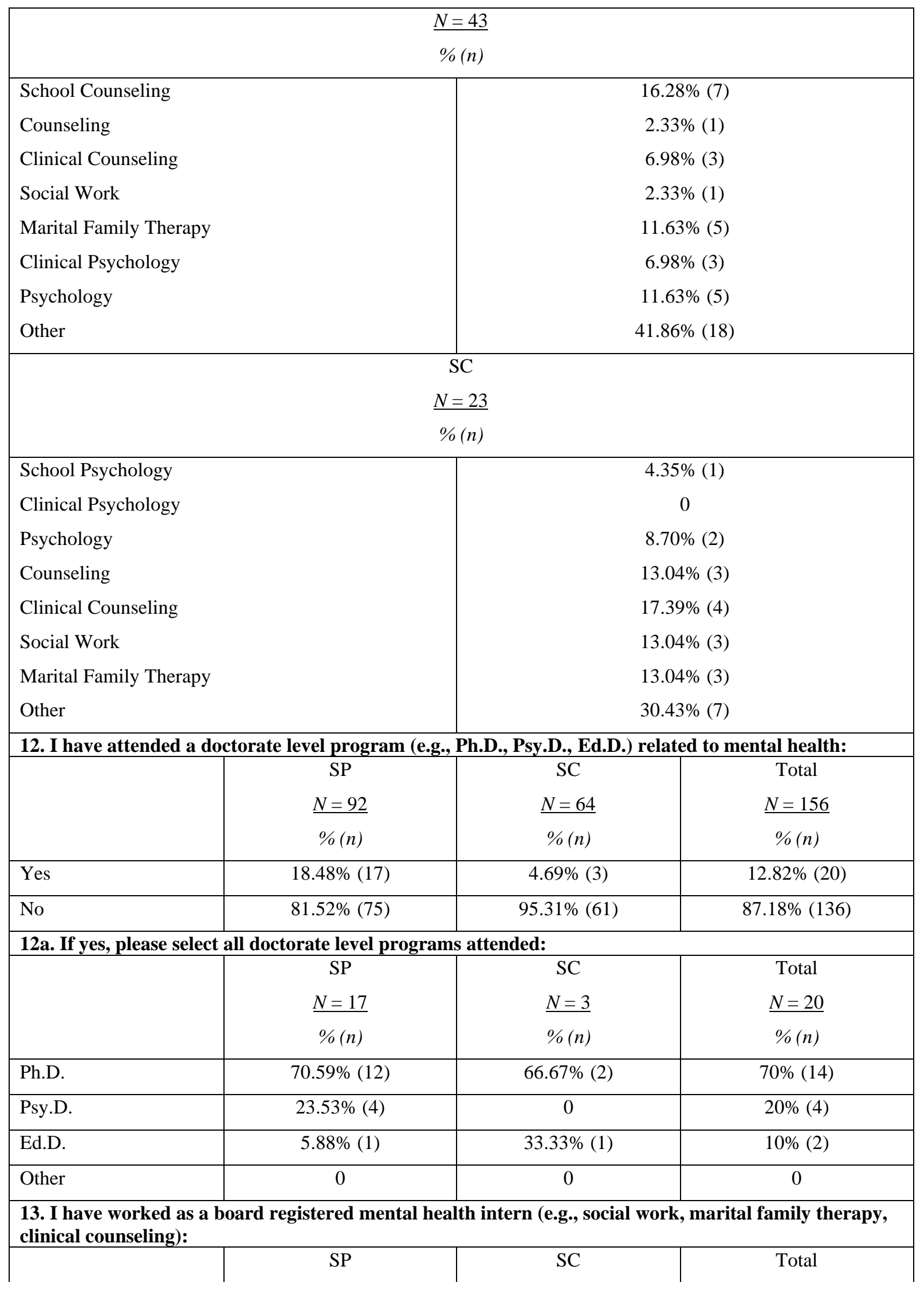




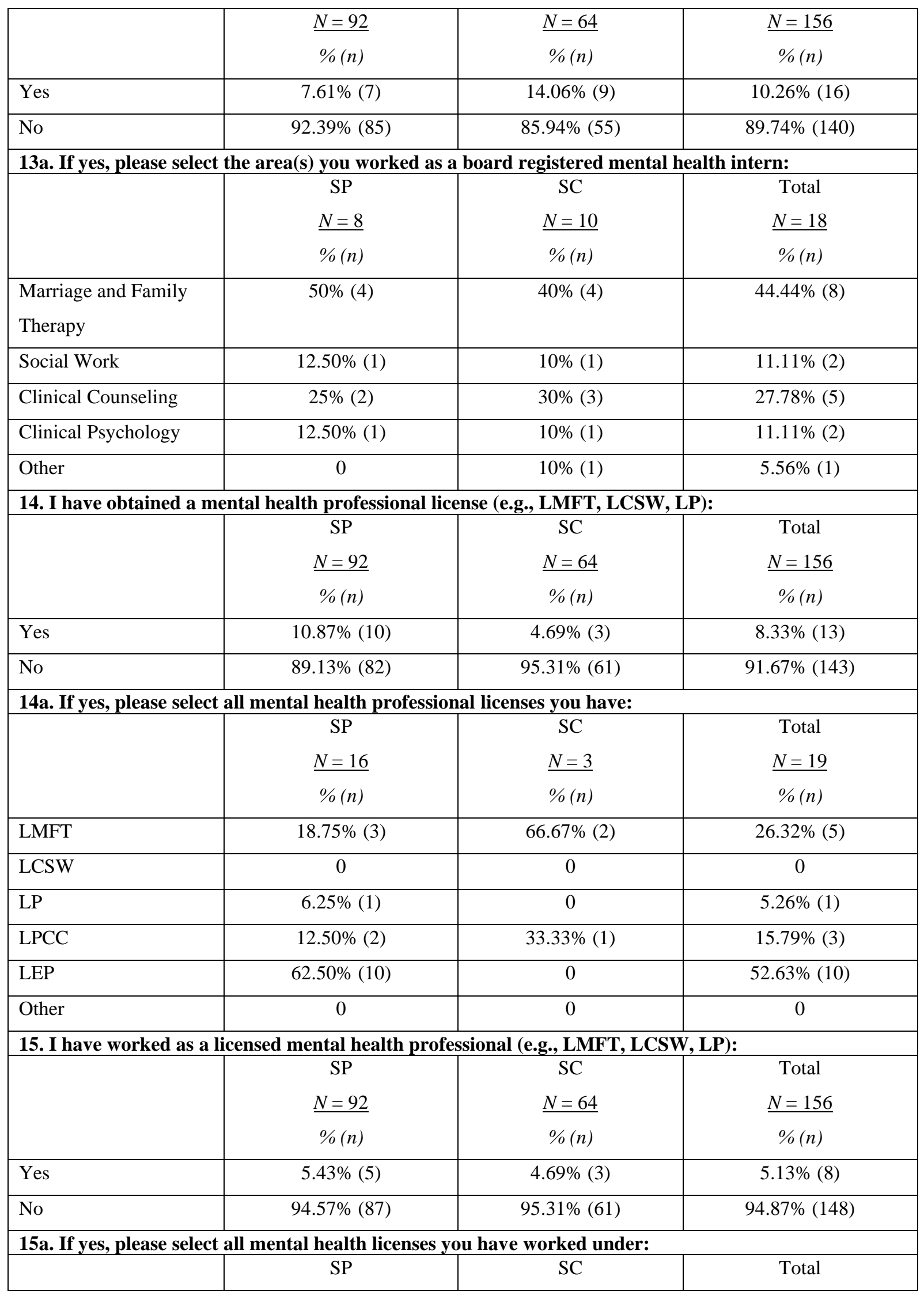




\begin{tabular}{|l|c|c|c|}
\hline & $\frac{N=10}{\%(n)}$ & $\frac{N=3}{\%(n)}$ & $\frac{N=13}{\%(n)}$ \\
\hline LMFT & $30 \%(3)$ & $66.67 \%(2)$ & $38.46 \%(5)$ \\
\hline LCSW & 0 & 0 & 0 \\
\hline LP & $10 \%(1)$ & 0 & $7.69 \%(1)$ \\
\hline LPCC & $10 \%(1)$ & $33.33 \%(1)$ & $15.38 \%(2)$ \\
\hline LEP & $50 \%(5)$ & 0 & $38.46 \%(5)$ \\
\hline Other & 0 & 0 & 0 \\
\hline
\end{tabular}

$\mathrm{SP}=$ School Psychologist; $\mathrm{SC}=$ School Counselor

The subscale regarding additional graduate-level course work and state registrations/licenses includes five items (items 11-15) that allow participants to provide a yesor-no response (see Table 5). A subitem is provided for each item if the respondent responded with a "Yes" to the item. The majority of participants responded that they had not completed another master's or specialist level program $(64.74 \%, n=101)$ for item 11 , doctorate level program $(87.18 \%, n=136)$ for item 12 , work as a board registered mental health intern $(89.74 \%$, $n=140)$ for item 13, obtain a mental health professional license $(91.67 \%, n=143)$ for item 14 , or work as a licensed mental professional $(94.87 \%, n=148)$ for item 15.

Of the 43 school psychologists who indicated that they had completed another master's level or specialist program on item 11, the majority of the respondents selected "Other" (41.86\%, $n=18$ ). Some respondents specified on item 11a that they completed additional programs such as Board-Certified Behavior Analyst (BCBA), Educational Psychology, or Educational Leadership. Out of the 23 school counselors who indicated "Yes" on item 11, the majority $(30.43 \%, n=18)$ also indicated "Other" programs such as Educational Leadership, Counseling Psychology, or Counselor Education on item 11a.

On item 12 regarding attending a doctorate level program, "Ph.D." program was indicated as the doctorate program that the majority of participants $(70 \%, n=14)$ who answered "Yes" $(12.82 \%, n=20)$ attended. It appears that having worked as a marriage and family therapist 
intern was the most common response for participants $(44.44 \%, n=8)$ who selected "Yes" $(10.26 \%, 16)$ on item 13 , which asked if they had worked as a board registered mental health intern.

Out of the 16 possible responses on item 14 regarding obtaining a mental health professional license by school psychologists, Licensed Educational Psychologist (LEP) was the most common selection $(62.50 \%, n=10)$ of the school psychologists' responses. Licensed Marriage and Family Therapist (LMFT) was indicated for $66.67 \%(n=2)$ responses out of the total of 3 school counselors who responded that they had obtained a license in response to item 14. Ten of the school psychologists responded that $50 \%(n=5)$ they worked as an LEP, and $66.67 \%(n=2)$ school counselors worked as an LMFT.

\section{Provision of SBMHS Subscale}

The provision of SBMHS subscale provides a list of various SBMHS (see Table 6). This subscale includes thirteen items (items 16-28; possible score of 13-26) that require a yes-or-no answer. Each of the thirteen items includes a sub-item based on a 5-point Likert-scale from $1=$ Strongly Disagree to 5 = Strongly Agree (possible score of 13-65).

\section{Table 6}

Provision of SBMHS Subscale

On a scale from 1 to 5 ( 1 = Strongly Disagree to $5=$ Strongly Agree), please select one response for each of the following items regarding your provision of school-based mental health services.

\begin{tabular}{|c|c|c|c|}
\hline \multicolumn{4}{|c|}{ 16. I have provided individual counseling to students: } \\
\hline & & & Total \\
\hline & $\underline{N}=92$ & $\underline{N=64}$ & $\underline{N=156}$ \\
\hline & $\%(n)$ & $\%(n)$ & $\%(n)$ \\
\hline Yes & $97.83 \%(90)$ & $98.44 \%(63)$ & $98.08 \%(153)$ \\
\hline No & $2.17 \%(2)$ & $1.56 \%(1)$ & $1.92 \%(3)$ \\
\hline \multicolumn{4}{|c|}{ 16a. I feel prepared to provide individual counseling to students: } \\
\hline \multirow[t]{3}{*}{$M(S D)$} & $\mathrm{SP}=4.10(0.77)$ & $\mathrm{SC}=4.42(0.81)$ & $d=0.40$ \\
\hline & SP & $\mathrm{SC}$ & Total \\
\hline & & $\underline{N}=64$ & $\underline{N=156}$ \\
\hline
\end{tabular}




\begin{tabular}{|c|c|c|c|}
\hline & $\%(n)$ & $\%(n)$ & $\%(n)$ \\
\hline Strongly Disagree & 0 & $1.56 \%(1)$ & $0.06 \%(1)$ \\
\hline Disagree & $4.35 \%(4)$ & $1.56 \%(1)$ & $3.21 \%(5)$ \\
\hline Neutral & $11.96 \%(11)$ & $6.25 \%(4)$ & $9.62 \%(15)$ \\
\hline Agree & $53.36 \%(49)$ & $34.38 \%(22)$ & $45.51 \%(71)$ \\
\hline Strongly Agree & $30.48 \%(28)$ & $56.25 \%(36)$ & $41.03 \%(64)$ \\
\hline \multicolumn{4}{|c|}{ 17. I have provided group counseling to students: } \\
\hline & $\begin{array}{c}\text { SP } \\
N=92 \\
\%(n)\end{array}$ & $\begin{array}{c}\mathrm{SC} \\
N=64 \\
\%(n)\end{array}$ & $\begin{array}{c}\text { Total } \\
N=156 \\
\%(n)\end{array}$ \\
\hline Yes & $91.30 \%(84)$ & $98.44 \%(63)$ & $94.23 \%(147)$ \\
\hline No & $8.70 \%(8)$ & $1.56 \%(1)$ & $5.77 \%(9)$ \\
\hline \multicolumn{4}{|c|}{ 17a. I feel prepared to provide group counseling to students: } \\
\hline \multirow[t]{2}{*}{$M(S D)$} & $\mathrm{SP}=3.95(0.84)$ & $\mathrm{SC}=4.17(1.04)$ & $d=0.23$ \\
\hline & $\begin{array}{c}\text { SP } \\
N=92 \\
\%(n)\end{array}$ & $\begin{array}{c}\mathrm{SC} \\
N=64 \\
\%(n)\end{array}$ & $\begin{array}{c}\text { Total } \\
\frac{N=156}{\%(n)}\end{array}$ \\
\hline Strongly Disagree & 0 & $3.13 \%(2)$ & $1.28 \%(2)$ \\
\hline Disagree & $6.52 \%(6)$ & $6.25 \%(4)$ & $6.41 \%(10)$ \\
\hline Neutral & $18.48 \%(17)$ & $9.38 \%(6)$ & $14.74 \%(23)$ \\
\hline Agree & $48.91 \%(45)$ & $32.81 \%(21)$ & $42.31 \%(66)$ \\
\hline Strongly Agree & $26.09 \%(24)$ & $48.44 \%(31)$ & $35.26 \%(55)$ \\
\hline \multicolumn{4}{|c|}{ 18. I have provided crisis intervention other than suicide risk assessment individually to students } \\
\hline & $\begin{array}{c}\text { SP } \\
N=92 \\
\%(n)\end{array}$ & $\begin{array}{c}\mathrm{SC} \\
N=64 \\
\%(n)\end{array}$ & $\begin{array}{c}\text { Total } \\
\frac{N=156}{\%(n)}\end{array}$ \\
\hline Yes & $86.96 \%(80)$ & $92.19 \%(59)$ & $89.10 \%(139)$ \\
\hline No & $13.04 \%(12)$ & $7.81 \%(5)$ & $10.90 \%(17)$ \\
\hline \multicolumn{4}{|c|}{ 18a. I feel prepared to provide crisis intervention individually to students: } \\
\hline \multirow[t]{2}{*}{$M(S D)$} & $\mathrm{SP}=3.87(0.96)$ & $\mathrm{SC}=4.02(0.91)$ & $d=0.16$ \\
\hline & $\begin{array}{c}\text { SP } \\
N=92 \\
\%(n)\end{array}$ & $\begin{array}{c}\mathrm{SC} \\
N=64 \\
\%(n)\end{array}$ & $\begin{array}{c}\text { Total } \\
N=156 \\
\%(n)\end{array}$ \\
\hline Strongly Disagree & $1.09 \%(1)$ & 0 & $0.06 \%(1)$ \\
\hline Disagree & $8.70 \%(8)$ & $7.81 \%(5)$ & $8.33 \%(13)$ \\
\hline Neutral & $20.65 \%(19)$ & $17.19 \%(11)$ & $19.23 \%(30)$ \\
\hline Agree & $41.30 \%(38)$ & $40.63 \%(26)$ & $41.03 \%(64)$ \\
\hline Strongly Agree & $28.26 \%(26)$ & $34.38 \%(22)$ & $30.77 \%(48)$ \\
\hline
\end{tabular}




\begin{tabular}{|c|c|c|c|}
\hline \multicolumn{4}{|c|}{ 19. I have provided crisis intervention other than suicide risk assessment to students in groups: } \\
\hline & SP & $\mathrm{SC}$ & Total \\
\hline & $N=92$ & $N=64$ & $N=156$ \\
\hline & $\%(n)$ & $\%(n)$ & $\%(n)$ \\
\hline Yes & $59.78 \%(55)$ & $54.69 \%(35)$ & $57.69 \%(90)$ \\
\hline No & $40.22 \%(37)$ & $45.31 \%(29)$ & $42.31 \%(66)$ \\
\hline \multicolumn{4}{|c|}{ 19a. I feel prepared to provide crisis intervention in groups to students: } \\
\hline \multirow[t]{4}{*}{$M(S D)$} & $\mathrm{SP}=3.38(1.07)$ & $\mathrm{SC}=3.47(1.17)$ & $d=0.08$ \\
\hline & SP & SC & Total \\
\hline & $N=92$ & $N=64$ & $N=156$ \\
\hline & $\%(n)$ & $\%(n)$ & $\%(n)$ \\
\hline Strongly Disagree & $1.09 \%(1)$ & $3.13 \%(2)$ & $1.92 \%(3)$ \\
\hline Disagree & $25 \%(23)$ & $23.44 \%(15)$ & $24.36 \%(38)$ \\
\hline Neutral & $26.09 \%(24)$ & $20.31 \%(13)$ & $23.72 \%(37)$ \\
\hline Agree & $30.43 \%(28)$ & $29.69 \%(19)$ & $30.13 \%(47)$ \\
\hline Strongly Agree & $17.39 \%(16)$ & $23.44 \%(15)$ & $19.87 \%(31)$ \\
\hline \multicolumn{4}{|c|}{ 20. I have provided suicide risk assessment to students: } \\
\hline & SP & $\mathrm{SC}$ & Total \\
\hline & $\underline{N=92}$ & $\underline{N=64}$ & $N=156$ \\
\hline & $\%(n)$ & $\%(n)$ & $\%(n)$ \\
\hline Yes & $94.57 \%(87)$ & $95.31 \%(61)$ & $94.87 \%(148)$ \\
\hline No & $5.43 \%(5)$ & $4.69 \%(3)$ & $5.13 \%(8)$ \\
\hline \multicolumn{4}{|c|}{ 20a. I feel prepared to provide suicide risk assessment to students. } \\
\hline \multirow[t]{4}{*}{$M(S D)$} & $\mathrm{SP}=4.27(0.77)$ & $\mathrm{SC}=4.11(0.97)$ & $d=0.18$ \\
\hline & SP & $\mathrm{SC}$ & Total \\
\hline & $\underline{N=92}$ & $\underline{N=64}$ & $\underline{N=156}$ \\
\hline & $\%(n)$ & $\%(n)$ & $\%(n)$ \\
\hline Strongly Disagree & $1.09 \%(1)$ & $1.56 \%(1)$ & $1.28 \%(2)$ \\
\hline Disagree & $1.09 \%(1)$ & $7.81 \%(5)$ & $3.85 \%(6)$ \\
\hline Neutral & $9.78 \%(9)$ & $9.38 \%(6)$ & $9.62 \%(15)$ \\
\hline Agree & $45.65 \%(42)$ & $40.63 \%(26)$ & $43.59 \%(68)$ \\
\hline Strongly Agree & $42.39 \%(39)$ & $40.63 \%$ (26) & $41.67 \%(65)$ \\
\hline \multicolumn{4}{|c|}{$\begin{array}{l}\text { 21. I have directly participated in programs related to primary prevention or mental health } \\
\text { promotion (e.g., suicide prevention campaigns, emotion regulation groups, mindfulness) with } \\
\text { students: }\end{array}$} \\
\hline & $\mathrm{SP}$ & $\mathrm{SC}$ & Total \\
\hline & $\underline{N=92}$ & $\underline{N=64}$ & $\underline{N=156}$ \\
\hline & $\%(n)$ & $\%(n)$ & $\%(n)$ \\
\hline Yes & $72.82 \%(67)$ & $79.69 \%(51)$ & $75.64 \%(118)$ \\
\hline
\end{tabular}




\begin{tabular}{|c|c|c|c|}
\hline No & $27.17 \%(25)$ & $20.31 \%(13)$ & $24.36 \%(38)$ \\
\hline \multicolumn{4}{|c|}{$\begin{array}{l}\text { 21a. I feel prepared to provide prevention related to mental health (e.g., suicide prevention } \\
\text { campaigns, emotion regulation groups, mindfulness) to students: }\end{array}$} \\
\hline \multirow[t]{2}{*}{$M(S D)$} & $\mathrm{SP}=3.73(1.03)$ & $\mathrm{SC}=3.91(1.07)$ & $d=0.17$ \\
\hline & $\begin{array}{c}\mathrm{SP} \\
N=92 \\
\%(n)\end{array}$ & $\begin{array}{c}\mathrm{SC} \\
N=64 \\
\%(n)\end{array}$ & $\begin{array}{c}\text { Total } \\
N=156 \\
\%(n)\end{array}$ \\
\hline Strongly Disagree & $1.09 \%(1)$ & $3.13 \%(2)$ & $1.19 \%(3)$ \\
\hline Disagree & $14.13 \%(13)$ & $7.81 \%(5)$ & $11.54 \%(18)$ \\
\hline Neutral & $21.74 \%(20)$ & $20.31 \%(13)$ & $21.15 \%(33)$ \\
\hline Agree & $36.96 \%(34)$ & $32.81 \%(21)$ & $35.26 \%(55)$ \\
\hline Strongly Agree & $26.09 \%(24)$ & $35.94 \%(23)$ & $30.13 \%(47)$ \\
\hline \multicolumn{4}{|c|}{ 22. I have developed and implemented Behavior Intervention Plans (BIPs) to students: } \\
\hline & $\begin{array}{c}\text { SP } \\
N=92 \\
\%(n)\end{array}$ & $\begin{array}{c}\mathrm{SC} \\
N=64 \\
\%(n)\end{array}$ & $\begin{array}{c}\text { Total } \\
\frac{N=156}{\%(n)}\end{array}$ \\
\hline Yes & $97.83 \%(90)$ & $40.63 \%(26)$ & $74.36 \%(116)$ \\
\hline No & $2.17 \%(2)$ & $59.38 \%(38)$ & $25.64 \%(40)$ \\
\hline \multicolumn{4}{|c|}{ 22a. I feel prepared to provide behavior interventions to students: } \\
\hline \multirow[t]{2}{*}{$M(S D)$} & $\mathrm{SP}=4.14(0.80)$ & $\mathrm{SC}=3.03(1.36)$ & $d=0.99$ \\
\hline & $\begin{array}{c}\text { SP } \\
N=92 \\
\%(n)\end{array}$ & $\begin{array}{c}\mathrm{SC} \\
N=64 \\
\%(n)\end{array}$ & $\begin{array}{c}\text { Total } \\
\frac{N=156}{\%(n)}\end{array}$ \\
\hline Strongly Disagree & 0 & $15.63 \%(10)$ & $6.41 \%(10)$ \\
\hline Disagree & $4.35 \%(4)$ & $25 \%(16)$ & $12.82 \%(20)$ \\
\hline Neutral & $13.04 \%(12)$ & $18.75 \%(12)$ & $15.38 \%(24)$ \\
\hline Agree & $46.74 \%(43)$ & $21.88 \%(14)$ & $36.54 \%(57)$ \\
\hline Strongly Agree & $35.87 \%(33)$ & $18.75 \%(12)$ & $28.85 \%(45)$ \\
\hline \multicolumn{4}{|c|}{ 23. I have provided case-management (e.g., communication, making referrals, utilizing resources) } \\
\hline & $\begin{array}{c}\text { SP } \\
N=92 \\
\%(n)\end{array}$ & $\begin{array}{c}\mathrm{SC} \\
N=64 \\
\%(n)\end{array}$ & $\begin{array}{c}\text { Total } \\
N=156 \\
\%(n)\end{array}$ \\
\hline Yes & $95.65 \%(88)$ & $89.06 \%(57)$ & $92.95 \%(145)$ \\
\hline No & $4.35 \%(4)$ & $10.94 \%(7)$ & $7.05 \%(11)$ \\
\hline \multicolumn{4}{|c|}{$\begin{array}{l}\text { 23a. I feel prepared to provide case-management (e.g., communication, making referrals, utilizing } \\
\text { resources): }\end{array}$} \\
\hline \multirow[t]{2}{*}{$M(S D)$} & $\mathrm{SP}=4.37(0.69)$ & $\mathrm{SC}=4.05(0.98)$ & $d=0.38$ \\
\hline & $\begin{array}{c}\mathrm{SP} \\
N=92 \\
\end{array}$ & $\begin{array}{c}\mathrm{SC} \\
N=64 \\
\end{array}$ & $\begin{array}{c}\text { Total } \\
N=156 \\
\end{array}$ \\
\hline
\end{tabular}




\begin{tabular}{|l|c|c|c|}
\hline & $\%(n)$ & $\%(n)$ & $\%(n)$ \\
\hline Strongly Disagree & 0 & $1.56 \%(1)$ & $0.64 \%(1)$ \\
\hline Disagree & $2.17 \%(2)$ & $6.25 \%(4)$ & $3.85 \%(6)$ \\
\hline Neutral & $5.43 \%(5)$ & $17.19 \%(11)$ & $10.26 \%(16)$ \\
\hline Agree & $45.65 \%(42)$ & $35.94 \%(23)$ & $41.67 \%(65)$ \\
\hline Strongly Agree & $46.74 \%(43)$ & $39.06 \%(25)$ & $43.59 \%(68)$ \\
\hline
\end{tabular}

24. I have conducted social-emotional/behavioral assessments and interpreted the results:

\begin{tabular}{|l|c|c|c|}
\hline & SP & SC & Total \\
& $\frac{N=92}{\%(n)}$ & $\frac{N=64}{\%(n)}$ & $\frac{N=156}{\%(n)}$ \\
\hline Yes & $98.91 \%(91)$ & $39.06 \%(25)$ & $74.36 \%(116)$ \\
\hline No & $1.09 \%(1)$ & $60.94 \%(39)$ & $25.64 \%(40)$ \\
\hline
\end{tabular}

24a. I feel prepared to conduct social-emotional/behavioral assessments and interpret the results:

\begin{tabular}{|l|c|c|c|}
\hline$M(S D)$ & $\mathrm{SP}=4.55(0.68)$ & $\mathrm{SC}=2.77(1.30)$ & $d=1.72$ \\
& $\mathrm{SP}$ & $\mathrm{SC}$ & $\frac{N=156}{\%=64}$ \\
& $\frac{N=92}{\%(n)}$ & $\%(n)$ & $6.41 \%(10)$ \\
\hline Strongly Disagree & 0 & $15.63 \%(10)$ & $15.38 \%(24)$ \\
\hline Disagree & $2.17 \%(2)$ & $34.38 \%(22)$ & $12.82 \%(20)$ \\
\hline Neutral & $4.35 \%(4)$ & $25 \%(16)$ & $20.51 \%(32)$ \\
\hline Agree & $29.35 \%(27)$ & $7.81 \%(5)$ & $44.87 \%(70)$ \\
\hline Strongly Agree & $64.13 \%(59)$ & $17.19 \%(11)$ & \\
\hline
\end{tabular}

25. I have provided consultation to individuals (e.g., school staff, community professionals) regarding students' mental health and/or school-based mental health services:

\begin{tabular}{|l|c|c|c|}
\hline & SP & SC & Total \\
& $\frac{N=92}{\%(n)}$ & $\underline{N=64} \frac{N=156}{\%(n)}$ \\
\hline Yes & $100 \%(92)$ & $84.38 \%(54)$ & $93.59 \%(146)$ \\
\hline No & 0 & $15.63 \%(10)$ & $6.41 \%(10)$ \\
\hline
\end{tabular}

25a. I feel prepared to provide consultation to individuals (e.g., school staff, outside professionals) regarding students' mental health and/or school-based mental health services:

\begin{tabular}{|l|c|c|c|}
\hline$M(S D)$ & $\mathrm{SP}=4.36(0.72)$ & $\mathrm{SC}=3.75(1.06)$ & $d=0.67$ \\
& $\mathrm{SP}$ & $\mathrm{SC}$ & $\frac{N=156}{N=64}$ \\
& $\frac{N=92}{\%(n)}$ & $\%(n)$ & $1.92 \%(3)$ \\
\hline Strongly Disagree & 0 & $4.69 \%(3)$ & $3.21 \%(5)$ \\
\hline Disagree & 0 & $7.81 \%(5)$ & $16.67 \%(26)$ \\
\hline Neutral & $14.13 \%(13)$ & $20.31 \%(13)$ & Total \\
\hline
\end{tabular}




\begin{tabular}{|c|c|c|c|}
\hline Agree & $35.87 \%(33)$ & $42.19 \%(27)$ & $38.46 \%(60)$ \\
\hline Strongly Agree & $50 \%(46)$ & $25 \%(16)$ & $39.74 \%(62)$ \\
\hline \multicolumn{4}{|c|}{ 26. I have provided counseling to school personnel: } \\
\hline & $\mathrm{SP}$ & $\mathrm{SC}$ & Total \\
\hline & $N=92$ & $N=64$ & $N=156$ \\
\hline & $\%(n)$ & $\%(n)$ & $\%(n)$ \\
\hline Yes & $44.57 \%(41)$ & $64.06 \%(41)$ & $52.56 \%(82)$ \\
\hline No & $55.43 \%(51)$ & $35.94 \%(23)$ & $47.44 \%(74)$ \\
\hline \multicolumn{4}{|c|}{ 26a. I feel prepared to provide counseling to school personnel: } \\
\hline \multirow[t]{4}{*}{$M(S D)$} & $\mathrm{SP}=3.13(1.09)$ & $\mathrm{SC}=3.42(1.23)$ & $d=0.25$ \\
\hline & SP & $\mathrm{SC}$ & Total \\
\hline & $N=92$ & $N=64$ & $\underline{N=156}$ \\
\hline & $\%(n)$ & $\%(n)$ & $\%(n)$ \\
\hline Strongly Disagree & $5.43 \%(5)$ & $9.38 \%(6)$ & $7.05 \%(11)$ \\
\hline Disagree & $26.09 \%(24)$ & $14.06 \%(9)$ & $21.15 \%(33)$ \\
\hline Neutral & $29.35 \%(27)$ & $23.44 \%(15)$ & $26.92 \%(42)$ \\
\hline Agree & $28.26 \%(26)$ & $31.25 \%(20)$ & $29.49 \%(46)$ \\
\hline Strongly Agree & $10.87 \%(10)$ & $21.88 \%(14)$ & $15.38 \%(24)$ \\
\hline \multicolumn{4}{|c|}{$\begin{array}{l}\text { 27. I have provided in-service trainings (e.g., on topics such as social/emotional components, } \\
\text { behavior, mental health, interventions, etc.): }\end{array}$} \\
\hline & $\mathrm{SP}$ & $\mathrm{SC}$ & Total \\
\hline & $\underline{N=92}$ & $\underline{N=64}$ & $\underline{N=156}$ \\
\hline & $\%(n)$ & $\%(n)$ & $\%(n)$ \\
\hline Yes & $72.83 \%(67)$ & $60.94 \%$ (39) & $67.95 \%(106)$ \\
\hline No & $27.17 \%(25)$ & $39.06 \%(25)$ & $32.05 \%(50)$ \\
\hline \multicolumn{4}{|c|}{$\begin{array}{l}\text { 27a. I feel prepared to provide in-service training (e.g., on topics such as social/emotional } \\
\text { components, behavior, mental health, interventions, etc.): }\end{array}$} \\
\hline \multirow[t]{4}{*}{$M(S D)$} & $\mathrm{SP}=3.91(0.94)$ & $\mathrm{SC}=3.45(1.24)$ & $d=0.49$ \\
\hline & SP & $\mathrm{SC}$ & Total \\
\hline & $N=92$ & $N=64$ & $\underline{N=156}$ \\
\hline & $\%(n)$ & $\%(n)$ & $\%(n)$ \\
\hline Strongly Disagree & 0 & $10.94 \%(7)$ & $4.49 \%(7)$ \\
\hline Disagree & $9.78 \%(9)$ & $12.50 \%(8)$ & $10.90 \%(17)$ \\
\hline Neutral & $19.57 \%(18)$ & $15.63 \%(10)$ & $17.95 \%(28)$ \\
\hline Agree & $40.22 \%(37)$ & $42.19 \%(27)$ & $41.03 \%(64)$ \\
\hline Strongly Agree & $30.43 \%(28)$ & $18.75 \%(12)$ & $25.64 \%(40)$ \\
\hline \multicolumn{4}{|c|}{ 28. I have provided family/parent counseling: } \\
\hline & SP & $\mathrm{SC}$ & Total \\
\hline & $\underline{N=92}$ & $\underline{N=64}$ & $\underline{N=156}$ \\
\hline
\end{tabular}




\begin{tabular}{|l|c|c|c|}
\hline & $\%(n)$ & $\%(n)$ & $\%(n)$ \\
\hline Yes & $40.22 \%(37)$ & $70.31 \%(45)$ & $52.56 \%(82)$ \\
\hline No & $59.78 \%(55)$ & $29.69 \%(19)$ & $47.44 \%(74)$ \\
\hline 28a. I feel prepared to provide family/parent counseling: & \multicolumn{2}{|c|}{} \\
\hline$M(S D)$ & $\mathrm{SP}=3.17(1.20)$ & $\mathrm{SC}=3.42(1.18)$ & $d=0.21$ \\
\hline & $\mathrm{SP}$ & $\underline{N=64}$ & Total \\
& $\underline{N=92}$ & $\%(n)$ & $\%(n)$ \\
\hline Strongly Disagree & $\%(n)$ & $7.81 \%(5)$ & $7.69 \%(12)$ \\
\hline Disagree & $7.61 \%(7)$ & $14.06 \%(9)$ & $20.51 \%(32)$ \\
\hline Neutral & $25 \%(23)$ & $26.56 \%(17)$ & $26.92 \%(42)$ \\
\hline Agree & $27.17 \%(25)$ & $31.25 \%(20)$ & $26.23 \%(41)$ \\
\hline Strongly Agree & $22.83 \%(21)$ & $20.31 \%(13)$ & $18.59 \%(29)$ \\
\hline
\end{tabular}

$\mathrm{SP}=$ School Psychologist; $\mathrm{SC}=$ School Counselor

$M=$ Mean $; D=$ Standard Deviation; $d=$ Cohen's $d$

Provision of SBMHS analysis. Out of 156 respondents, the majority of both school psychologist and school counselor participants indicated that they provided the following: item 16- individual counseling to students $(98.08 \%, n=153$; SP: $97.83 \%, n=90$; SC: $98.44 \%, n=$ 63); item 17- group counseling to students $(94.23 \%, n=147$; SP: $91.30 \%, n=84$; SC: $98.44 \%$, $n=63$ ); item 18- crisis intervention other than suicide risk assessment individually to students $(89.10 \%, n=139 ; \mathrm{SP}: 86.96 \%, n=80$; SC: $92.19 \%, n=59)$; item 19- crisis intervention other than suicide risk assessment in groups to students $(57.69 \%, n=90 ; \mathrm{SP}: 59.78 \%, n=55$; SC: $54.69 \%, n=35)$; item 20- suicide risk assessment to students $(94.87 \%, n=148$; SP: $94.57 \%, n$ $=87$; $\mathrm{SC}: 95.31 \%, n=61)$; item 21 - directly participated in programs related to primary prevention or mental health promotion (e.g., suicide prevention campaign, emotional regulation groups, mindfulness) with students $(75.64 \%, n=118 ; \mathrm{SP}: 72.82 \%, n=67 ; \mathrm{SC}: 79.69 \%, n=51)$; item 23- case-management (e.g., communication, making referrals, utilizing resources) (92.95\%, $n=145$; SP: $95.65 \%, n=88$; SC: $89.06 \%, n=57$ ); item 25 - consultation to individuals (e.g., school staff, community professionals) regarding students' mental health and SBMHS (93.59\%, 
$n=156$; SP: $100 \%, n=92$; SC: $84.38 \%, n=54$ ); item 27 - counseling; in-service trainings (e.g., on topics such as social/emotional components, behavior, mental health, interventions, etc.) $(67.95 \%, n=106 ;$ SP: $72.83 \%, n=67$; SC: $60.94 \%, n=39)$.

Although out of the total 156 participants most respondents indicated that they provided counseling to other school personnel $(52.56 \%, n=82)$ on item 26 , the majority of school psychologists, indicated that they did not provide this service $(55.43 \%, n=51)$ while most school counselors indicated that they did provide this service $(64.06 \%, n=41)$. A difference between school counselors and school psychologists was also seen for item 28 regarding providing family/parent counseling. The majority $(52.56 \%, n=82)$ of the total responses showed 'yes'; however, most school psychologists $(59.78 \%, n=55)$ indicated that they had not provided this service, while most school counselors $(70.31 \%, n=45)$ had provided this service.

There are also significant differences between the two groups of respondents on two other items. On item 22, responses showed that more school psychologists $(97.87 \%, n=90)$ developed and implemented behavior intervention plans (BIPs) for students than school counselors $(40.63 \%, n=26)$. In addition, a large difference in responses is also seen on item 24 regarding conducting social-emotional/behavioral assessments and interpreting results (SP: $98.91 \%, n=91 ;$ SC: $39.06 \%, n=25)$.

Feeling prepared to provide SBMHS analysis. Regarding feeling prepared to provide SBMHS (items 16a-28a) the following items indicate that majority of the total participants "Agree" that they feel prepared to provide the following SBMHS: item 16a- individual counseling [45.51\%, $n=71$; SP (Agree): 53.36\%, $n=49, M=4.10, S D=0.77$; SC (Strongly Agree): $56.25 \%, n=36, M=4.42, S D=0.81 ; d=0.40]$; item 17a- group counseling [42.31\%, $n$ $=66$; $\mathrm{SP}$ (Agree): $48.91 \%, n=45, M=3.95, S D=0.84$; $\mathrm{SC}$ (Strongly Agree): 48.44\%, $n=31$, 
$M=4.17, S D=1.04 ; d=0.23)$; item $18 \mathrm{a}$ - crisis intervention individually $(41.03 \%, n=64$; SP:

$M=3.87, S D=0.96 ; \mathrm{SC}: M=4.02, S D=0.91 ; d=0.16)$; item 19a- crises intervention in groups $(30.13 \%, n=47 ; \mathrm{SP}: M=3.38, S D=1.07 ; \mathrm{SC}: M=3.47, S D=1.17 ; d=0.08)$; item 20a- suicide risk assessment $(43.59 \%, n=68$; SP: $M=4.27, S D=0.77$; $\mathrm{SC}: M=4.11, S D=$ $0.97 ; d=0.18$ ); item 21 a- directly participated in primary prevention or mental health promotion [35.26\%, $n=55 ; \mathrm{SP}$ (Agree): 36.96\%, $n=34, M=3.73, \mathrm{SD}=1.03$; SC (Strongly Agree): $35.94 \%, n=23, M=3.91, S D=1.07 ; d=0.17]$; item 26a- counseling to school personnel [29.49\%, $n=46$; SP (Neutral): 29.35\%, $n=27, M=3.13, S D=1.09 ;$ SC (Agree): $31.25 \%, n=$ $20, M=3.42, S D=1.23 ; d=0.25)$; item $27 \mathrm{a}$ - in-service trainings $(41.03 \%, n=64 ; \mathrm{SP}: M=$ 3.91, $S D=0.94 ; \mathrm{SC}: M=3.45, S D=1.24 ; d=0.49)$.

The next two items fall in the "Strongly Agree" range based on responses: item 23acase-management $(43.59 \%, n=6$; SP: $M=4.37, S D=0.69 ; \mathrm{SC}: M=4.05, S D=0.98 ; d=$ 0.38); item 25a- consultation to individuals [39.74\%, $n=62$; SP (Strongly Agree): $50 \%, n=46$, $M=4.36, S D=0.72 ; \mathrm{SC}$ (Agree): $42.19 \%, n=27 ; M=3.75, S D=1.06 ; d=0.67]$. Item 28a regarding feeling prepared to provide family/parent counseling item shows that most overall responses fall in the "Neutral" range [26.92\%, $n=42 ; \mathrm{SP}$ (Neutral): 27.17\%, $n=25, M=3.17$, $S D=1.20 ; \mathrm{SC}$ (Agree): $31.25 \%, n=20, M=3.42, S D=1.18 ; d=0.21]$.

Similar to the items regarding having provided SBMHS, there are large differences in responses for two items that addressed feeling prepared to provide SBMHS. On item 22a regarding feeling prepared to provide behavior interventions, there is a large difference $(d=$ 0.99) between school psychologists and school counselors. Most school psychologists (46.74\%, $n=43, M=4.14, S D=0.80$ ) reported that they "Agree" that they are prepared to provide behavior interventions, while most school counselors $(25 \%, n=16, M=3.03, S D=1.36)$ 
reported that they "Disagree." There is also a large difference $(d=1.72)$ for item 24a regarding feeling prepared to conduct social-emotional/behavioral assessments and interpreting results items where most school psychologists $(64.13 \%, n=59, M=4.55, S D=0.68)$ report that they "Strongly Agree" while most school counselors $(34.38 \%, n=22, M=2.77, S D=1.30)$ report that they "Disagree."

\section{Importance and Competence Subscale}

The importance and competence subscale (see Table 7) consists of four items (items 2932; possible score range of 4-20). The items in this subscale focus on examining respondents' perceptions regarding the importance of providing SBMHS and feeling competent to provide these services.

\section{Table 7}

Importance and Competence Subscale

Please complete the following scales:

SP: 29. Please indicate how important it is for school psychologists to provide school-based mental health services:

SC: 29. Please indicate how important it is for school counselors to provide school-based mental health services:

\begin{tabular}{|l|c|c|c|}
\hline$M(S D)$ & $\mathrm{SP}=3.60(0.63)$ & $\mathrm{SC}=4.41(0.80)$ & $d=1.12$ \\
& $\mathrm{SP}$ & $\mathrm{SC}$ & $\frac{N=156}{N=64}$ \\
& $\frac{N=92}{\%(n)}$ & $\%(n)$ & $0.64 \%(1)$ \\
\hline Not Important & $1.09 \%(1)$ & 0 & $1.28 \%(2)$ \\
\hline Slightly Important & 0 & $3.13 \%(2)$ & $7.05 \%(11)$ \\
\hline Moderately Important & $4.35 \%(4)$ & $10.94 \%(7)$ & $28.21 \%(44)$ \\
\hline Important & $28.26 \%(26)$ & $28.13 \%(18)$ & $62.82 \%(98)$ \\
\hline Very Important & $66.30 \%(61)$ & $57.81 \%(37)$ & Total \\
\hline
\end{tabular}

SP: 30. Please indicate how important it is for school psychologists to be competent to provide schoolbased mental health services:

SC: 30. Please indicate how important it is for school counselors to be competent to provide schoolbased mental health services:

\begin{tabular}{|l|c|c|c|}
\hline$M(S D)$ & $\mathrm{SP}=3.85(0.36)$ & $\mathrm{SC}=4.61(0.72)$ & $d=1.34$ \\
\hline & $\mathrm{SP}$ & $\mathrm{SC}$ & Total \\
\hline
\end{tabular}




\begin{tabular}{|l|c|c|c|}
\hline & $\frac{N=92}{\%(n)}$ & $\frac{N=64}{\%(n)}$ & $\frac{N=156}{\%(n)}$ \\
\hline Not Important & 0 & 0 & 0 \\
\hline Slightly Important & 0 & $1.56 \%(1)$ & $0.64 \%(1)$ \\
\hline Moderately Important & 0 & $9.38 \%(6)$ & $3.85 \%(6)$ \\
\hline Important & $15.22 \%(14)$ & $15.63 \%(10)$ & $15.38 \%(24)$ \\
\hline Very Important & $84.78 \%(78)$ & $73.44 \%(47)$ & $80.13 \%(125)$ \\
\hline
\end{tabular}

SP: 31. Please indicate how important it is for you personally, as a school psychologist, to be competent to provide school-based mental health services:

SC: 31. Please indicate how important it is for you personally, as a school counselor, to be competent to provide school-based mental health services:

\begin{tabular}{|l|c|c|c|}
\hline$M(S D)$ & $\mathrm{SP}=3.82(0.42)$ & $\mathrm{SC}=4.55(0.92)$ & $d=1.02$ \\
\hline & $\mathrm{SP}$ & $\mathrm{SC}$ & Total \\
& $\underline{N=92}$ & $\underline{N=64}$ & $\frac{N=156}{\%(n)}$ \\
\hline Not Important & $\%(n)$ & $3.13 \%(2)$ & $1.28 \%(2)$ \\
\hline Slightly Important & 0 & $1.56 \%(1)$ & $0.64 \%(1)$ \\
\hline Moderately Important & $1.09 \%(1)$ & $6.25 \%(4)$ & $3.21 \%(5)$ \\
\hline Important & $16.30 \%(15)$ & $15.63 \%(10)$ & $16.03 \%(25)$ \\
\hline Very Important & $82.61 \%(76)$ & $74.44 \%(47)$ & $78.85 \%(123)$ \\
\hline
\end{tabular}

SP: 32. Please indicate how competent you feel to provide school-based mental health services as a school psychologist:

SC: 32. Please indicate how competent you feel to provide school-based mental health services as a school counselor:

\begin{tabular}{|l|c|c|c|}
\hline$M(S D)$ & $\mathrm{SP}=4.13(0.80)$ & $\mathrm{SC}=4.41(0.80)$ & $d=0.35$ \\
\hline & $\begin{array}{c}\mathrm{SP} \\
\frac{N=92}{(n)}\end{array}$ & $\begin{array}{c}\mathrm{NC} \\
\%(n)\end{array}$ & $\begin{array}{c}\text { Total } \\
\%(n)\end{array}$ \\
\hline $\begin{array}{l}\text { I feel very incompetent } \\
\text { incompetent }\end{array}$ & 0 & 0 & 0 \\
\hline $\begin{array}{l}\text { I feel neither competent } \\
\text { nor incompetent }\end{array}$ & $5.43 \%(5)$ & $3.13 \%(2)$ & $4.49 \%(7)$ \\
\hline $\begin{array}{l}\text { I feel somewhat } \\
\text { competent }\end{array}$ & $51.09 \%(47)$ & $28.13 \%(18)$ & $41.67 \%(65)$ \\
\hline I feel very competent & $33.70 \%(31)$ & $57.81 \%(37)$ & $43.59 \%(68)$ \\
\hline
\end{tabular}

$\mathrm{SP}=$ School Psychologist; $\mathrm{SC}=$ School Counselor

$M=$ Mean; $S D=$ Standard Deviation; $d=$ Cohen's $d$ 
Overall, most responses on items 29-31 that used the Likert-scale of $1=$ Not Important to $5=$ Very Important on this subscale fall in the "Very Important" range. However, there are significant differences between the two groups based on their responses. For instance, item 29 regarding how important is for their profession to provide SBMHS (SP: $M=3.60, S D=0.63$; SC: $M=4.41, S D=0.80$ ) shows a large difference at $d=1.12$.

Item 30 regarding how important is it for their profession to be competent to provide SBMHS (SP: $M=3.85, S D=0.36$; SC: $M=4.61, S D=0.72$ ) also shows a large difference at $d=$ 1.34. Item 31 regarding how important is it for the participant to be competent to provide SBMHS (SP: $M=3.82, S D=0.42 ; \mathrm{SC}: M=4.55, S D=0.92$ ) also shows a large difference at $d=$ 1.02. However, item 32, which asks the participant to indicate how competent he or she feels to provide SBMHS as a school psychologist or school counselor, the majority of school psychologists $(51.09 \%, n=47, M=4.13, S D=0.80$,) reported that they feel somewhat competent while majority of school counselors $(57.81 \%, n=37, M=4.41, S D=0.80)$ reported that they feel very competent $(d=0.35)$.

Table 8

\section{Correlational Analyses}

Correlation Among Subscales

\begin{tabular}{|l|c|c|c|}
\hline SP: Variable & Formal Education & Experience & Importance/Competence \\
\hline Formal Education & -- & & \\
\hline Experience & $.329^{* *}$ & -- & \\
\hline Importance/Competence & $.425^{* *}$ & $.349^{* *}$ & -- \\
\hline SC: Variable & Formal Education & Experience & Importance/Competence \\
\hline Formal Education & -- & & \\
\hline Experience & $.399^{* *}$ & -- & - \\
\hline Importance/Competence & $.481^{* *}$ & $.474^{* *}$ & \\
\hline
\end{tabular}

$\mathrm{SP}=$ School Psychologist; $\mathrm{SC}=$ School Counselor

$* * p \leq .01, * p \leq .05$ 
Table 8 presents the results from the Spearman's rho correlation coefficients calculated with SPSS. Correlations were run regarding formal education (items 1-4), experience (item 5), and importance/competence (items 29-32). As mentioned earlier in this chapter, a positive correlation suggests that as a variable increases, the other variable also increases, and a negative correlation implies that as a variable increases, the other variable decreases (Pallant, 2016). For school psychologists, the formal education subscale correlates with the experience subscale at $r=$ .329. The experience subscale correlates with the importance/competence subscale at $r=.349$. The importance/competence subscale correlates with the formal education scale correlates with the formal education subscale at $r=.425$. All of these are moderate correlations that are statistically significant at $p<.01$. As for school counselors, the formal education subscale correlates with the experience subscale at $r=.399$. The experience subscale correlates with the importance/competence subscale at $r=.474$. The importance/competence subscale correlates with the formal education scale at $r=.481$. These are also moderate correlations that are statistically significant at $p<.01$.

Table 9 Correlations Among Independent Variable and Subscale Scores

\begin{tabular}{|l|c|c|c|}
\hline SP: Variable & Formal Education & Experience & Importance/Competence \\
\hline Years of Experience & -.014 & -.006 & .035 \\
\hline SC: Variable & Formal Education & Experience & Importance/Competence \\
\hline Years of Experience & -.052 & .190 & .082 \\
\hline
\end{tabular}

$\mathrm{SP}=$ School Psychologist; $\mathrm{SC}=$ School Counselor

$* * p \leq .01, * p \leq .05$

Spearman's rho correlation coefficients were run to examine the relationships among the three subscales (formal education, experience, and importance/competence) to years of experience (see Table 9). For school psychologists, years of experience correlates with the formal education subscale at $r=-.014$, with the experience subscale at $r=-.006$, and with the 
importance/competence subscale at $r=.035$. These subscales indicate weak, non-significant correlations to years of experience. As for school counselors, years of experience correlates with the formal education scale at $r=-.052$, with the experience scale at $r=.190$, and with the importance/competence scale at $r=.082$. These scales also indicate weak, non-significant correlations to years of experience.

\section{Additional Comments and Feedback from Survey}

Item 33 on the survey allowed for participants to provide additional comments and feedback regarding the provision of SBMHS. For the school psychologist survey, 36 school psychologist participants responded. Some responses indicate that participants feel well prepared to provide SBMHS due to their school psychology program, while others responded that they feel well prepared due to the additional training and the mental health license they obtained in addition to their school psychologist credential. A couple of school psychologists noted that they could see the difference in training between newer school psychologists compared to more veteran school psychologists. Some participants acknowledged that their districts contract out to mental health providers for the delivery of SBMHS or refer students to outside counseling agencies. A few participants mentioned that their districts should use other providers to deliver SBMHS due to their focus on other school psychologist's duties such as assessments and evaluations and not being able to carry a counseling caseload. There are also acknowledgments that each school psychology program is different regarding the courses that they offer that are geared towards mental health or mental health services. Others acknowledged that their school psychology graduate program did not give much focus to counseling.

On the school counselor survey, 59 participants responded to item 33. A couple of responses suggest that school counselors should be licensed professionals, while others acknowledged that school counselors are not therapists nor adequately trained to deliver SBMHS 
because this is not their area of focus. On the other hand, a participant mentioned that school counselors are "mental health experts," while others mentioned that school counselors should be providing SBMHS, not therapists. Some participants mentioned that they need more support (e.g., administrative support, resources, more staff) in their roles and a smaller caseload in order to provide SBMHS.

\section{Chapter Summary}

Overall, participants agreed that their formal educational preparation prepared them to provide SBMHS, except for their undergraduate coursework. The majority of participants strongly agreed that training and professional experience prepared them to provide SBMHS. There are no significant differences between school psychologists and school counselors regarding their perceptions of their formal education and professional experiences that prepared them to provide SBMHS. The majority of school psychologists acknowledge that NASP approved their school psychology programs, and the majority of school counselors admit that their school counseling programs followed the ASCA National Model. The majority of participants did not receive additional graduate-level course work or state registrations/licenses.

Most items regarding the provision of SBMHS and feeling prepared to provide SBMHS showed consistency between school psychologists and school counselors' responses. However, there are noted significant differences between the two groups regarding developing and implementing BIPs, providing behavior interventions, and conducting socialemotional/behavioral assessments and interpreting the results. School psychologists provided these services and felt more prepared to provide these services when compared to school counselors. The two groups are somewhat consistent regarding the majority of the responses for each group regarding the importance of school psychologists and school counselors providing 
and feeling competent to provide SBMHS, even though there were large differences between the two groups based on Cohen's $d$.

The top response regarding courses taken during their graduate program by school psychologists is counseling courses, and school counselors is group counseling courses. School psychologist participants would have liked to have taken additional counseling (not specified) courses while school counselors would have liked to have taken additional group counseling courses. Both groups reported that they would need to attend trainings/professional developments/workshops to feel more competent in their position to provide SBMHS.

The correlations within the three subscales, including formal education, experience, and importance/competence, resulted in moderate correlations. However, there are weak correlations among the three scales and the independent variable of years of experience. 


\section{Chapter Five: Discussion}

The purpose of this study was to explore California school psychologists and school counselors' perceptions of their preparation to provide SBMHS. Specifically, this research sought to determine the extent to which school psychologists and school counselors in California believe that their formal pre-service education and later in-service professional experiences have prepared them to provide SBMHS. This study also examined the extent that school psychologists and school counselors in California feel prepared to deliver different types of mental health services, and how important they thought it is to be competent to provide those services.

Data for the study were collected via two 44-item anonymous online surveys from a total of 156 participants. The two research questions were analyzed with descriptive statistics, and the two sub-research questions were analyzed using Cohen's $d$. Spearman's rho correlation coefficient analyses were used to determine correlations between subscales (i.e., educational preparation, professional experience, importance/competence) in addition to correlations between these subscales and years of experience. This chapter addresses each of the study's research questions and includes a summary of the findings. This chapter also includes limitations and strengths of the study, implications for practice and training, and implications for future research.

\section{Discussion of Findings}

Research Question 1: To what extent do school psychologists and school counselors in California believe that their formal education (i.e., undergraduate, graduate, training/workshops) has prepared them to provide school-based mental health services?

The overall consensus based on the results of the sample is that the California school psychologists and school counselors agree that their formal graduate education has prepared them to provide SBMHS. This determination is evident by the majority of responses indicating 
"Agree" for items 2-4 and "Strongly Agree" for item 5. Item 2- program coursework (42.31\%, $n$ $=66 ; \mathrm{SP}: 43.48 \%, n=40 ; \mathrm{SC}: 40.63 \%, n=26)$, item 3 - practicum experience $(42.31 \%, n=66$; SP: $40.22 \%, n=37$; SC: $45.31 \%, n=29)$, item 4 - internship experience $(46.15 \%, n=72$; SP: 51.09\%, $n=47$; SC: 39.06\%, $n=25)$, and item 5- workshops/trainings $(43.39 \%, n=68$; SP: $44.57 \%, n=41$; SC: $42.19 \%, n=27)$. However, the following percentages and numbers of participants indicated that they either "Strongly Disagree, " "Disagree," or feel "Neutral" for these items: item 2- program coursework $(33.98 \%, n=53$; SP: 36.95\%, $n=34$; SC: $29.70 \%, n=$ 19), item 3- practicum experience ( $43.59 \%, n=68$; SP: $50 \%, n=46$; SC: $34.38 \%, n=22)$, item 4- internship experience $(27.57 \%, n=43 ; \mathrm{SP}: 27.17 \%, n=25 ; \mathrm{SC}: 28.13 \%, n=18)$, and item 5 workshops/trainings (17.31\%, $n=27$; SP: $21.73 \%, n=20$; SC: $10.94 \%, n=7)$.

The majority of the participants responded "Disagree" for item 1 regarding undergraduate coursework $(38.46 \%, n=60)$, indicating that undergraduate coursework does not appear to add substantially to their perceptions of their preparation for providing SBMHS. However, participants either responded with "Agree" or "Strongly Agree" (19.87\%, $n=31$; SP: 16.3\%, $n=$ $15 ;$ SC: $25 \%, n=16)$ for item 1.

\section{Research question 1a. Do school psychologists and school counselors in California} differ from one another in their perceptions of how well their formal education (i.e., undergraduate, graduate, training/workshops) has prepared them to provide school-based mental health services?

Based on the responses, California school psychologists and school counselors do not differ significantly from each other regarding their perceptions of how well their formal education has prepared them to provide SBMHS. This determination is based on the finding that there were only small effect sizes obtained from Cohen's $d$ for items 1-5. Item 1- undergraduate 
coursework $(d=0.13)$, item 2- program coursework $(d=0.20)$, item 3- practicum experience $(d$ $=0.31)$, item 4 - internship experience $(d=0.08)$, and item 5- attending workshops/trainings $(d=$ $0.15)$.

Research question 2. To what extent do school psychologists and school counselors in California believe that their professional experiences have prepared them to provide school-based mental health services?

The majority of the California school psychologists and school counselors strongly agree that their professional experience has prepared them to provide SBMHS. This determination is based on responses to survey question number 6 regarding professional experiences, where the majority of participants indicated "Strongly Agree" $(57.05 \%, n=89)$ for this item. Specifically, 51.09\% ( $n=47)$ school psychologists and 65.63\% $(n=42)$ school counselors "Strongly Agree" that their professional experiences prepared them to provide SBMHS. However, there are $8.4 \%$ [ $n=14$ (SP: $11.96 \%, n=11 ;$ SC: $4.69 \%, n=3)]$ of total participants who either "Strongly Disagree, " "Disagree," or feel "Neutral" in this area.

Research question 2a. Do school psychologists and school counselors in California differ from one another in their perceptions of how well their professional experiences have prepared them to provide school-based mental health services?

Based on the responses, California school psychologists and school counselors do not differ significantly regarding their perceptions of how well their professional experience has prepared them to provide SBMHS. This determination is evident by the small effect size computed through Cohen's $d$ for item 6 regarding professional experiences $(d=0.34)$.

\section{Summary of Findings}

Overall, the findings suggest that the California school psychologists and school counselors who participated in this study agree that their formal pre-service education, except for 
their undergraduate program, prepared them to provide SBMHS. Also, participants strongly agree that both workshops/trainings and in-service professional experiences as school psychologists and school counselors prepared them to provide SBMHS. There were no significant differences between the school psychologists and school counselors' responses to these items. However, there were significant differences between the school psychologists and school counselors' responses to questions regarding the provision of certain SBMHS. These differences were seen for SBMHS that include developing and implementing BIPs, providing behavior interventions, and conducting social-emotional/behavioral assessments and interpreting results. In each of these cases, school psychologists expressed feeling more prepared than school counselors to provide these services.

Based on the open-ended responses, most participants expressed a need to receive more training in the form of workshops or other professional development to support them in their positions for the provision of SBMHS. According to the Spearman's rho correlation coefficient analyses, there are significant moderate correlations between the three subscales of the survey. These include 1) formal education, 2) experience, and 3) importance/competence for the school psychologists and school counselors. However, the correlations between the years of experience variable and the variables of 1) formal education, 2) professional experience, and 3) importance/competence subscales indicate weak nonsignificant correlations for both groups.

\section{Study Limitations}

There were six limitations to this study that should be discussed. The first three limitations are related to the administration of the surveys, while the second three are related to the questionnaire itself. For instance, the first limitation involves the CASP and CASC online organizations' different processes for submitting a survey to their websites. As presented in 
chapter 2, CASP required a one-time payment of $\$ 150$ to post a survey to their website and to send it out in a weekly email blast. Fortunately, the survey was sent out in two of their weekly blasts and posted on the website's homepage for easy access. Although CASC did not require a fee for posting a survey, some difficulties were experienced during the CASC survey submission process. A required online form, which included the link to the school counselor questionnaire, was completed and emailed to the CASC review board for approval for the link to be submitted in their weekly online CASC Connection. This submission to CASC took place once a week during four different weeks. Unfortunately, the link that CASC posted to the survey did not function during the first and third weeks when it was sent out in the CASC Connection email and when the link was posted online. This mishap could have impacted the number of responses that could have been obtained during those two weeks.

The second limitation is that there were not as many school counselors as there were school psychologists who participated in this study. There was a total of 92 school psychologists and a total of 64 school counselors. The lower number of school counselors could have been a result of the school counselor survey link posted in the CASC Connection not functioning during weeks 1 and 3 or school counselors choosing not to participate in the survey.

A third limitation includes having to send out the survey links through email to a broader selection of California school psychologists and school counselors due to the low number of responses obtained during the first three weeks that the surveys were posted and sent out by CASP and CASC. Because of having to email the survey links to accessible California school psychologists and school counselors, some of the surveys may not have been completed by members of the CASP or CASC organization. For this reason, there is a potential bias in how 
participants accessed the surveys (e.g., completing the survey through the links posted to the CASP or CASC website versus completing the surveys through the links received via email).

The following three additional limitations are related to the questionnaires. The first of these limitations has to do with not including an item that asked participants if they were members of the CASP or CASC organization. The assumption going into this study was that those who would be completing the surveys would be members of CASP or CASC online organizations. However, there is no way to determine if participants were registered members or not because the survey did not ask. This information could have been useful to see how many participants were members of CASP or CASC and how many participants were not members.

The fifth limitation includes this researcher not knowing that there was a set survey timeline on how long an individual had to complete the survey. For instance, during the first couple of weeks that the surveys were posted online, the surveys were unknowingly preset in Qualtrics to allow participants one week to complete the surveys before the surveys timed out, which meant that some potential participants who wished to complete the questionnaires were locked out. This overlook may have impacted the number of surveys that could have been completed. After realizing this mistake, the amount of time to complete the survey was lengthened from one week to a month to allow individuals more time to participate once they accessed the survey.

The final limitation includes not including the response option of "Don't Know" for item 43 regarding the number of student enrollment at their primary school site. Because of this oversight and this item not being inputted as a required item for participants to answer, five school psychologists did not respond to this item. Despite these observed limitations, there were several strengths to the study. 


\section{Study Strengths}

The first strength of this study includes the focus of the research. Although there is data regarding perceptions of SBMHS from other states, a review of the literature suggests that this is the first study of its kind examining California school psychologists and school counselors. This study also provided more detail than prior research by examining a variety of experiences, ranging from perceptions of the formal pre-service education and later professional in-service experiences and professional development they received for the provision of SBMHS. Therefore, this study fills an essential gap in the literature. The topic is especially important because of AB114 and the transition of SBMHS to school districts.

The second strength of this study is regarding the number of participants obtained. As previously mentioned in chapter 3, a sample size of 100 for the main subgroup and 20-50 for any minor subgroups was recommended by Gall et al. (as cited in Mertens, 2015) when using surveys. A total of 156 participants participated in the study, and there were 92 participants in the school psychologists' subgroup and 64 in the school counselors' subgroup. Thus, these numbers of participants appear to be adequate for survey research.

The third strength involves the construction of the survey. The online format of the survey allowed individuals to self-select into the study and complete the questionnaire at their convenience. Using an online survey method approach allowed participants to choose whether they wanted to participate in the survey without any undue pressure. The participants' responses were anonymous, which hopefully allowed participants to answer honestly on the questionnaires.

The fourth strength involves the demographics of participants. As presented in Table 1 in chapter 3, participants seemed rather diverse regarding their ages (ages ranging from 24-71), years of experience, and in their primary placement setting that they serve (e.g., preschool, elementary, middle school, high school, alternative program/placement). This diversity assured 
that the data gathered reflected the spectrum of individuals serving as school psychologists and school counselors in California.

The final strength includes the geographic locations of the participants. The Qualtrics system shows the region that the participant completed the survey on a small map located at the end of the participant's survey results. When reviewing completed questionnaires, it was observed that school psychologists and school counselors completed the survey throughout different California regions. This observation shows that there were participants that completed the surveys throughout California and not just in one area, giving more credibility to the survey results.

\section{Implications for Practice and Training}

According to this study, there appears to be a need for service providers to be trained and continue to receive training as it relates to the provision of SBMHS based on the literature review and the survey data obtained from this study. As mentioned in chapters 1 and 2, about 14$20 \%$ of children have a mental health disorder (National Academy of Sciences, 2009), such as internalizing disorders (e.g., anxiety disorders, mood disorders) and externalizing disorders (e.g., behavioral disorders, substance use disorders). Of children that have mental health disorders, Burns and colleagues (1995) found that only $16 \%$ received mental health services. Of those children, 70-80\% received mental health support from professionals within the educational setting. Some researchers (e.g., Foster et al., 2005; Green et al., 2013) showed that between 80$90 \%$ of U.S. schools in their studies offered some form of SBMHS. These statistics show the prevalence of mental health among children and adolescents and highlight the role schools play in providing mental health support. Furthermore, as we continue to see a rise in schools becoming the primary location for mental health services for children and adolescents, school 
psychologists and school counselors should continue to receive ongoing training to support them in their roles as SBMHS providers.

The majority of participants in this study indicated that they "Strongly Agree" that attending workshops/trainings helped prepare them to deliver SBMHS. Some participants mentioned in their open-ended responses that the training they received during their school psychology or school counseling programs helped them provide these services. Though the majority of the school psychologists and school counselors indicated that they feel somewhat or very competent to provide SBMHS, there still appears to be a need for participants to have more training to continue to develop their skills in delivering SBMHS. Therefore, school psychology and school counseling programs and school districts can use the information obtained from this study to build upon their programs and practices that they have in supporting future and current professionals in delivering SBMHS.

School psychologists feel better prepared to provide social-emotional/behavioral assessments, interpret the results of those assessments, and feel better equipped to implement behavior interventions compared to school counselors. This higher level of confidence in these areas may be because school psychologists' training is known to focus more on these areas than school counselors' training. It is recommended that school counselors receive further training in understanding social-emotional and behavioral assessment results and implementing behavior interventions for students. This training would allow them to become more familiar with a broader spectrum of the social-emotional and behavioral struggles students may have and how to intervene with these students when needed.

\section{Implications for Future Research}

Presented in this study is information from items regarding the provision of SBMHS, which focused on finding out if participants provided certain SBMHS and how much they agree 
that they feel prepared to provide those services. This area could be expanded on in future research. For example, Hanchon and Fernald (2013) believed that future research should explore where counseling services fall within the provider's broader role as mental health service providers. Therefore, it would be interesting to determine which SBMHS are provided in schools and which of those involve school psychologists and school counselors. The data obtained from item 44 regarding the percentage of time providing mental health services can also be expanded on in future research to determine what portion of providers' time is allotted to other duties not related to the delivery of SBMHS.

Foster et al. (2005) believed that there is a need for research to examine not only specific staff and service assignments, qualifications of mental health service providers, and professional development and experiences of staff but also how effective combinations of prevention and intervention services are for schools. Although this study touched on these areas, it is recommended that future research should further explore the efficacy and effectiveness of SBMHS. Specifically, exploring areas similar to those mentioned by Foster and colleagues. These include the following: 1) duration and intensity of services, 2) which services were delivered for which mental health concerns, 3) the sufficiency of services to the students' needs, and 4) the extent to which the demand for different services was sustained. Further research in these areas could guide school staff to a better understanding of what combinations of prevention and intervention services are the most effective in their school setting. Also, future research may want to consider proposing questions to providers that assess the effectiveness of services such as asking, "How effective do you think the SBMHS are that you provide?" and "How do you measure effectiveness of SBMHS?" 
Villarreal (2018) argues that even though schools and providers of SBMHS possess the capability to improve mental health outcomes for children, the provision of effective SBMHS, however, is insufficient. This insufficiency may be due to providers, such as school psychologists, spending the majority of their time on tasks (e.g., assessments) that are not related to the delivery of direct SBMHS (Villarreal, 2018). As a result, determining the efficacy and effectiveness of SBMHS may be difficult if not enough of the providers' time is devoted to the provision of SBMHS. Therefore, more research on the efficacy and effectiveness of SBMHS delivered by school psychologists and school counselors could help determine how beneficial these services are for children and adolescents.

Another area that future research should explore is specifically how school psychology and school counseling graduate students are trained during their graduate programs for the provision of SBMHS, and if they believe that the training was adequate. The research can include taking an in-depth look into graduate students' perceptions of the programs they attend that follow either the National Association of School Psychologists (NASP) or American School Counselor Association (ASCA) models and exploring students' perceptions of graduate programs that may not follow these models. According to Splett et al. (2013), graduate training programs must make sure that the students in their programs are informed of the barriers and enablers/facilitators that they face when providing mental health services within schools, so they are ready to practice in the real-world. Exploring this area can help school psychology and school counseling graduate programs ensure that they are adequately preparing future school psychologists and school counselors to be competent providers of SBMHS.

\section{Conclusion}

Schools play a significant role in addressing the mental health needs of students (Nichols, Goforth, Sacra, \& Ahlers, 2017) and are the primary location of mental health services to support 
children's and adolescents' mental health needs. Thus, schools should be proud of the role they take on in the provision of mental health services and should not shy away from their role (Maag \& Katsiyannis, 2010). As the need for mental health services continues to grow, we will hopefully see an increase of mental health services within schools, which in turn will provide children and adolescents more opportunities to receive needed mental health support.

Furthermore, as school-based practitioners such as school psychologists and school counselors become more involved in providing SBMHS, both graduate programs and school districts should provide continuous education and training so that school psychologists and school counselors will be more prepared and competent in delivering SBMHS. 


\section{References}

Adelman, H. S., \& Taylor, L. (2000). Promoting mental health in schools in the midst of school reform. Journal of School Health, 70(5), 171-178. doi:10.1111/j.17461561.2000.tb06467.x

Adelman, H. S., \& Taylor, L. (2006). Mental health in schools and public health. Public Health Reports, 121(3), 294-298. doi:10.1177/003335490612100312

Adelman, H. S., \& Taylor L. (2012). Mental health in schools: Moving in new directions. Contemporary School Psychology, 16, 9-18. Retrieved from https://www.casponline.org/pdfs/pdfs/journal_2012_vol16_web2.pdf\#page=9

Akoglu, H. (2018). User's guide to correlation coefficients. Turkish Journal of Emergency Medicine, 18(3), 91-93. doi:10.1016/j.tjem.2018.08.001

Allison, P. D. (1999). Multiple regression: A primer. Thousand Oaks, CA: Pine Forge Press. American Psychiatric Association. (2013). Diagnostic and statistical manual of mental disorders (5th ed.). Arlington, VA: American Psychiatric Association.

American School Counselor Association. (2015). The school counselor and student mental health. ASCA Position Statements. Retrieved from https://www.schoolcounselor.org/asca/media/asca/PositionStatements/PS_StudentMental Health.pdf

Anello, V., Weist, M., Eber, L., Barrett, S., Cashman, J., Rosser, M., \& Bazyk, S. (2016). Readiness for positive behavioral interventions and supports and school mental health interconnection: Preliminary development of a stakeholder survey. Journal of Emotional and Behavioral Disorders, 25(2), 82-95. doi:10.1177/1063426616630536 
Astramovich, R. L., \& Loe, S. A. (2006). Comparing the roles of school counselors and school psychologists: A study of preservice teachers. Journal of School Counseling, 4(12), 1-20. Retrieved from https://files.eric.ed.gov/fulltext/EJ901148.pdf

Atkins, M. S., Hoagwood, K. E., Kutash, K., \& Seidman, E. (2010). Toward the integration of education and mental health in schools. Administration and Policy in Mental Health and Mental Health Services Research, 37(1-2), 40-47. doi:10.1007/s10488-010-0299-7

Baskin, T., Slaten, C., Crosby, N., Pufahl, T., Schneller, C., \& Ladell, M. (2010). Efficacy of counseling and psychotherapy in schools: A meta-analytic review of treatment outcome studies. The Counseling Psychologist, 38(7), 878-903. doi:10.1177/0011000010369497

Baskin, T., \& Slaten, C. (2014). Contextual school counseling approach. The Counseling Psychologist, 42(1), 73-96. doi:10.1177/0011000012473664

Bassett, E. H., \& O'Riordan, K. (2002). Ethics of Internet research: Contesting the human subjects research model. Ethics and Information Technology, 4(3), 233-247. doi:10.1023/A:1021319125207

Beam, E., Brady, J., \& Sopp, T. J. (2011). School psychologists are the best equipped to deliver mental health services in the schools. California Association of School Psychologists. Sacramento: CA. Retrieved from https://www.casponline.org/pdfs/legislative/casp_mental_health_papers.pdf

Brener, N., \& Demissie, Z. (2018). Counseling, psychological, and social services staffing: Policies in US school districts. American Journal of Preventive Medicine, 54(6), S215S219. doi:10.1016/j.amepre.2018.01.031 
Burns, B. J., Costello, E. J., Angold, A., Tweed, D., Stangl, D., Farmer, E. M., \& Erkanli, A. (1995). Children's mental health service use across service sectors. Health Affairs, 14(3), 147-159. doi:10.1377/hlthaff.14.3.147

California Association of School Counselors. (2019). CASC connections. Retrieved from http://www.schoolcounselor-ca.org

California Association of School Psychologists. (2019). CASPOnline. Retrieved from https://casponline.org

California Association of School Psychologist Ad Hoc Committee on ERMHS. (2014). Educationally related counseling services in an AB114 world. CASP Today. Retrieved from https://www.casponline.org/pdfs/position-papers/ERMHS-final.pdf

California Department of Education. (2019a). School counseling programs - CalEdFacts. Retrieved from https://www.cde.ca.gov/ls/cg/mc/cefschoolcounsel.asp

California Department of Education. (2019b). School psychologist: Qualifications and definition. Retrieved from https://www.cde.ca.gov/ls/cg/pr/psychec.asp

Campbell, A., \& Anderson, C. M. (2011). Check-in/check-out: A systematic evaluation and component analysis. Journal of applied behavior analysis, 44(2), 315-326. doi:10.1901/jaba.2011.44-315

Carlson, L. A., \& Kees, N. L. (2013). Mental health services in public schools: A preliminary study of school counselor perceptions. Professional School Counseling, 16(4), doi:10.5330/PSC.n.2013-16.221

Child Mind Institute. (2017). 2017 Children's Mental Health Report. Retrieved from childmind.org/2017report 
Cohen, J. (1988). Statistical power analysis for the behavioral sciences (2ed.). Hillsdale, NJ: L. Erlbaum Associates. Retrieved from http://www.utstat.toronto.edu/ brunner/oldclass/378f16/readings/CohenPower.pdf

Committee on School Health. (2004). School-based mental health services. Pediatrics, 113(6), 1839-1845. doi:10.1542/peds.113.6.1839

Crespi, T. D., \& Hughes, T. L. (2004). School-based mental health services for adolescents. Journal of Applied School Psychology, 20(1), 67-78. doi:10.1300/J370v20n01_05

Crisp, H. L., Gudmundsen, G. R., \& Shirk, S. R. (2006). Transporting evidence-based therapy for adolescent depression to the school setting. Education and Treatment of Children, 29(2). Retrieved from https://www.jstor.org/stable/42899886

DeFosset, A. R., Gase, L. N., Ijadi-Maghsoodi, R., \& Kuo, T. (2017). Youth descriptions of mental health needs and experiences with school-based services: Identifying ways to meet the needs of underserved adolescents. Journal of Health Care for the Poor and Underserved, 28(3), 1191-1207. doi:10.1353/hpu.2017.0105

DeVellis, R. F. (2003). Scale development: Theory and applications (Vol. 26). Thousand Oaks, CA: Sage Publications.

Dikel, W. (2014). The teacher's guide to student mental health. New York, NY: W.W. Norton \& Company.

Dillman, D. A., Smyth, J. D., \& Christian, L. M. (2014). Internet, phone, mail, and mixed-mode surveys: The tailored design method (4th ed.). Hoboken, New Jersey: John Wiley \& Sons.

Dixon, D. N. (2009). Mental health service delivery systems and perceived qualifications of 
mental health service providers in school settings (Doctoral dissertation). Retrieved from http://scholarcommons.usf.edu/etd/1935

Eklund, K., Meyer, L., Way, S., \& Mclean, D. (2017). School psychologists as mental health providers: The impact of staffing ratios and Medicaid on service provisions. Psychology in the Schools, 54(3), 279-293. doi:10.1002/pits.21996

Etikan, I., Musa, S. A., \& Alkassim, R. S. (2016). Comparison of convenience sampling and purposive sampling. American Journal of Theoretical and Applied Statistics, 5(1), 1-4. doi:10.11648/j.ajtas.20160501.11

Eynon, R., Fry, J., \& Schroeder, R. (2017). The ethics of online research. In N. G. Fielding, R. M. Lee, \& G. Blank (Eds.), The SAGE handbook of online research methods (pp. 19-37). London: SAGE Publications Ltd. doi:10.4135/9781473957992.n2

Fazel, M., Hoagwood, K., Stephan, S., \& Ford, T. (2014). Mental health interventions in schools in high-income countries. The Lancet Psychiatry, 1(5), 377-387. doi:10.1016/S22150366(14)70312-8

Flaherty, L. T., Weist, M. D., \& Warner, B. S. (1996). School-based mental health services in the United States: History, current models and needs. Community Mental Health Journal, 32(4), 341-352. doi:10.1007/BF02249452

Forness, S. R., Freeman, S. F., Paparella, T., Kauffman, J. M., \& Walker, H. M. (2012). Special education implications of point and cumulative prevalence for children with emotional or behavioral disorders. Journal of Emotional and Behavioral Disorders, 20(1), 4-18. doi:10.1177/1063426611401624

Foster, S., Rollefson, M., Doksum, T., Noonan, D., Robinson, G., \& Teich, J. (2005). School mental health services in the United States, 2002-2003. Rockville, MD: Center for 
Mental Health Services, Substance Abuse and Mental Health Services Administration. Retrieved from https://files.eric.ed.gov/fulltext/ED499056.pdf

Fowler Jr., F. J. (2014). Survey research methods (5th ed.). Thousand Oaks, California: SAGE Publications.

Fricker Jr., R. D. (2008). Sampling Methods for Web and E-Mail Surveys. In N. Fielding, R. M. Lee, \& G. Blank (Eds.), The SAGE handbook of online research methods (pp. 195-217). London: SAGE Publications Ltd. doi:10.4135/9780857020055

Furlong, M. J., Morrison, G. M., \& Jimerson, S. R. (2004). Externalizing behaviors of aggression and violence and the school context. In R. B. Rutherford Jr., M. M. Quinn, \& S. R. Mathur (Eds.), Handbook of research in emotional and behavioral disorders (pp. 243261). New York, NY: Guilford. Retrieved from https://www.researchgate.net/publication/267776923

Gaiser, T. J., \& Schreiner, A. E. (2009). A guide to conducting online research. London: SAGE Publications Ltd. doi:10.4135/9780857029003

Gamble, B. E., \& Lambros, K. M. (2014). Provider perspectives on school-based mental health for urban minority youth: Access and services. Journal of Urban Learning, Teaching, and Research, 10, 25-38. Retrieved from https://search.ebscohost.com/login.aspx?direct=true\&AuthType=ip,uid,cookie,url\&db=er ic \&AN=EJ1044126\&site=ehost-live

Ghandour, R. M., Sherman, L. J., Vladutiu, C. J., Ali, M. M., Lynch, S. E., Bitsko, R. H., \& Blumberg, S. J. (2019). Prevalence and treatment of depression, anxiety, and conduct problems in U.S. children. The Journal of Pediatrics, 206(3), 256-267. doi:10.1016/j.jpeds.2018.09.021 
Goldstein, S., \& DeVries, M. (Eds.). (2017). Handbook of DSM-5 disorders in children and adolescents. Springer International Publishing. doi:10.1007/978-3-319-57196-6

Green, J. G., McLaughlin, K. A., Alegría, M., Costello, E. J., Gruber, M. J., Hoagwood, K., . . . Kessler, R. C. (2013). School mental health resources and adolescent mental health service use. Journal of the American Academy of Child \& Adolescent Psychiatry, 52(5), 501-510. doi:10.1016/j.jaac.2013.03.002

Guerra, L. A., Rajan, S., \& Roberts, K. J. (2019). The implementation of mental health policies and practices in schools: An examination of school and state factors. Journal of School Health, 89(4), 328-338. doi:10.1111/josh. 12738

Hanchon, T. A., \& Fernald, L. N. (2013). The provision of counseling services among school psychologists: An exploration of training, current practices, and perceptions. Psychology in the Schools, 50(7), 651-671. doi:10.1002/pits.21700

Hill, J., Ohmstede, T., \& Mims, M. (2012). A look into mental health in the schools. International Journal of Psychology: A Biopsychosocial Approach, 11,.119-131. doi:10.7220/1941-7233.11.6

Hill, R. (1998). What sample size is "enough" in internet survey research? Interpersonal Computing and Technology: An Electronic Journal for the 21st Century, 6(3-4), 1-10. Retrieved from http://www.reconstrue.co.nz/IPCTJ\%20Vol\%206\%20Robin\%20hill\%20SampleSize.pdf

Ho, R. (2014). Handbook of univariate and multivariate data analysis with IBM SPSS (2 ed.). Boca Raton, FL: Taylor \& Francis Group.

Hoagwood, K., Burns, B. J., Kiser, L., Ringeisen, H., \& Schoenwald, S. K. (2001). Evidence- 
based practice in child and adolescent mental health services. Psychiatric Services, 52(9), 1179-1189. doi:10.1176/appi.ps.52.9.1179

Hoagwood, K., \& Erwin, H. (1997). Effectiveness of school-based mental health services for children: A 10-year research review. Journal of Child and Family Studies, 6(4), 435-451. doi:10.1023/A:1025045412689

Jacob, S., Decker, D. M., \& Timmerman-Lugg, E. (2016). Ethics and law for school psychologists (7 ed.). Hoboken, NJ: John Wiley \& Sons.

Joe, S., Joe, E., \& Rowley, L. L. (2009). Consequences of physical health and mental illness risks for academic achievement in grades $\mathrm{K}-12$. Review of Research in Education, 33(1), 283-309. doi:10.3102/0091732X08327355

Johnson, C., Eva, A. L., Johnson, L., \& Walker, B. (2011). Don't turn away: Empowering teachers to support students' mental health. Clearing House, 84, 9-14. doi:10.1080/00098655.2010.484441

Kaye, B. K., \& Johnson, T. J. (1999). Research methodology: Taming the cyber frontiertechniques for improving online surveys. Social Science Computer Review, 17(3), 323337. doi:10.1177/089443939901700307

Kessler, R. C., Berglund, P., Demler, O., Jin, R., Merikangas, K. R., \& Walters, E. E. (2005). Lifetime prevalence and age-of-onset distributions of DSM-IV disorders in the National Comorbidity Survey Replication. Archives of General Psychiatry, 62(6), 593-602. doi:10.1001/archpsyc.62.6.593

Kieling, C., Baker-Henningham, H., Belfer, M., Conti, G., Ertem, I., Omigbodun, O., ... \& Rahman, A. (2011). Child and adolescent mental health worldwide: Evidence for action. The Lancet, 378(9801), 1515-1525. doi:10.1016/S0140-6736(11)60827-1 
Kutash, K., Duchnowski, A. J., \& Lynn, N. (2006). School-based mental health: An empirical guide for decision-makers. Tampa, Fl: University of South Florida, Louis de la Parte Florida Mental Health Institute, Department of Child \& Family Studies, Research and Training Center for Children's Mental Health. Retrieved from http://rtckids.fmhi.usf.edu

Lawson, J. E., \& Cmar, J. L. (2016). Implications of state policy changes on mental health service models for students with disabilities. The Journal of Special Education Apprenticeship, 5(1), 1-15. Retrieved from https://scholarworks.lib.csusb.edu/josea/vol5/iss $1 / 3$

Maag, J. W., \& Katsiyannis, A. (2010). School-based mental health services: Funding options and issues. Journal of Disability Policy Studies, 21(3), 173-180. doi:10.1177/1044207310385551

Madigan, S., Atkinson, L., Laurin, K., \& Benoit, D. (2013). Attachment and internalizing behavior in early childhood: A meta-analysis. Developmental Psychology, 49(4), 672689. doi:10.1037/a0028793

Marsh, R. J. (2016). Identifying students with mental health issues: A guide for classroom teachers. Intervention in School and Clinic, 51(5), 318-322. doi: $10.1177 / 1053451215606706$

Massey, O. T., Armstrong, K., Boroughs, M., \& Henson, K. (2005). Mental health services in schools: A qualitative analysis of challenges to implementation, operation, and sustainability, 42(4), 361-372. doi:10.1002/pits.20063

Merikangas, K. R., He, J.P., Burstein, M., Swanson, S. A., Avenevoli, S., Cui, L., . . Swendsen, J. (2010). Lifetime prevalence of mental disorders in US adolescents: Results from the National Comorbidity Survey Replication-Adolescent Supplement (NCS-A). Journal of 
the American Academy of Child \& Adolescent Psychiatry, 49(10), 980-989.

doi:10.1016/j.jaac.2010.05.017

Merikangas, K. R., He, J.P., Burstein, M., Swendsen, J., Avenevoli, S., Case, B., . . Olfson, M. (2011). Service utilization for lifetime mental disorders in US adolescents: Results of the National Comorbidity Survey-Adolescent Supplement (NCS-A). Journal of the American Academy of Child \& Adolescent Psychiatry, 50(1). doi:10.1016/j.jaac.2010.10.006

Mertens, D. M. (2015). Research and evaluation in education and psychology (4 ed.). Thousand Oaks, California: SAGE Publications.

Meyers, J. L., \& Dick, D. M. (2010). Genetic and environmental risk factors for adolescent-onset substance use disorders. Child and Adolescent Psychiatric Clinics of North America, 19(3), 465-77. doi:10.1016/j.chc.2010.03.013

Moore, K. A., Murphey, D., Beltz, M., Martin, M. C., Bartlett, J., \& Caal, S. (2016). Child wellbeing: Constructs to measure child well-being and risk and protective factors that affect the development of young children. Bethesda, MD: Child Trends. Retrieved from https://www.childtrends.org/wp-content/uploads/2017/03/201661ConstructsMeasureChildWellbeing.pdf

Muijs, D. (2011). Doing quantitative research in education with SPSS (2 ed.). Thousand Oaks, CA: SAGE Publications.

Nastasi, B. K. (2004). Meeting the challenges of the future: Integrating public health and public education for mental health promotion. Journal of Educational and Psychological Consultation, 15(3-4), 295-312. doi:10.1080/10474412.2004.9669519 
National Association of School Psychologists. (2010). National Association of School Psychologists model for comprehensive and integrated school psychological services. School Psychology Review, 39(2), 320-333. Retrieved from http://www.nasponline.org/publications/periodicals/spr/volume-39/volume-39-issue2/national-association-of-school-psychologists-model-for-comprehensive-and-integratedschool-psychological-services

Nichols, L. M., Goforth, A. N., Sacra, M., \& Ahlers, K. (2017). Collaboration to support rural student social-emotional needs. The Rural Educator, 38(1), 38-48. doi:10.35608/ruraled.v38i1.234

Pallant, J. (2016). SPSS survival manual: A step by step guide to data analysis using IBM SPSS (6 ed.). Maidenhead: Open University Press.

Paternite, C. E. (2005). School-based mental health programs and services: Overview and introduction to the special issue. Journal of Abnormal Child Psychology, 22, 657-663.

Patten, M. L. (2014). Questionnaire research: A practical guide (4 ed.). Glendale, CA: Pyrczak Publishing.

Paulus, F. W., Ohmann, S., \& Popow, C. (2016). Practitioner review: School-based interventions in child mental health. Journal of Child Psychology and Psychiatry, 57(12), 1337-1359. doi:10.1111/jcpp. 12584

Perkins, G., Oescher, J., \& Ballard, M. B. (2010). The evolving identity of school counselors as defined by the stakeholders. Journal of School Counseling, 8(31), 1-28. Retrieved from https://files.eric.ed.gov/fulltext/EJ895917.pdf 
Pumariega, A. J., \& Vance, H. R. (1999). School-based mental health services: The foundation of systems of care for children's mental health. Psychology in the Schools, 36(5), 371378. doi:10.1002/(SICI)1520-6807(199909)36:5<371::AID-PITS1>3.0.CO;2-O

Ritter, L. A., \& Sue, V. M. (Fall 2007). Selecting a sample. New Directions for Evaluation, 115, 23-28. doi:10.1002/ev.232

Roberts, R. E., Roberts, C. R., \& Xing, Y. (2007). Comorbidity of substance use disorders and other psychiatric disorders among adolescents: Evidence from an epidemiologic survey. Drug and Alcohol Dependence, 88, S4-S13. doi:10.1016/j.drugalcdep.2006.12.010

Rones, M., \& Hoagwood, K. (2000). School-based mental health services: A research review. Clinical Child and Family Psychology Review, 3(4), 223-241. doi:10.1023/A:1026425104386

Santiago, C. D., Kataoka, S. H., Forness, S. R., \& Miranda, J. (2014). Mental health services in special education: An analysis of quality of care. Children \& Schools, 36(3), 175-182. doi:10.1093/cs/cdu014

Schmidt, R. C. (2016). Mental health practitioners' perceived levels of preparedness, levels of confidence and methods used in the assessment of youth suicide risk. Professional Counselor, 6(1), 76-88. doi:10.15241/rs.6.1.76

Simonsen, B., Myers, D., \& Briere III, D. E. (2011). Comparing a behavioral check-in/check-out (CICO) intervention to standard practice in an urban middle school setting using an experimental group design. Journal of Positive Behavior Interventions, 13(1), 31-48. doi:10.1177/1098300709359026

Skowyra, K. R., \& Cocozza, J. J. (2007). Blueprint for change: A comprehensive model for the 
identification and treatment of youth with mental health needs in contact with the juvenile justice system. Retrieved from http://www.ncmhjj.com/wpcontent/uploads/2013/07/2007_Blueprint-for-Change-Full-Report.pdf

Slade, E. P. (2002). Effects of school-based mental health programs on mental health service use by adolescents at school and in the community. Mental Health Services Research, 4(3), 151-166. doi:10.1023/A:1019711113312

Smith, B. H., Molina, B. S. H., Massetti, G. M., Waschbusch, D. A., \& Pelham, W. E. (2007). School-wide interventions: The foundation of a public health approach to school-based mental health. In S. W. Evans, M. D. Weist, \& Z. N. Serpell (Eds.), Advances in SchoolBased Mental Health Interventions: Best Practices and Program Models (2ed., pp.7.17.21). Kingston, NJ: Civic Research Institute. Retrieved from https://www.researchgate.net/profile/Daniel_Waschbusch/publication/228085310_School -wide_interventions_The_foundations_of_a_public_health_approach_to_schoolbased_mental_health/links/00b7d52c6d944a9e71000000.pdf

Splett, J. W., Fowler, J., Weist, M. D., McDaniel, H., \& Dvorsky, M. (2013). The critical role of school psychology in the school mental health movement. Psychology in the Schools, 50(3), 245-258. doi:10.1002/pits.21677

Splett, J. W., George, M. W., Zaheer, I., Weist, M. D., Evans, S. W., \& Kern, L. (2018). Symptom profiles and mental health services received among referred adolescents. School Mental Health, 10(2), 96-110. doi:10.1007/s12310-017-9244-1

Streiner, D. L. (2002). The 2 "Es" of research: Efficacy and effectiveness trials. The Canadian Journal of Psychiatry, 47(6), 552-556. doi:10.1177/070674370204700607

Sue, V. M., \& Ritter, L. A. (2012). Conducting online surveys. Thousand Oaks, CA: SAGE 
Publications. doi:10.4135/9781506335186

Suldo, S. M., Friedrich, A., \& Michalowski, J. (2010). Personal and systems-level factors that limit and facilitate school psychologists' involvement in school-based mental health services. Psychology in the School, 47(4), 354-373. doi:10.1002/pits.20475

Swendsen, J., Burstein, M., Case, B., Conway, K. P., Dierker, L., He, J., \& Merikangas, K. R. (2012). Use and abuse of alcohol and illicit drugs in US adolescents: Results of the National Comorbidity Survey-Adolescent Supplement. Archives of General Psychiatry, 69(4), 390-398. doi:10.1001/archgenpsychiatry.2011.1503

Toepoel, V. (2016). Doing surveys online. London: SAGE Publications Ltd. doi:10.4135/9781473967243

Toepoel, V. (2017). Online survey design. In N. G. Fielding, R. M. Lee, \& G. Blank (Eds.), The SAGE handbook of online research methods (pp. 184-202). London: SAGE Publications Ltd. doi:10.4135/9781473957992

United States Department of Health and Human Services (1999). Mental health: A report of the Surgeon General. Rockville, MD: U.S. Department of Health and Human Services, Substance Abuse and Mental Health Services Administration, Center for Mental Health Services, National Institutes of Health, National Institute of Mental Health. Retrieved from https://profiles.nlm.nih.gov/ps/access/NNBBHS.pdf

Van Selm, M., \& Jankowski, N. W. (2006). Conducting online surveys. Quality and Quantity, 40(3), 435-456. doi:10.1007/s11135-005-8081-8

Vehovar, V., \& Manfreda, K. L. (2017). Overview: Online surveys. In N. G. Fielding, R. M. Lee, \& G. Blank (Eds.), The SAGE handbook of online research methods (pp. 143-161). London: SAGE Publications Ltd. doi:10.4135/9781473957992 
Walley, C. T., \& Grothaus, T. (2013). A qualitative examination of school counselors' training to recognize and respond to adolescent mental health issues. Journal of School Counseling, 11(11), 1-32. Retrieved from https://files.eric.ed.gov/fulltext/EJ1012315.pdf

Williams, K. A., \& Chapman, M. V. (2015). Mental health service use among youth with mental health needs: do school-based services make a difference for sexual minority youth?

School Mental Health, 7(2), 120-131. doi:10.1007/s12310-014-9132-X

World Health Organization. (2003). Caring for children and adolescents with mental disorders: Setting WHO directions. Retrieved from https://apps.who.int/iris/bitstream/handle/10665/42679/9241590637.pdf?sequence=1\&is Allowed=y

Wright, K. B. (2005). Researching Internet-based populations: Advantages and disadvantages of online survey research, online questionnaire authoring software packages, and web survey services. Journal of Computer-Mediated Communication, 10(3). Retrieved from https://doi.org/10.1111/j.1083-6101.2005.tb00259.x 


\section{APPENDICES}




\section{Appendix A}

\section{Invitation: Survey on School Psychologists' Perceptions of Preparation Received for the Provision of School-Based Mental Health Services}

Dear Participant,

My name is Sherika McKenzie, and I am a doctorate student in the Ph.D. in Education with an Emphasis in School Psychology program at Chapman University. I am conducting a study for my dissertation research to examine the perceptions of school psychologists in California regarding their formal education (i.e., undergraduate, graduate, training/workshops) and professional preparation for the provision of school-based mental health services. For my dissertation research, I am working under the guidance of my Dissertation Chair, Michael Hass, Ph.D. As a credentialed school psychologist and member of the California Association of School Psychologists (CASP), your responses to the attached survey will play an important role in understanding the needs of school psychologists in providing school-based mental health services. Thank you in advance for your participation.

Participation in this study is voluntary. The following survey should take approximately 10-15 minutes to complete. Please do not include your name or any identifying information so that your responses remain confidential and anonymous. There is no compensation, nor are there any known risks for completing the survey. Please read the directions very carefully for each section and answer all items and questions as honestly as possible. The completed online questionnaire should be submitted as soon as possible.

The data collected for this study will provide valuable information regarding how school psychologists in California perceive the usefulness of their formal education and professional preparation they have received concerning the provision of school-based mental health services. If you require additional information or have questions, please contact me at the email address provided below.

For study related questions, please contact the investigator(s) listed at the beginning of this form: Sherika McKenzie at mcken143@mail.chapman.edu or Dr. Michael Hass at mhass@chapman.edu. For questions concerning your rights or complaints about the research, please contact Chapman University's Institutional Review Board (IRB) at (714) 628-2833 or irb@ chapman.edu.

Thank you for completing the survey and taking the time to assist me in my educational endeavors.

Sincerely,

Sherika McKenzie, M.S., M.A.Ed., LMFT, LEP

Ph.D. in Education Student

School Psychology Emphasis

Chapman University

College of Educational Studies

mcken143@mail.chapman.edu 
*For more information regarding 'informed consent', please feel free to click on the following link before beginning this survey: Informed Consent - Adult 


\section{Appendix B}

\section{Invitation: Survey on School Counselors' Perceptions of Preparation Received for the Provision of School-Based Mental Health Services}

Dear Participant,

My name is Sherika McKenzie, and I am a doctorate student in the Ph.D. in Education program at Chapman University. I am conducting a study for my dissertation research to examine the perceptions of school counselors in California regarding their formal education (i.e., undergraduate, graduate, training/workshops) and professional preparation for the provision of school-based mental health services. For my dissertation research, I am working under the guidance of my Dissertation Chair, Michael Hass, Ph.D. As a credentialed school counselor and member of the California Association of School Counselors (CASC), your responses to the attached survey will play an important role in understanding the needs of school counselors in providing school-based mental health services. Thank you in advance for your participation.

Participation in this study is voluntary. The following survey should take approximately 10-15 minutes to complete. Please do not include your name or any identifying information so that your responses remain confidential and anonymous. There is no compensation, nor are there any known risks for completing the survey. Please read the directions very carefully for each section and answer all items and questions as honestly as possible. The completed online questionnaire should be submitted as soon as possible.

The data collected for this study will provide valuable information regarding how school counselors in California perceive the usefulness of their formal education and professional preparation they have received concerning the provision of school-based mental health services. If you require additional information or have questions, please contact me at the email address provided below.

For study related questions, please contact the investigator(s) listed at the beginning of this form: Sherika McKenzie at mcken143@mail.chapman.edu or Dr. Michael Hass at mhass@chapman.edu. For questions concerning your rights or complaints about the research, please contact Chapman University's Institutional Review Board (IRB) at (714) 628-2833 or irb@ chapman.edu.

Thank you for completing the survey and taking the time to assist me in my educational endeavors.

Sincerely,

Sherika McKenzie, M.S., M.A.Ed., LMFT, LEP

Ph.D. in Education Student

Chapman University

College of Educational Studies

mcken143@mail.chapman.edu 
*For more information regarding 'informed consent', please feel free to click on the following link before beginning this survey: Informed Consent - Adult 


\title{
Appendix C
}

\section{ADULT INFORMED CONSENT TO PARTICIPATE IN RESEARCH}

Title of Study: School Psychologists and School Counselors' Perceptions of Preparation Received for the Provision of School-Based Mental Health Services

\section{Members of the Research Team}

Student Researcher:

\author{
Sherika McKenzie, M.S., M.A.Ed., LMFT, LEP \\ Doctoral Candidate \\ Attallah College of Educational Studies \\ Emphasis School Psychology \\ Work Cell: (951) 249-1570 \\ mcken143@mail.chapman.edu
}

Lead Researcher:

\author{
Michael Hass, Ph.D. \\ Professor of Scholarly Practice Counseling and School Psychology \\ Attallah College of Educational Studies \\ Office: (714) 628-7217 \\ mhass@chapman.edu
}

\section{Key Information}

You are being invited to take part in a research study. Research studies include only people who choose to take part. Participation is completely voluntary. You should take your time in deciding whether or not you want to participate. Please read the information below and ask questions about anything that you do not understand. Contact a researcher listed above if you have any questions.

If you agree to participate in this study, the project will involve:

- Males and females who are 18 years of age or older

- We expect that at least 100 California school psychologists and school counselors will participate in this research study

- All study procedures will be conducted through a generic email sent to school psychologists and school counselors with a link to an anonymous online questionnaire

- By clicking on the link and completing the questionnaire you will be providing anonymous consent to participate in the study

- There are not risks associated with this study that exceed what would typically be encountered in daily life 
- No one on the study team has a disclosable financial interest related to this research project

- You will not be paid for your participation

\section{Invitation}

You are invited to take part in this research study. The information in this form is meant to help you decide whether or not to participate. If you have any questions, please ask.

\section{Why are you being asked to be in this research study?}

You are being asked to be in this study because you are either a member of the California Association of School Psychologists (CASP) or the California Association of School Counselors (CASC). You must be 18 years of age or older to participate.

\section{What is the reason for doing this research study?}

The purpose of this study is to determine the extent to which school psychologists and school counselors in California believe that their formal pre-service education and later professional experiences and professional development have prepared them to provide school-based mental health services. This study will also examine the extent that school psychologists and school counselors in California feel prepared to deliver various mental health services.

\section{What will be done during this research study?}

You will be asked to complete a survey using an online questionnaire that asks questions about your perceptions regarding your educational preparation and professional experiences regarding the provision of school-based mental health services. The survey will take approximately 10-15 minutes to complete and you may complete it from your home computer.

\section{How will my data be used?}

An individually based anonymous online questionnaire will be used to collect the data, via an online survey system called Qualtrics. The data from the online survey will be analyzed. Demographic data will be collected, including gender, age, job title, state of graduate program, number of years in profession, school placement, the general socioeconomic status of the school site, ethnic/racial makeup of students you serve, total number of student enrollment at school site, and the percentage of time spent providing school-based mental health services. No personally identifying information (e.g., names, email address) will be collected.

\section{What are the possible risks of being in this research study?}

There are no known risks to you for being in this research study beyond those encountered in normal daily life.

\section{What are the possible benefits to you?}

You are not expected to get any direct benefit from being in this study.

\section{What are the possible benefits to other people?}

The benefits to science and/or society may include adding to the fields of school psychology and school counseling by providing survey data that could be used as a basis for future research. In addition, data from this study can hopefully provide graduate programs and school districts in 
California information on how to possibly support future and current school psychologists and school counselors in the provision of school-based mental health services.

What are the alternatives to being in this research study?

Instead of being in this research study you can choose not to participate.

\section{What will participating in this research study cost you?}

There is no cost to you to be in this research study.

Will you be compensated for being in this research study?

You will not be compensated for your participation in this research study.

What should you do if you have a problem during this research study?

Your welfare is the major concern of every member of the research team. If you have a problem as a direct result of being in this study, you should immediately contact one of the people listed at the beginning of this consent form.

\section{How will information about you be protected?}

Reasonable steps will be taken to protect your privacy and the confidentiality of your study data.

The data will be stored electronically through a secure server and will only be seen by the research team during the study and kept indefinitely after the study is complete.

The only people who will have access to the research records are the members of the research team, the Institutional Review Board (IRB), and any other person, agency, or sponsor as required by law. Information from this study may be published in scientific journals or presented at scientific meetings but the data will be reported as group or summarized data and there will be no identifiable information about you without your separate consent.

Whereas the research team will make every effort to keep your personal information confidential, it is possible that an unauthorized person might see it in the unlikely event that the online survey is hacked. We cannot guarantee total privacy.

\section{What are your rights as a research subject?}

You may ask any questions about this research and have those questions answered before agreeing to participate in the study or during the study.

For study related questions, please contact the investigator(s) listed at the beginning of this form.

For questions concerning your rights or complaints about the research, contact the Institutional Review Board (IRB) at (714) 628-2833 or irb@ chapman.edu.

What will happen if you decide not to be in this research study or decide to stop participating once you start? 
You can decide not to be in this research study, or you can stop being in this research study (i.e., "withdraw") at any time before, during, or after the research begins for any reason. Deciding not to be in this research study or deciding to withdraw will not affect your relationship with the investigator or with Chapman University.

\section{How do I agree to participate in this study?}

By clicking on the link and completing the survey you are providing your consent to participate. You should not agree to participate until any and all of your questions about this study have been answered by a member of the research team listed at the top of this form. Participation in this study is voluntary. You may refuse to answer any question or discontinue your involvement at any time without penalty or loss of benefits to which you might otherwise be entitled. Your decision will not affect your future relationship with Chapman University. 


\section{Appendix D}

\section{Content Validation Protocol}

Thank you for agreeing to review this survey. Please feel free to suggest any edits that should be made and write comments regarding the survey in addition to responding to the content questions below.

Please select a number to indicate your level of agreement with the following questions. Select the lowest value to indicate that you disagree entirely, or the highest value to indicate that you agree completely.

The wording is clear.

1. Disagree entirely

2. Neutral

3. Agree completely

The intent of the survey is understood.

1. Disagree entirely

2. Neutral

3. Agree completely

The order of the questions is appropriate.

1. Disagree entirely

2. Neutral

3. Agree completely

The questions are understandable.

1. Disagree entirely

2. Neutral

3. Agree completely

The survey makes sense.

1. Disagree entirely

2. Neutral

3. Agree completely

The questions are worded in ways that make sense.

1. Disagree entirely 
2. Neutral

3. Agree completely

The instructions are clear.

1. Disagree entirely

2. Neutral

3. Agree completely

The response choices make sense.

1. Disagree entirely

2. Neutral

3. Agree completely

The questions were not offensive or objectionable.

1. Disagree entirely

2. Neutral

3. Agree completely

Do you think this tool will help gather information about school psychologists' experiences and feelings of competence with providing school-based mental health services?

1. Disagree entirely

2. Neutral

3. Agree completely

Is there anything that you think needs to be included?

Are there any constructs that are missing from the survey?

Were there any questions that you thought were irrelevant?

Additional comments:

THANK YOU!!! 


\section{Appendix E}

\section{Content Validation Protocol}

Thank you for agreeing to review this survey. Please feel free to suggest any edits that should be made and write comments regarding the survey in addition to responding to the content questions below.

Please select a number to indicate your level of agreement with the following questions. Select the lowest value to indicate that you disagree entirely, or the highest value to indicate that you agree completely.

The wording is clear.

1. Disagree entirely

2. Neutral

3. Agree completely

The intent of the survey is understood.

1. Disagree entirely

2. Neutral

3. Agree completely

The order of the questions is appropriate.
4. Disagree entirely
5. Neutral
6. Agree completely

The questions are understandable.
7. Disagree entirely
8. Neutral
9. Agree completely

The survey makes sense.

1. Disagree entirely

2. Neutral

3. Agree completely

The questions are worded in ways that make sense.

1. Disagree entirely 
2. Neutral

3. Agree completely

The instructions are clear.

1. Disagree entirely

2. Neutral

3. Agree completely

The response choices make sense.

1. Disagree entirely

2. Neutral

3. Agree completely

The questions were not offensive or objectionable.

1. Disagree entirely

2. Neutral

3. Agree completely

Do you think this tool will help gather information about school counselors' experiences and feelings of competence with providing school-based mental health services?

1. Disagree entirely

2. Neutral

3. Agree completely

Is there anything that you think needs to be included?

Are there any constructs that are missing from the survey?

Were there any questions that you thought were irrelevant?

Additional comments:

THANK YOU!!! 


\title{
Survey on School Psychologists' Perceptions of Preparation Received for the Provision of School-Based Mental Health Services
}

\author{
(PAPER FORM)
}

\section{What are school-based mental health services?}

According to the California Department of Education, mental health services in schools include a broad range of services, settings, and strategies. These services vary across the state and may be provided by different school personnel. Providing school-based mental health services helps to address barriers to learning and provides appropriate student and family support in a safe and supportive environment.

School-based mental health services may include:

- Individual or group counseling that focuses on educational counseling, career counseling, personal counseling, crisis intervention, suicide risk assessment, or social skills development

- Developing or overseeing primary prevention or mental health promotion with students

- Developing and implementing Behavior Intervention Plans (BIPs)

- Case-management (i.e., communication, making referrals, utilizing resources)

- Conducting and interpreting social-emotional/behavioral assessments

- Consultation with school staff, community professionals, or parents regarding mental health issues.

- Counseling school staff

- Providing professional development trainings on topics such as social/emotional development, dealing with problem behaviors, mental health, interventions, etc.

- Family or parent counseling

Questionnaire Directions: Please read each of the following sections very carefully.

I. On a scale from 1 to $5(\mathbf{1}=$ Strongly Disagree to $5=$ Strongly Agree $)$, please select one response for each of the following items regarding your perceptions of your educational preparation and experiences for the provision of school-based mental health services as a school psychologist.

\begin{tabular}{|l|c|c|c|c|c|}
\hline & $\begin{array}{c}\text { Strongly } \\
\text { Disagree }\end{array}$ & Disagree & Neutral & Agree & $\begin{array}{c}\text { Strongly } \\
\text { Agree }\end{array}$ \\
\hline $\begin{array}{l}\text { 1. My undergraduate program coursework prepared me } \\
\text { to provide school-based mental health services. }\end{array}$ & 1 & 2 & 3 & 4 & 5 \\
\hline $\begin{array}{l}\text { 2. My school psychology program coursework } \\
\text { prepared me to provide school-based mental health } \\
\text { services. }\end{array}$ & 1 & 2 & 3 & 4 & 5 \\
\hline $\begin{array}{l}\text { 3. My school psychology practicum experience } \\
\text { prepared me to provide school-based mental health } \\
\text { services. }\end{array}$ & 1 & 2 & 3 & 4 & 5 \\
\hline $\begin{array}{l}\text { 4. My school psychology internship prepared me to } \\
\text { provide school-based mental health services. }\end{array}$ & 1 & 2 & 3 & 4 & 5 \\
\hline
\end{tabular}




\begin{tabular}{|l|c|c|c|c|c|}
\hline $\begin{array}{l}\text { 5. Attending workshops/trainings has helped me in my } \\
\text { role in providing school-based mental health services. }\end{array}$ & 1 & 2 & 3 & 4 & 5 \\
\hline $\begin{array}{l}\text { 6. My experience as a school psychologist has } \\
\text { prepared me to provide school-based mental health } \\
\text { services. }\end{array}$ & 1 & 2 & 3 & 4 & 5 \\
\hline
\end{tabular}

7. Was your school psychology program approved by the National Association of School Psychologists (NASP)?

Yes

No

Don't Know

8. What course(s) did you take during your school psychology program related to mental health? Please specify in the box below:

9. What would you have liked to have learned but didn't in your school psychology program regarding the provision of school-based mental health services? Please specify in the box below:

10. What kind of support would you need in your current position to feel more competent in providing school-based mental health services? Please specify in the box below:

II. Please select from the following items regarding your completed graduate-level course work and/or state registrations or licenses related to the provision of mental health services.

11. In addition to my school psychology training, I have completed another master's or specialist level program (e.g., school counseling, social work, marital family therapy):

Yes No

\section{If ' $\mathrm{No}$ ' is selected skip to item 12}

11a. If yes, please select the area(s) of the other master's or specialist level program(s) you attended:

School Counseling

Counseling

Clinical Counseling

Social Work

Marital Family Therapy 
Clinical Psychology

Psychology

Other (please specify in the box below):

12. I have attended a doctorate level program (e.g., Ph.D., Psy.D., Ed.D.) related to mental health: Yes No

If ' $\mathrm{No}$ ' is selected skip to item 13

12a. If yes, please select all doctorate level programs attended:

Ph.D.

Psy.D.

Ed.D.

Other (please specify in the box below):

13. I have worked as a board registered mental health intern (e.g., social work, marital family therapy, clinical counseling): Yes No

If 'No' is selected skip to item 14

13a. If yes, please select the area(s) you worked as a board registered mental health intern:

Marriage and Family Therapy

Social Work

Clinical Counseling

Clinical Psychology

Other (please specify in the box below):

14. I have obtained a mental health professional license (e.g., LMFT, LCSW, LP): Yes No

If 'No' is selected skip to item 15

14a. If yes, please select all mental health professional licenses you have:

LMFT

LCSW

LP

LPCC

LEP

Other (please specify in the box below):

15. I have worked as a licensed mental health professional (e.g., LMFT, LCSW, LP): Yes No

\section{If 'No' is selected skip to item 16}

15a. If yes, please select all mental health licenses you have worked under:

LMFT 


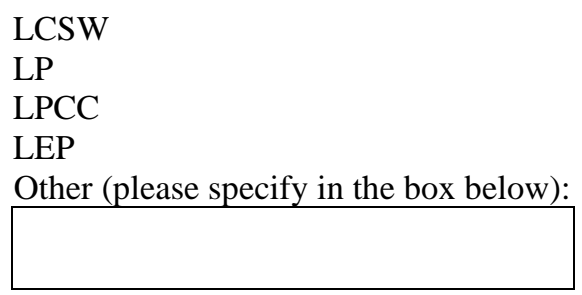

III. On a scale from 1 to 5 (1 = Strongly Disagree to 5 = Strongly Agree), please select one response for each of the following items regarding your provision of school-based mental health services.

16. I have provided individual counseling to students: Yes No

\begin{tabular}{|l|c|c|c|c|}
\hline & $\begin{array}{c}\text { Strongly } \\
\text { Disagree }\end{array}$ & Disagree & Neutral & $\begin{array}{c}\text { Agree } \\
\text { Strongly } \\
\text { Agree }\end{array}$ \\
\hline $\begin{array}{l}\text { 16a. I feel prepared to provide individual counseling to } \\
\text { students. }\end{array}$ & 1 & 2 & 3 & 4 \\
\hline
\end{tabular}

17. I have provided group counseling to students: Yes No

\begin{tabular}{|l|c|c|c|c|c|}
\hline & $\begin{array}{l}\text { Strongly } \\
\text { Disagree }\end{array}$ & Disagree & Neutral & $\begin{array}{c}\text { Agree } \\
\text { Strongly } \\
\text { Agree }\end{array}$ \\
\hline $\begin{array}{l}\text { 17a. I feel prepared to provide group counseling to } \\
\text { students. }\end{array}$ & 1 & 2 & 3 & 4 & 5 \\
\hline
\end{tabular}

18. I have provided crisis intervention other than suicide risk assessment to students individually: Yes No

\begin{tabular}{|l|c|c|c|c|c|}
\hline & $\begin{array}{l}\text { Strongly } \\
\text { Disagree }\end{array}$ & Disagree & Neutral & $\begin{array}{c}\text { Agree } \\
\text { Strongly } \\
\text { Agree }\end{array}$ \\
\hline $\begin{array}{l}\text { 18a. I feel prepared to provide crisis intervention } \\
\text { individually to students. }\end{array}$ & 1 & 2 & 3 & 4 & 5 \\
\hline
\end{tabular}

19. I have provided crisis intervention other than suicide risk assessment to students in groups: Yes No

\begin{tabular}{|l|c|c|c|c|c|}
\hline & $\begin{array}{l}\text { Strongly } \\
\text { Disagree }\end{array}$ & Disagree & Neutral & $\begin{array}{c}\text { Agree } \\
\text { Strongly } \\
\text { Agree }\end{array}$ \\
\hline $\begin{array}{l}\text { 19a. I feel prepared to provide crisis intervention in } \\
\text { groups to students. }\end{array}$ & 1 & 2 & 3 & 4 & 5 \\
\hline
\end{tabular}

20. I have provided suicide risk assessment to students: $\quad$ Yes No

\begin{tabular}{|l|c|c|c|c|}
\hline & $\begin{array}{l}\text { Strongly } \\
\text { Disagree }\end{array}$ & Disagree & Neutral & $\begin{array}{c}\text { Agree } \\
\text { Strongly } \\
\text { Agree }\end{array}$ \\
\hline $\begin{array}{l}\text { 20a. I feel prepared to provide suicide risk assessment } \\
\text { to students. }\end{array}$ & 1 & 2 & 3 & 4 \\
\hline
\end{tabular}


\begin{tabular}{|l|l|l|l|l|l|}
\hline & & & & & \\
\hline
\end{tabular}

21. I have directly participated in programs related to primary prevention or mental health promotion (e.g., suicide prevention campaigns, emotion regulation groups, mindfulness) with students: Yes No

\begin{tabular}{|l|c|c|c|c|c|}
\hline & $\begin{array}{c}\text { Strongly } \\
\text { Disagree }\end{array}$ & Disagree & Neutral & Agree & $\begin{array}{c}\text { Strongly } \\
\text { Agree }\end{array}$ \\
\hline $\begin{array}{l}\text { 21a. I feel prepared to provide prevention related to } \\
\text { mental health (e.g., suicide prevention campaigns, } \\
\text { emotion regulation groups, mindfulness) to students. }\end{array}$ & 1 & 2 & 3 & 4 & 5 \\
\hline
\end{tabular}

22. I have developed and implemented Behavior Intervention Plans (BIPs) to students: Yes $\quad$ No

\begin{tabular}{|l|c|c|c|c|c|}
\hline & $\begin{array}{c}\text { Strongly } \\
\text { Disagree }\end{array}$ & Disagree & Neutral & Agree & $\begin{array}{c}\text { Strongly } \\
\text { Agree }\end{array}$ \\
\hline $\begin{array}{l}\text { 22a. I feel prepared to provide behavior interventions } \\
\text { to students. }\end{array}$ & 1 & 2 & 3 & 4 & 5 \\
\hline
\end{tabular}

23. I have provided case-management (e.g., communication, making referrals, utilizing resources): Yes No

\begin{tabular}{|l|c|c|c|c|c|}
\hline & $\begin{array}{c}\text { Strongly } \\
\text { Disagree }\end{array}$ & Disagree & Neutral & Agree & $\begin{array}{c}\text { Strongly } \\
\text { Agree }\end{array}$ \\
\hline $\begin{array}{l}\text { 23a. I feel prepared to provide case-management (e.g., } \\
\text { communication, making referrals, utilizing resources). }\end{array}$ & 1 & 2 & 3 & 4 & 5 \\
\hline
\end{tabular}

24. I have conducted social-emotional/behavioral assessments and interpreted the results: Yes No

\begin{tabular}{|l|c|c|c|c|c|}
\hline & $\begin{array}{c}\text { Strongly } \\
\text { Disagree }\end{array}$ & Disagree & Neutral & Agree & $\begin{array}{c}\text { Strongly } \\
\text { Agree }\end{array}$ \\
\hline $\begin{array}{l}\text { 24a. I feel prepared to conduct social- } \\
\text { emotional/behavioral assessments and interpret the } \\
\text { results. }\end{array}$ & 1 & 2 & 3 & 4 & 5 \\
\hline
\end{tabular}

25. I have provided consultation to individuals (e.g., school staff, community professionals) regarding students' mental health and/or school-based mental health services: Yes No

\begin{tabular}{|l|c|c|c|c|c|}
\hline & $\begin{array}{c}\text { Strongly } \\
\text { Disagree }\end{array}$ & Disagree & Neutral & Agree & $\begin{array}{c}\text { Strongly } \\
\text { Agree }\end{array}$ \\
\hline $\begin{array}{l}\text { 25a. I feel prepared to provide consultation to } \\
\text { individuals (e.g., school staff, outside professionals) } \\
\text { regarding students' mental health and/or school-based } \\
\text { mental health services. }\end{array}$ & 1 & 2 & 3 & 4 & 5 \\
\hline
\end{tabular}


26. I have provided counseling to school personnel: Yes

\begin{tabular}{|l|c|c|c|c|c|}
\hline & $\begin{array}{c}\text { Strongly } \\
\text { Disagree }\end{array}$ & Disagree & Neutral & Agree & $\begin{array}{c}\text { Strongly } \\
\text { Agree }\end{array}$ \\
\hline $\begin{array}{l}\text { 26a. I feel prepared to provide counseling to school } \\
\text { personnel. }\end{array}$ & 1 & 2 & 3 & 4 & 5 \\
\hline
\end{tabular}

27. I have provided in-service trainings (e.g., on topics such as social/emotional components, behavior, mental health, interventions, etc.): Yes No

\begin{tabular}{|l|c|c|c|c|c|}
\hline & $\begin{array}{c}\text { Strongly } \\
\text { Disagree }\end{array}$ & Disagree & Neutral & Agree & $\begin{array}{c}\text { Strongly } \\
\text { Agree }\end{array}$ \\
\hline $\begin{array}{l}\text { 27a. I feel prepared to provide in-service training (e.g., } \\
\text { on topics such as social/emotional components, } \\
\text { behavior, mental health, interventions, etc.): }\end{array}$ & 1 & 2 & 3 & 4 & 5 \\
\hline
\end{tabular}

28. I have provided family/parent counseling: Yes No

\begin{tabular}{|l|c|c|c|c|c|}
\hline & $\begin{array}{c}\text { Strongly } \\
\text { Disagree }\end{array}$ & Disagree & Neutral & Agree & $\begin{array}{c}\text { Strongly } \\
\text { Agree }\end{array}$ \\
\hline $\begin{array}{l}\text { 28a. I feel prepared to provide family/parent } \\
\text { counseling. }\end{array}$ & 1 & 2 & 3 & 4 & 5 \\
\hline
\end{tabular}

IV. Please complete the following scales:

\begin{tabular}{|l|c|c|c|c|c|}
\hline $\begin{array}{l}\text { On a scale from 1 to 5 (1 = Not Important } \\
\text { to 5 = Very important): }\end{array}$ & $\begin{array}{c}\text { Not } \\
\text { Important }\end{array}$ & $\begin{array}{c}\text { Slightly } \\
\text { Important }\end{array}$ & $\begin{array}{c}\text { Moderately } \\
\text { Important }\end{array}$ & Important & $\begin{array}{c}\text { Very } \\
\text { Important }\end{array}$ \\
\hline $\begin{array}{l}\text { 29. Please indicate how important it is for } \\
\text { school psychologists to provide school- } \\
\text { based mental health services: }\end{array}$ & 1 & 2 & 3 & 4 & 5 \\
\hline $\begin{array}{l}\text { 30. Please indicate how important it is for } \\
\text { school psychologists to be competent to } \\
\text { provide school-based mental health } \\
\text { services: }\end{array}$ & 1 & 2 & 3 & 4 & 5 \\
\hline $\begin{array}{l}31 . \text { Please indicate how important it is for } \\
\text { you personally, as a school psychologist, } \\
\text { to be competent to provide school-based } \\
\text { mental health services: }\end{array}$ & 1 & 2 & 3 & 4 & 5 \\
\hline
\end{tabular}




\begin{tabular}{|l|c|c|c|c|c|}
\hline $\begin{array}{l}\text { On a scale from 1 to 5 (1= I feel very } \\
\text { incompetent to 5= I feel very } \\
\text { competent): }\end{array}$ & $\begin{array}{c}\text { I feel very } \\
\text { incompetent }\end{array}$ & $\begin{array}{c}\text { I feel } \\
\text { somewhat } \\
\text { incompetent }\end{array}$ & $\begin{array}{c}\text { I feel } \\
\text { neither } \\
\text { competent } \\
\text { nor } \\
\text { incompetent }\end{array}$ & $\begin{array}{c}\text { I feel } \\
\text { somewhat } \\
\text { competent }\end{array}$ & $\begin{array}{c}\text { I feel very } \\
\text { competent }\end{array}$ \\
\hline $\begin{array}{l}\text { 32. Please indicate how competent } \\
\text { you feel to provide school-based } \\
\text { mental health services as a school } \\
\text { psychologist: }\end{array}$ & 1 & 2 & 3 & 4 & 5 \\
\hline
\end{tabular}

V. Additional comments and feedback:

33. Please provide any other comments or feedback regarding the provision of school-based mental health services by school psychologists in the box below:

\section{Background Information}

34. I identify as: Male

Female

Other

35. Age (please specify in the box below):

36. I am currently working as a school psychologist: Yes No

\section{If 'No' is selected skip to item 37}

36a. If yes, my title is: School Psychologist/Psychologist

ERMHS Psychologist/ERICS Psychologist (Mental Health)

Other (please specify in the box below):

37. Which state did you attend your school psychology graduate program in?

38. How many years have you worked as a school psychologist?

Less than a year

$1-5$ years

6-10 years

$11-15$ years 
15-20 years

More than 20 years

39. What is your primary placement as a school psychologist?

Preschool

Elementary

Middle School

High School

Alternative Program/Placement (please specify in the box below):

39a. If you have a secondary placement, please indicate level:

Preschool

Elementary

Middle School

High School

Alternative Program/Placement (please specify in the box below):

40. Type of primary school site:

Urban

Suburban

Rural

40a. If you have a secondary placement, please indicate type of secondary school site:

Urban

Suburban

Rural

41. Is your primary site a Title I school? Yes No Don't Know

41a. If you have a secondary placement, is your secondary site a Title I school? Yes No Don't Know

42. Ethnic/racial makeup of the majority of students at the primary school site:

African American

American Indian/Alaska Native

Asian/Asian American

Caucasian

Filipino

Hispanic/Latino

Native Hawaiian/Pacific Islander

Multiracial

42a. If you have a secondary placement, please indicate the ethnic/racial makeup of the majority of students at the secondary school site:

African American

American Indian/Alaska Native

Asian/Asian American

Caucasian

Filipino 


\author{
Hispanic/Latino \\ Native Hawaiian/Pacific Islander \\ Multiracial
}

43. Total student enrollment at primary school site:

Less than 100

$100-500$

$501-1000$

$1001-5000$

More than 5000

43a. If you have a secondary placement, please indicate the total student enrollment at secondary school site:
Less than 100
$100-500$
$501-1000$
$1001-5000$
More than 5000
Don't Know

44. In my role as a school psychologist, I currently spend

$\%(0-100 \%)$ of my time providing mental health services (e.g., providing counseling, conducting mental health focus assessments, etc.). 


\title{
Appendix G
}

\section{Survey on School Counselors' Perceptions of Preparation Received for the Provision of School-Based Mental Health Services}

\author{
(PAPER FORM)
}

\section{What are school-based mental health services?}

According to the California Department of Education, mental health services in schools include a broad range of services, settings, and strategies. These services vary across the state and may be provided by different school personnel. Providing school-based mental health services helps to address barriers to learning and provides appropriate student and family support in a safe and supportive environment.

School-based mental health services may include:

- Individual or group counseling that focuses on educational counseling, career counseling, personal counseling, crisis intervention, suicide risk assessment, or social skills development

- Developing or overseeing primary prevention or mental health promotion with students

- Developing and implementing Behavior Intervention Plans (BIPs)

- Case-management (e.g., communication, making referrals, utilizing resources)

- Conducting and interpreting social-emotional/behavioral assessments

- Consultation with school staff, community professionals, or parents regarding mental health issues.

- Counseling school staff

- Providing professional development trainings on topics such as social/emotional development, dealing with problem behaviors, mental health, interventions, etc.

- Family or parent counseling

Questionnaire Directions: Please read each of the following sections very carefully.

I. On a scale from 1 to 5 ( 1 = Strongly Disagree to 5 = Strongly Agree $)$, please select one response for each of the following items regarding your perceptions of your educational preparation and experiences for the provision of school-based mental health services as a school counselor.

\begin{tabular}{|l|c|c|c|c|c|}
\hline & $\begin{array}{c}\text { Strongly } \\
\text { Disagree }\end{array}$ & Disagree & Neutral & Agree & $\begin{array}{c}\text { Strongly } \\
\text { Agree }\end{array}$ \\
\hline $\begin{array}{l}\text { 1. My undergraduate program coursework prepared } \\
\text { me to provide school-based mental health services. }\end{array}$ & 1 & 2 & 3 & 4 & 5 \\
\hline $\begin{array}{l}\text { 2. My school counseling program coursework } \\
\text { prepared me to provide school-based mental health } \\
\text { services. }\end{array}$ & 1 & 2 & 3 & 4 & 5 \\
\hline $\begin{array}{l}\text { 3. My school counseling practicum experience } \\
\text { prepared me to provide school-based mental health } \\
\text { services. }\end{array}$ & 1 & 2 & 3 & 4 & 5 \\
\hline $\begin{array}{l}\text { 4. My school counseling internship prepared me to } \\
\text { provide school-based mental health services. }\end{array}$ & 1 & 2 & 3 & 4 & 5 \\
\hline
\end{tabular}




\begin{tabular}{|l|c|c|c|c|c|}
\hline & & & & \\
\hline $\begin{array}{l}\text { 5. Attending workshops/trainings has helped me in } \\
\text { my role in providing school-based mental health } \\
\text { services. }\end{array}$ & 1 & 2 & 3 & 4 & 5 \\
\hline $\begin{array}{l}\text { 6. My experience as a school counselor has prepared } \\
\text { me to provide school-based mental health services. }\end{array}$ & 1 & 2 & 3 & 4 & 5 \\
\hline
\end{tabular}

7. Did your school counseling program follow the American School Counselor Association (ASCA) National Model?
Yes
No
Don’t Know

8. What course(s) did you take during your school counseling program related to mental health? Please specify in the box below:

9. What would you have liked to have learned but didn't in your school counseling program regarding the provision of school-based mental health services? Please specify in the box below:

10. What kind of support would you need in your current position to feel more competent in providing school-based mental health services? Please specify in the box below:

II. Please select from the following items regarding your completed graduate-level course work and/or state registrations or licenses related to the provision of mental health services.

11. In addition to my school counseling training, I have completed another master's or specialist level program (e.g., school psychology, social work, marital family therapy):

$$
\text { Yes No }
$$

\section{If ' $N$ '' is selected skip to item 12}

11a. If yes, please select the area(s) of the other master's or specialist level program(s) you attended: School Psychology

Clinical Psychology

Psychology 
Counseling

Clinical Counseling

Social Work

Marital Family Therapy

Other (please specify in the box below):

12. I have attended a doctorate level program (e.g., Ph.D., Psy.D., Ed.D.) related to mental health: Yes No

\section{If 'No' is selected skip to item 13}

12a. If yes, please select all doctorate level programs attended?

Ph.D.

Psy.D.

Ed.D.

Other (please specify in the box below):

13. I have worked as a board registered mental health intern (e.g., social work, marital family therapy, clinical counseling): Yes No

\section{If 'No' is selected skip to item 14}

13a. If yes, please select the area(s) you worked as a board registered mental health intern:

Marriage and Family Therapy

Social Work

Clinical Counseling

Clinical Psychology

Other (please specify in the box below):

14. I have obtained a mental health professional license (e.g., LMFT, LCSW, LP): Yes No

\section{If 'No' is selected skip to item 15}

14a. If yes, please select all mental health professional licenses you have:

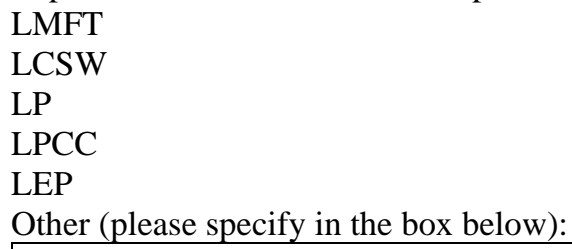

15. I have worked as a licensed mental health professional (e.g., LMFT, LCSW, LP): Yes No

\section{If 'No' is selected skip to item 16}


15a. If yes, please select all mental health licenses you have worked under:

LMFT
LCSW
LP
LPCC
LEP
Other (please specify in the box below):

III. On a scale from 1 to $5(\mathbf{1}=$ Strongly Disagree to 5 = Strongly Agree $)$, please select one response for each of the following items regarding your provision of school-based mental health services.

16. I have provided individual counseling to students: Yes No

\begin{tabular}{|l|c|c|c|c|c|}
\hline & $\begin{array}{c}\text { Strongly } \\
\text { Disagree }\end{array}$ & Disagree & Neutral & Agree & $\begin{array}{c}\text { Strongly } \\
\text { Agree }\end{array}$ \\
\hline $\begin{array}{l}\text { 16a. I feel prepared to provide individual } \\
\text { counseling to students. }\end{array}$ & 1 & 2 & 3 & 4 & 5 \\
\hline
\end{tabular}

17. I have provided group counseling to students: $\quad$ Yes $\quad$ No

\begin{tabular}{|l|c|c|c|c|c|}
\hline & $\begin{array}{c}\text { Strongly } \\
\text { Disagree }\end{array}$ & Disagree & Neutral & Agree & $\begin{array}{c}\text { Strongly } \\
\text { Agree }\end{array}$ \\
\hline $\begin{array}{l}\text { 17a. I feel prepared to provide group counseling to } \\
\text { students. }\end{array}$ & 1 & 2 & 3 & 4 & 5 \\
\hline
\end{tabular}

18. I have provided crisis intervention other than suicide risk assessment to students individually: Yes No

\begin{tabular}{|l|c|c|c|c|c|}
\hline & $\begin{array}{c}\text { Strongly } \\
\text { Disagree }\end{array}$ & Disagree & Neutral & Agree & $\begin{array}{c}\text { Strongly } \\
\text { Agree }\end{array}$ \\
\hline $\begin{array}{l}\text { 18a. I feel prepared to provide crisis intervention } \\
\text { individually to students. }\end{array}$ & 1 & 2 & 3 & 4 & 5 \\
\hline
\end{tabular}

19. I have provided crisis intervention other than suicide risk assessment to students in groups: $\quad$ Yes $\quad$ No

\begin{tabular}{|l|c|c|c|c|c|}
\hline & $\begin{array}{l}\text { Strongly } \\
\text { Disagree }\end{array}$ & Disagree & Neutral & Agree & $\begin{array}{c}\text { Strongly } \\
\text { Agree }\end{array}$ \\
\hline $\begin{array}{l}\text { 19a. I feel prepared to provide crisis intervention in } \\
\text { groups to students. }\end{array}$ & 1 & 2 & 3 & 4 & 5 \\
\hline
\end{tabular}


20. I have provided suicide risk assessment to students: $\quad$ Yes $\quad$ No

\begin{tabular}{|l|c|c|c|c|c|}
\hline & $\begin{array}{c}\text { Strongly } \\
\text { Disagree }\end{array}$ & Disagree & Neutral & Agree & $\begin{array}{c}\text { Strongly } \\
\text { Agree }\end{array}$ \\
\hline $\begin{array}{l}\text { 20a. I feel prepared to provide suicide risk } \\
\text { assessment to students. }\end{array}$ & 1 & 2 & 3 & 4 & 5 \\
\hline
\end{tabular}

21. I have directly participated in programs related to primary prevention or mental health promotion (e.g., suicide prevention campaigns, emotion regulation groups, mindfulness, etc.) with students: $\quad$ Yes No

\begin{tabular}{|l|c|c|c|c|c|}
\hline & $\begin{array}{l}\text { Strongly } \\
\text { Disagree }\end{array}$ & Disagree & Neutral & Agree & $\begin{array}{c}\text { Strongly } \\
\text { Agree }\end{array}$ \\
\hline $\begin{array}{l}\text { 21a. I feel prepared to provide prevention related to } \\
\text { mental health (e.g., suicide prevention campaigns, } \\
\text { emotion regulation groups, mindfulness, etc.) to } \\
\text { students. }\end{array}$ & 1 & 2 & 3 & 4 & 5 \\
\hline
\end{tabular}

22. I have developed and implemented Behavior Intervention Plans (BIPs) to students: $\quad$ Yes $\quad$ No

\begin{tabular}{|l|c|c|c|c|c|}
\hline & $\begin{array}{c}\text { Strongly } \\
\text { Disagree }\end{array}$ & Disagree & Neutral & Agree & $\begin{array}{c}\text { Strongly } \\
\text { Agree }\end{array}$ \\
\hline $\begin{array}{l}\text { 22a. I feel prepared to provide behavior } \\
\text { interventions to students. }\end{array}$ & 1 & 2 & 3 & 4 & 5 \\
\hline
\end{tabular}

23. I have provided case-management (e.g., communication, making referrals, utilizing resources): Yes No

\begin{tabular}{|l|c|c|c|c|c|}
\hline & $\begin{array}{l}\text { Strongly } \\
\text { Disagree }\end{array}$ & Disagree & Neutral & Agree & $\begin{array}{c}\text { Strongly } \\
\text { Agree }\end{array}$ \\
\hline $\begin{array}{l}\text { 23a. I feel prepared to provide case-management } \\
\text { (e.g., communication, making referrals, utilizing } \\
\text { resources). }\end{array}$ & 1 & 2 & 3 & 4 & 5 \\
\hline
\end{tabular}

24. I have conducted social-emotional/behavioral assessments and interpreted the results: Yes No

\begin{tabular}{|l|c|c|c|c|c|}
\hline & $\begin{array}{c}\text { Strongly } \\
\text { Disagree }\end{array}$ & Disagree & Neutral & Agree & $\begin{array}{c}\text { Strongly } \\
\text { Agree }\end{array}$ \\
\hline $\begin{array}{l}\text { 24a. I feel prepared to conduct social- } \\
\text { emotional/behavioral assessments and interpret the } \\
\text { results. }\end{array}$ & 1 & 2 & 3 & 4 & 5 \\
\hline
\end{tabular}

25. I have provided consultation to individuals (e.g., school staff, community professionals) regarding students' mental health and/or school-based mental health services: Yes No 


\begin{tabular}{|l|c|c|c|c|c|}
\hline & $\begin{array}{c}\text { Strongly } \\
\text { Disagre }\end{array}$ & Disagree & Neutral & Agree & $\begin{array}{c}\text { Strongly } \\
\text { Agree }\end{array}$ \\
\hline $\begin{array}{l}\text { 25a. I feel prepared to provide consultation to } \\
\text { individuals (e.g., school staff, outside professionals) } \\
\text { regarding students' mental health and/or school- } \\
\text { based mental health services. }\end{array}$ & 1 & 2 & 3 & 4 & 5 \\
\hline
\end{tabular}

26. I have provided counseling to school personnel: Yes No

\begin{tabular}{|l|c|c|c|c|c|}
\hline & $\begin{array}{l}\text { Strongly } \\
\text { Disagree }\end{array}$ & Disagree & Neutral & Agree & $\begin{array}{c}\text { Strongly } \\
\text { Agree }\end{array}$ \\
\hline $\begin{array}{l}\text { 26a. I feel prepared to provide counseling to school } \\
\text { personnel. }\end{array}$ & 1 & 2 & 3 & 4 & 5 \\
\hline
\end{tabular}

27. I have provided in-service trainings (e.g., on topics such as social/emotional components, behavior, mental health, interventions, etc.): Yes No

\begin{tabular}{|l|c|c|c|c|c|}
\hline & $\begin{array}{l}\text { Strongly } \\
\text { Disagree }\end{array}$ & Disagree & Neutral & Agree & $\begin{array}{c}\text { Strongly } \\
\text { Agree }\end{array}$ \\
\hline $\begin{array}{l}\text { 27a. I feel prepared to provide in-service training } \\
\text { (e.g., on topics such as social/emotional } \\
\text { components, behavior, mental health, interventions, } \\
\text { etc.): }\end{array}$ & 1 & 2 & 3 & 4 & 5 \\
\hline
\end{tabular}

28. I have provided family/parent counseling: Yes No

\begin{tabular}{|l|c|c|c|c|c|}
\hline & $\begin{array}{c}\text { Strongly } \\
\text { Disagree }\end{array}$ & Disagree & Neutral & Agree & $\begin{array}{c}\text { Strongly } \\
\text { Agree }\end{array}$ \\
\hline $\begin{array}{l}\text { 28a. I feel prepared to provide family/parent } \\
\text { counseling. }\end{array}$ & 1 & 2 & 3 & 4 & 5 \\
\hline
\end{tabular}

IV. Please complete the following scales:

\begin{tabular}{|l|c|c|c|c|c|}
\hline $\begin{array}{l}\text { On a scale from 1 to 5 (1 = Not Important } \\
\text { to 5 = Very important): }\end{array}$ & $\begin{array}{c}\text { Not } \\
\text { Important }\end{array}$ & $\begin{array}{c}\text { Slightly } \\
\text { Important }\end{array}$ & $\begin{array}{c}\text { Moderately } \\
\text { Important }\end{array}$ & Important & $\begin{array}{c}\text { Very } \\
\text { Important }\end{array}$ \\
\hline $\begin{array}{l}\text { 29. Please indicate how important it is for } \\
\text { school counselors to provide school-based } \\
\text { mental health services: }\end{array}$ & 1 & 2 & 3 & 4 & 5 \\
\hline $\begin{array}{l}\text { 30. Please indicate how important it is for } \\
\text { school counselors to be competent to } \\
\text { provide school-based mental health } \\
\text { services: }\end{array}$ & 1 & 2 & 3 & 4 & 5 \\
\hline
\end{tabular}




\begin{tabular}{|l|l|l|l|l|l|}
\hline $\begin{array}{l}31 . \text { Please indicate how important it is for } \\
\text { you personally, as a school counselor, to } \\
\text { be competent to provide school-based } \\
\text { mental health services: }\end{array}$ & 1 & 2 & 3 & 4 & 5 \\
\hline
\end{tabular}

\begin{tabular}{|l|c|c|c|c|c|}
\hline $\begin{array}{l}\text { On a scale from 1 to 5 (1 = I feel very } \\
\text { incompetent to } \mathbf{5}=\text { I feel very } \\
\text { competent): }\end{array}$ & $\begin{array}{c}\text { I feel very } \\
\text { incompetent }\end{array}$ & $\begin{array}{c}\text { I feel } \\
\text { somewhat } \\
\text { incompetent }\end{array}$ & $\begin{array}{c}\text { I feel } \\
\text { neither } \\
\text { competent } \\
\text { nor } \\
\text { incompetent }\end{array}$ & $\begin{array}{c}\text { I feel } \\
\text { somewhat } \\
\text { competent }\end{array}$ & $\begin{array}{c}\text { I feel very } \\
\text { competent }\end{array}$ \\
\hline $\begin{array}{l}\text { 32. Please indicate how competent } \\
\text { you feel to provide school-based } \\
\text { mental health services as a school } \\
\text { counselor: }\end{array}$ & 1 & 2 & 3 & 4 & 5 \\
\hline
\end{tabular}

V. Additional comments and feedback:

33. Please provide any other comments or feedback regarding the provision of school-based mental health services by school counselors in the box below:

\section{Background Information}

34. I identify as: Male

Female

Other

35. Age (please specify in the box below):

36. I am currently working as a school counselor: Yes No

If 'No' is selected skip to item $\mathbf{3 7}$

36a. If yes, my title is: School Counselor

Counselor

Academic Counselor

Guidance Counselor

Other (please specify in the box below): 
37. Which state did you attend your school counseling graduate program in?

38. How many years have you worked as a school counselor?

Less than a year

$1-5$ years

6-10 years

$11-15$ years

$15-20$ years

More than 20 years

39. What is your primary placement as a school counselor?

Preschool

Elementary

Middle School

High School

Alternative Program/Placement (please specify in the box below):

39a. If you have a secondary placement, please indicate level:

Preschool

Elementary

Middle School

High School

Alternative Program/Placement (please specify in the box below):

40. Type of primary school site:

Urban

Suburban

Rural

40a. If you have a secondary placement, please indicate type of secondary school site:

Urban

Suburban

Rural

41. Is your primary site a Title I school? Yes No Don't Know

41a. If you have a secondary placement, is your secondary site a Title I school? Yes No Don't Know

42. Ethnic/racial makeup of the majority of students at the primary school site:

African American

American Indian/Alaska Native

Asian/Asian American

Caucasian

Filipino

Hispanic/Latino

Native Hawaiian/Pacific Islander

Multiracial 
42a. If you have a secondary placement, please indicate the ethnic/racial makeup of the majority of students at the secondary school site:

African American

American Indian/Alaska Native

Asian/Asian American

Caucasian

Filipino

Hispanic/Latino

Native Hawaiian/Pacific Islander

Multiracial

43. Total student enrollment at primary school site:

Less than 100

$100-500$

$501-1000$

$1001-5000$

More than 5000

43a. If you have a secondary placement, please indicate the total student enrollment at secondary school site:

Less than 100

$100-500$

$501-1000$

$1001-5000$

More than 5000

Don't Know

44. In my role as a school counselor, I currently spend $\%(0-100 \%)$ of my time providing mental health services (e.g., providing counseling, conducting mental health focus assessments, etc.). 